\title{
AN INVESTIGATION OF METAL AND CERAMIC THERMAL BARRIER COATINGS IN A SPARK-IGNITION ENGINE
}

by

Michael Anderson Marr

A thesis submitted in conformity with the requirements for the degree of Master of Applied Science

Graduate Department of Mechanical and Industrial Engineering University of Toronto

Copyright (c) 2009 by Michael Anderson Marr 


\begin{abstract}
An investigation of metal and ceramic thermal barrier coatings in a spark-ignition engine

Michael Anderson Marr

Master of Applied Science

Graduate Department of Mechanical and Industrial Engineering

University of Toronto

2009

Surface temperature and heat flux measurements were made in a single cylinder SI engine piston when uncoated and with two different surface coatings: a metal TBC and YSZ. A new thermocouple was developed to accurately measure surface temperatures. The engine was operated in a standard full load mode and a knock promoting mode featuring heated intake air and advanced spark timing. Cylinder pressures were measured to quantify knock.

It was found that average heat flux into the piston substrate was $33 \%$ higher with the metal TBC and unchanged with the YSZ relative to the uncoated surface. The increase with the metal TBC was attributed to its surface roughness. However, the metal TBC and YSZ reduced peak heat flux by 69 and $77 \%$, respectively. Both the metal TBC and YSZ reduced knock compared to the uncoated surface. After testing, the metal TBC was undamaged and the YSZ was slightly chipped.
\end{abstract}




\section{Dedication}

To my late grandpa Joseph. 


\section{Acknowledgements}

I would like to thank Professor James Wallace for the opportunity to work on such an interesting project and his support over the last two years. I would also like to thank Tiegang Li, Dr. Larry Pershin and Professors Sanjeev Chandra and Javad Mostaghimi from the Centre for Advanced Coating Technologies (CACT) for their time and use of their facilities. I am also grateful to Silvio Memme, as completion of the project would not have been possible without his hard work on the experimental apparatus.

I would like to appreciate the many additional people that generously provided their time and expertise to help complete this thesis. My lab mates Paul Charbonneau, Matt Foster, Justin Ketteter and Dave Wager were always there to help no matter how many times I asked. Gordon Boudreau, Fred Gebeshuber, Ryan Mendell and Jeff Sansome always paused from their own work to demonstrate machining techniques and Sheila Baker cheerfully assisted with numerous purchase orders.

Financial support of this project was provided by the BMW Technology Office in Palo Alto and the Natural Sciences and Engineering Research Council of Canada (NSERC). I am also grateful to NSERC for personal financial support.

I am grateful to my parents, Dennis and Sharon, my sister Sarah, and my Grandma Clara for always being there. And last, but definitely not least, I would like to thank my Sunči for the joy she brings to my life, not to mention all her help running tests and editing. 


\section{Contents}

$\begin{array}{lll}\text { Abstract } & \text { ii }\end{array}$

$\begin{array}{ll}\text { Dedication } & \text { iii }\end{array}$

Acknowledgements $\quad$ iv

Contents $\quad$ v

List of Tables $\quad$ ix

List of Figures $\quad$ x

Nomenclature $\quad$ xiii

1 Introduction $\quad 1$

1.1 Thermal Barrier Coatings . . . . . . . . . . . . . . . 1

1.1.1 Research on Thermal Barrier Coatings in Diesel Engines . . . . . 3

1.1.2 Research on Thermal Barrier Coatings in Spark-Ignition Engines . 4

1.1.3 Research on Thermal Barrier Coating Materials . . . . . . . . 6

1.1.4 Thermal Barrier Coating Research Opportunities . . . . . . . . 7

1.2 Research Program Objectives and Overview . . . . . . . . . . 8

1.3 Document Overview ..................... 10 
2 General Experimental Setup and Methodology 11

2.1 Engine Description ...................... . . 11

2.2 Data Acquisition and Processing . . . . . . . . . . . . . . . 12

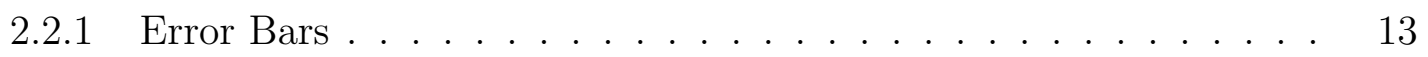

2.3 Cylinder Pressure Measurement . . . . . . . . . . . . . . . . . . 13

2.3.1 Knock Quantification .................. 15

2.4 Visual Display Sensors . . . . . . . . . . . . . . . . . . . . 15

3 Preliminary Cylinder Wall Tests $\quad 17$

3.1 Setup and Methodology . . . . . . . . . . . . . . 17

3.2 Temperature Test Results and Discussion . . . . . . . . . . . . . . . . 20

3.2.1 Effect of Surface Roughness . . . . . . . . . . . . . . . . . . 22

3.3 Knock Test Results and Discussion . . . . . . . . . . . . . . . . . . 22

3.4 Preliminary Cylinder Wall Test Summary . . . . . . . . . . . . . . . . . 24

4 Thermocouple Development $\quad 26$

4.1 Surface Thermocouple Development . . . . . . . . . . . . . . . 26

4.1.1 Surface Thermocouple Design . . . . . . . . . . . . . . . 29

4.1.2 Surface Thermocouple Finite Element Analysis . . . . . . . . . . 30

4.1.3 Surface Thermocouple Engine Testing . . . . . . . . . . . . . . . 35

4.1.4 Surface Thermocouple Development Summary . . . . . . . . . . . 41

4.2 In-Depth Thermocouple Development . . . . . . . . . . . . . . 43

4.2.1 In-Depth Thermocouple Design . . . . . . . . . . . . . . . 43

4.2.2 In-Depth Thermocouple Finite Element Analysis . . . . . . . . . 44

4.2.3 In-Depth Thermocouple Development Summary . . . . . . . . . . 45

5 Piston Test Setup and Methodology 47

5.1 Engine . . . . . . . . . . . . . . . . . . . . 47

5.2 Piston Instrumentation . . . . . . . . . . . . . . . . . . 48 
5.2 .1 Thermocouple Wire Routing . . . . . . . . . . . . . . . . 50

5.2.2 Thermocouple Signal Conditioning, Acquisition and Processing . 54

5.3 Additional Sensors . . . . . . . . . . . . . . . . . . . . . . . 59

5.4 Test Procedure . . . . . . . . . . . . . . . . . . . . . . . 60

5.5 Piston Test Setup and Methodology Summary . . . . . . . . . . . . 62

6 Piston Test Results and Discussion 63

6.1 Temperature Tests . . . . . . . . . . . . . . . . . . . . . 64

6.1.1 Piston Temperature and Heat Flux . . . . . . . . . . . . 64

6.1.2 Cylinder Pressure, Torque and Exhaust Temperature . . . . . . 74

6.2 Knock Tests . . . . . . . . . . . . . . . . . . . . . . . . . 79

6.3 Piston Test Results and Discussion Summary _ . . . . . . . . . . 80

7 Conclusions and Recommendations $\quad 82$

7.1 Surface Thermocouple Development . . . . . . . . . . . . . . . . . . 82

7.2 Thermal Barrier Coatings in Spark-Ignition Engines . . . . . . . . . . . 84

$\begin{array}{ll}\text { Bibliography } & 88\end{array}$

$\begin{array}{ll}\text { A Software Program Descriptions } & 94\end{array}$

A.1 LabVIEW Programs . . . . . . . . . . . . . . . . . . . . . 94

A.2 MATLAB Programs . . . . . . . . . . . . . . . 96

$\begin{array}{ll}\text { B Piston Modification Drawings } & 98\end{array}$

$\begin{array}{ll}\text { C Heat Flux Calculation } & 102\end{array}$

D Pictures of Piston Crown After Testing 104

$\begin{array}{ll}\text { E Heat Flux Error Analysis } & 108\end{array}$

E.1 Average Heat Flux Error Analysis . . . . . . . . . . . . . . . . . . 108 
E.1.1 Average Heat Flux Errors _ . . . . . . . . . . . . . . 108

E.1.2 Average Heat Flux Error and Uncertainty Adjustments . . . . . . 111

E.2 Instantaneous Heat Flux Error Analysis _ . . . . . . . . . . . . 114 


\section{List of Tables}

1.1 Thermal barrier coating properties $\ldots \ldots \ldots \ldots$

2.1 CFR engine specifications $\ldots \ldots \ldots \ldots \ldots \ldots$

2.2 Data acquisition boards . . . . . . . . . . . . . . . 13

3.1 Cylinder wall test engine operating parameters . . . . . . . . . . 19

4.1 Surface thermocouple FEA material properties . . . . . . . . . . . . 32

4.2 Surface thermocouple engine tests operating parameters . . . . . . . . 38

4.3 Surface thermocouple engine testing results - summary table . . . . . . 39

5.1 Piston test coating thicknesses . . . . . . . . . . . . . . . 60

5.2 Piston test engine operating parameters $\ldots \ldots \ldots 61$

6.1 Piston test temperature and heat flux results - summary of average values 65 


\section{List of Figures}

2.1 Sample cylinder pressure traces showing different knock intensities . . . . 16

3.1 Cylinder wall test cylinder assembly - cross section viewed from above . . 18

3.2 Plug dimensions . . . . . . . . . . . . . . . . . . . . . . . . . . . 18

3.3 Average plug temperatures before and after coating . . . . . . . . . . 20

3.4 Average damaged plug temperatures before and after coating . . . . . . . 21

3.5 Average uncoated plug temperatures before and after grit blasting . . . . 22

3.6 Average metal TBC coated plug temperatures before and after polishing 23

3.7 Average knock intensity . . . . . . . . . . . . . . . . . . . . 24

4.1 Heichal et al. surface thermocouple . . . . . . . . . . . . . . . . 28

4.2 Surface thermocouple schematic . . . . . . . . . . . . . . . . 30

4.3 Surface thermocouple FEA model geometry and boundary conditions . . 31

4.4 Convective heat flux data from Alkidas and Myers . . . . . . . . . . . . . 32

4.5 Hot junction temperature with varied copper thickness . . . . . . . . . 33

4.6 Hot junction temperature with 100 and $125 \mu$ m copper layers . . . . . . 33

4.7 Hot junction temperature with 2X Alkidas and Myers convective heat flux 34

4.8 Hot junction temperature with Woschni heat transfer coefficient . . . . . 34

4.9 Hot junction temperature with $0.5 \mathrm{~mm} \mathrm{YSZ} \mathrm{TBC} \mathrm{.} \mathrm{.} \mathrm{.} \mathrm{.} \mathrm{.} \mathrm{.} \mathrm{.} \mathrm{.} \mathrm{.} 35$

4.10 Surface thermocouple setup for engine testing . . . . . . . . . . . 36

4.11 Representative cycles of Thermocouple 2 in Port B . . . . . . . . . . . 40 
4.12 Representative cycles of Thermocouple 3 in Port C . . . . . . . . . . 41

4.13 Ratios of average temperature swing to average temperature swing at 400 $\mu \mathrm{m}$ copper layer thickness . . . . . . . . . . . . . . . . . 42

4.14 Sample cycle of Thermocouple 3 with YSZ coating in Port C . . . . . . . 42

4.15 In-depth thermocouple schematic . . . . . . . . . . . . . . . 44

4.16 Ratio of temperature swing to surface temperature swing . . . . . . . . 45

4.17 In-depth thermocouple FEA model geometry and boundary conditions . 46

4.18 In-depth thermocouple FEA results . . . . . . . . . . . . . . . 46

5.1 Piston test cylinder assembly - cross section viewed from above . . . . . . 48

5.2 Thermocouple position in piston crown . . . . . . . . . . . . . . 49

5.3 Thermocouple pair spacing . . . . . . . . . . . . . . . . . . 49

5.4 Piston thermocouple wiring schematic . . . . . . . . . . . 50

5.5 Wire routing from piston crown to connecting rod . . . . . . . . . 52

5.6 Pictures of the piston at different stages in the instrumentation process . 52

5.7 Mechanical telemetry linkage . . . . . . . . . . . . . . . 53

5.8 Linkage connection to connecting rod big end . . . . . . . . . . 53

5.9 Linkage housing . . . . . . . . . . . . . . . . . . 53

5.10 Wired linkage, connecting rod and piston . . . . . . . . . . . . 54

5.11 Thermocouple wire splitting . . . . . . . . . . . . . . . 55

5.12 Piston aluminum-constantan calibration data . . . . . . . . . . 57

6.1 Average piston temperatures . . . . . . . . . . . . . 66

6.2 Surface Thermocouple 3 representative temperature cycles - normalized to average temperature of $0^{\circ} \mathrm{C} \ldots \ldots \ldots 67$

6.3 Representative uncoated piston temperature cycles - all thermocouples . 67

6.4 Thermocouple Pair 3 representative instantaneous heat flux - calculated

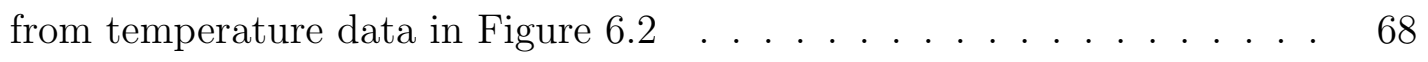


6.5 Thermocouple Pair 3 instantaneous heat flux - average of 40 cycles . . . 69

6.6 Average heat flux into piston crown . . . . . . . . . . . . . 70

6.7 Pictures of TBCs prior to testing . . . . . . . . . . . . . . 71

6.8 TBC surface temperature FEA model geometry and boundary conditions 72

6.9 FEA predicted surface temperatures . . . . . . . . . . . . 73

6.10 FEA predicted heat flux at substrate surface . . . . . . . . . . 73

6.11 Average peak pressure . . . . . . . . . . . . . . . 75

6.12 Average angle of peak pressure occurrence . . . . . . . . . . . . . 75

6.13 Average IMEP . . . . . . . . . . . . . . . . . . 76

6.14 Temperature test average knock intensity . . . . . . . . . . . . . . 77

6.15 Corrected torque vs. oil temperature . . . . . . . . . . . . 78

6.16 Average exhaust gas temperature . . . . . . . . . . . . . . . 78

6.17 Knock test average knock intensity . . . . . . . . . . . . . . . . . 79

B.1 Unmodified aluminum CFR piston drawing . . . . . . . . . . . . . . . 99

B.2 Modified piston drawing . . . . . . . . . . . . . . . . . 100

B.3 Modified piston - section view drawing . . . . . . . . . . . . 101

D.1 Uncoated piston crown after testing . . . . . . . . . . . . 105

D.2 Metal TBC coated piston crown after testing . . . . . . . . . . . 106

D.3 YSZ coated piston crown after testing . . . . . . . . . . . . . 107

E.1 Average heat flux into piston crown after accuracy error adjustment . . . 112

E.2 Average heat flux into piston crown after accuracy error adjustment with full $95 \%$ confidence level uncertainty windows . . . . . . . . . . . . 113

E.3 Average heat flux into piston crown after accuracy error adjustment with hypothetical $95 \%$ confidence level uncertainty windows . . . . . . . . . . 114 


\section{Nomenclature}

\section{Symbols}

\section{Greek}

$\begin{array}{ll}\alpha & \text { thermal diffusivity } \\ \omega & \text { cycle frequency } \\ \rho & \text { density }\end{array}$

Latin

$\begin{array}{ll}A_{n} & \text { Fourier coefficient } \\ B_{n} & \text { Fourier coefficient } \\ c & \text { specific heat capacity } \\ k & \text { thermal conductivity } \\ l & \text { depth of in-depth thermocouple within substrate } \\ N & \text { number of harmonics, or number of samples } \\ p & \text { pressure } \\ q & \text { heat } \\ R a & \text { average roughness }\end{array}$




\section{Superscripts}

O

degrees

derivative with respect to time

\section{Subscripts}

$\begin{array}{ll}\alpha & \text { alpha level } \\ e & \text { experimental } \\ i & \text { in-depth } \\ m & \text { mean } \\ s & \text { surface } \\ s t & \text { standard } \\ & \\ v & \text { vapour, or degrees of freedom }\end{array}$

\section{Acronyms}

BTC Before Top Centre

BC Bottom Centre 


$\begin{array}{ll}\text { CA } & \text { Crank Angle } \\ \text { CFR } & \text { Cooperative Fuels Research } \\ \text { CI } & \text { confidence interval } \\ \text { CO } & \text { Carbon Monoxide } \\ \text { CTE } & \text { Coefficient of Thermal Expansion } \\ \text { DAQ } & \text { Data Acquistion } \\ \text { FEA } & \text { Finite Element Analysis } \\ \text { HC } & \text { Hydrocarbon } \\ \text { IC } & \text { Internal Combustion } \\ \text { IMEP } & \text { Indicated Mean Effective Pressure } \\ \text { NOx } & \text { Nitrogen Oxides } \\ \text { PSZ } & \text { Partially Stabilized Zirconia } \\ \text { TBC } & \text { Thermal Barrier Coating } \\ \text { WN } & \text { Yttria-Stabilized Zirconia } \\ \text { WN } & \text { Wide Open Thrion } \\ \text { Ticon Nitride }\end{array}$




\section{Chapter 1}

\section{Introduction}

The automobile industry is facing a serious challenge to improve vehicle fuel efficiency. Global demand for cars is soaring - one forecast has the number of worldwide cars increasing five-fold by 2050 to 2.9 billion [1] - while the grim consequences of greenhouse gas induced climate change and a finite oil supply are becoming increasingly apparent. Governments are legislating stricter fuel consumption regulations and consumers are purchasing more fuel efficient models to reduce their environmental impact and spending on dearer fuel.

Reductions in fuel consumption can be achieved by a variety of measures, including improved aerodynamics, weight reductions and hybrid power trains. Significant improvements must also be made to the efficiency of the internal combustion (IC) engine that powers nearly all the world's vehicles. One promising technology for improving IC engine efficiency, as well as performance and durability, is the Thermal Barrier Coating (TBC).

\subsection{Thermal Barrier Coatings}

Thermal barrier coatings can be applied in the IC engine to insulate combustion chamber surfaces. The coatings can be applied to the entire combustion chamber or to select surfaces like the piston crown or valves. The primary purpose of the TBC is to raise 
surface temperatures during the expansion stroke, thereby decreasing the temperature difference between the wall and the gas to reduce heat transfer. Some of the additional heat energy in the cylinder can be converted into useful work, increasing power and efficiency. Reducing heat transfer also increases exhaust gas temperatures, providing greater potential for energy recovery with a turbocharger or possibly a thermoelectric generator. Additional benefits include protection of metal combustion chamber components from thermal stresses and reduced cooling requirements. A simpler cooling system would reduce the weight and cost of the engine while improving reliability.

Thermal barrier coatings are most commonly stabilized zirconias such as YttriaStabilized Zirconia (YSZ), but other ceramics like Silicon Nitride (SN) have been used. Thermal conductivities $(k)$ have ranged from less than $0.5 \mathrm{~W} / \mathrm{m} \cdot \mathrm{K}[2]$ to $10 \mathrm{~W} / \mathrm{m} \cdot \mathrm{K}[3]$, and thicknesses have ranged from $0.1 \mathrm{~mm}$ [2] to $4.5 \mathrm{~mm}$ [4]. Ceramic coatings can be applied by a variety of methods, although thermal spraying techniques such as plasma spray are the most common [5]. A bond layer with a Coefficient of Thermal Expansion (CTE) in between that of the TBC and metal substrate is typically used to improve coating adhesion.

At this time TBCs have not been adopted in production engines, but extensive research has been performed. While research has been performed on both diesel and Spark-Ignition (SI) engines, most work has focused on diesel engines because they are not susceptible to knock. In SI engines, elevated wall temperatures can promote knock, which is auto-ignition of the homogeneous air-fuel mixture in the end gas region. As such, less insulation must be used in SI engines to avoid overly high wall temperatures. The following sub-sections summarize some of the major research that has been performed on TBCs in IC engines. In some cases the insulation was provided by means other than TBCs but with the same effect of raising surface temperatures. 


\subsubsection{Research on Thermal Barrier Coatings in Diesel Engines}

Early research on insulated diesel engines produced conflicting results about their effect on heat flux, as some notable researchers actually observed increased peak heat flux rates. Furuhama and Enomoto covered the piston crown with a $4.5 \mathrm{~mm}$ SN disk over an air gap to raise the average surface temperature by several hundred degrees K [4]. Surface temperature measurements found that heat flux into the insulated piston crown was higher during the expansion stroke compared to an aluminum alloy piston. Woschni et al. made similar observations during experiments on a heavily insulated piston [6]. Both sets of authors suspected this result was due to changes in the convective heat transfer coefficient due to shrinking of the thermal boundary layer at significantly higher surface temperatures. Additionally, both studies found heat flux to be negative during the intake and compression strokes as heat was transfered from the hot walls to the cooler gas, with the effect of reduced volumetric efficiency and increased pumping work.

At the same time, other studies found TBCs did reduce heat flux as predicted. Assanis et al. measured surface temperatures of cast iron plugs coated with $1 \mathrm{~mm}$ of Partially Stabilized Zirconia (PSZ) installed in the cylinder head [7]. The coating increased mean surface temperatures by over $100 \mathrm{~K}$ and reduced peak transient heat flux by $80 \%$. Morel et al. coated the cylinder head, valves and piston with $1.25 \mathrm{~mm}$ of YSZ and measured reductions in peak heat flux of up to $50 \%$ in the cylinder head [8].

Other studies observed poor performance with insulated diesel engines that was attributed primarily to degraded combustion $[9,10]$. Heat release analysis showed lower premixed energy release and longer combustion duration. However, Cheng et al. believed the degraded combustion was due to poor injector performance, and insulated engines still had potential if the injector could be optimized for higher temperatures [9].

The trend recently has been towards thinner TBCs to balance a reduction in peak heat flux without overly affecting volumetric efficiency and pumping work. Wong et al. conducted a simple parametric modeling study to determine the optimum thickness for 
efficiency [11]. It was found that the optimum thickness for typical ceramic coatings on the piston and cylinder head was only $0.1 \mathrm{~mm}$. Coatings thicker than $0.5 \mathrm{~mm}$ would have a negative effect on efficiency. A number of experimental studies using thin coatings in the range of $0.3-0.35 \mathrm{~mm}$ on the piston crown and cylinder head demonstrated gains in efficiency ranging from 1 - $9 \%[12,13,14,15]$.

Jaichandar and Tamilporai completed a thorough review of the research on insulated diesel engines prior to 2003 [16]. The survey found that all numerical studies predicted efficiency improvements with insulation. The majority of experimental studies show performance improvements with insulation, although in many cases the improvements were achieved after engine modifications such as injector optimization and increased intake pressure. While the increased heat flux observations by Furuhama and Enomoto and Woschni et al. have yet to be resolved, TBCs do show promise to improve diesel engine efficiency.

\subsubsection{Research on Thermal Barrier Coatings in Spark-Ignition Engines}

Although there has been less interest in using TBCs in SI engines, the research that has been performed shows potential for performance improvements. Kamo et al. conducted a series of analytical studies to investigate the use of thin ceramics in engines [5]. The researchers found that a thin coating with low thermal inertia would actually reduce heat transfer to the gas during intake and compression, thereby increasing volumetric efficiency and reducing compression work. Furthermore, moderately elevated surface temperatures would reduce or eliminate the accumulation of carbonaceous deposits. In uninsulated engines, deposits accumulate over time, acting as insulators and causing pre-ignition and knock in SI engines. Retarding spark timing or switching to higher octane fuel is typically required over time to avoid these abnormal combustion phenomena. Therefore, if peak wall temperatures can be raised enough to reduce deposit build-up but not so 
much to induce auto-ignition, a TBC could reduce the need for changing spark timing or increasing fuel octane as the engine ages.

Assanis and Mathur tested a gasoline engine with a combustion chamber fully coated with plasma sprayed zirconia of thickness ranging from $0.10-0.27 \mathrm{~mm}$ [2]. The results confirmed that coatings could be used in SI engines to increase power and efficiency without increasing the incidence of pre-ignition or knock. The gains were most significant at low speeds, where the coated engine achieved $18 \%$ higher brake power and $10 \%$ reduced brake specific fuel consumption. At higher speeds, the coated engine did not perform as well as when uncoated, although this was attributed to issues with increased engine friction as the cylinder wall was coated. Mendera coated a piston with $0.2-0.4 \mathrm{~mm}$ of plasma sprayed zirconia and achieved reductions of fuel consumption ranging from 2 - $6 \%$ [17]. Parlak and Ayan coated portions of a piston with $0.15 \mathrm{~mm}$ of zirconium and observed reductions in fuel consumption at low compression ratios, but at a higher compression ratio of 8.2:1, knock hindered performance [18].

Nakic et al. conducted detailed experiments to study the effect of surface temperatures on deposit growth [19]. The piston was insulated with ceramic wafers of varying thickness under an iron cap to control surface temperatures. A single cylinder, four stroke research engine was utilized running with a slightly rich air fuel mixture. Test results showed that no deposits accumulate above a critical surface temperature of $320^{\circ} \mathrm{C}$. This result was attributed to decreasing condensation of the higher boiling point components of the gasoline, which are typically the source of the deposits.

Thermal barrier coatings also provide opportunities for emissions improvements. In two-stroke SI engines, TBCs have been shown to improve fuel evaporation and combustion stability, thereby reducing carbon monoxide (CO) and hydrocarbon (HC) emissions $[20,21]$. As two-stroke engines typically run rich to promote combustion stability, elevated wall temperatures allow for leaner operation, which further improves fuel efficiency and reduces emissions. Unfortunately, higher temperatures may increase formation of 
Nitrogen Oxides (NOx).

\subsubsection{Research on Thermal Barrier Coating Materials}

The primary obstacle to the adoption of TBCs in commercial engines is durability. Ceramics have low CTEs, ranging from approximately $3 \mathrm{E}-6 /{ }^{\circ} \mathrm{C}$ for $\mathrm{SN}$ to $10 \mathrm{E}-6 /{ }^{\circ} \mathrm{C}$ for YSZ [16], compared to $12 \mathrm{E}-6 /{ }^{\circ} \mathrm{C}$ for iron and steel and $24 \mathrm{E}-6 /{ }^{\circ} \mathrm{C}$ for aluminum. The difference in CTEs stresses the interface between the ceramic coating and metal substrate. This stress is particularly large when the substrate is aluminum. As the ceramic is brittle, small imperfections can easily propagate into large cracks and the coating may delaminate from the bond layer and substrate.

Research on ceramic TBCs in diesel engines has repeatedly found issues with durability. Woods et al. completed a 100 hour endurance test on an engine insulated with $0.5 \mathrm{~mm}$ of plasma sprayed zirconia [22]. The researchers developed custom titanium combustion chamber components that were optimized for TBC durability, yet still found visible cracks in the piston, cylinder wall and head surfaces after the test.

A number of researchers have been developing advanced TBCs with improved durability compared to standard ceramics. For example, Adiabatics Inc. developed a proprietary high temperature polymer binder that can be mixed with ceramic powders [23]. According to the authors, heating the coating after application promotes "conversion of the polymer to ceramic". Thermal shock tests and engine trials found the polymer-based TBCs to be more durable than YSZ, and the polymer-based TBC displayed no evidence of cracking or chipping after 53 hours of engine trials.

Other methods of improving coating durability have been proposed. Soltani et al. investigated the benefits of using nanostructured ceramic powders as opposed to conventional micron sized powders typically used in plasma spray application [24]. Earlier research on gas turbine blades suggests the nanostructured coatings have better crack resistance and adhesion strength. The authors also propose using multilayer coatings 
to reduce CTE mismatches and interface stresses. Both concepts require further development, including engine testing. In 1984 Tolokan et al. proposed using a fiber metal "strain isolator" layer between the ceramic coating and the metal substrate [25]. The layer would be brazed or soldered to the metal substrate and the ceramic would be plasma sprayed on top. Preliminary shock test results showed the fiber metal greatly improved ceramic adhesion and reduced cracking, although the technology required further development including engine testing. Twenty five years later, a lack of further reports or commercialization suggests the technology has not developed as expected.

The concept of a metal-based TBC was presented by Shin et al. [26]. Coated samples were produced by plasma spraying a nanostructured iron based alloy powder. The powder itself had low thermal conductivity, with $k$ of approximately $5-6 \mathrm{~W} / \mathrm{m} \cdot \mathrm{K}$, and the structure of the coating reduced this value to between $2.0-3.4 \mathrm{~W} / \mathrm{m} \cdot \mathrm{K}$. These values are not considerably greater than that of YSZ which the authors measured as $1.2 \mathrm{~W} / \mathrm{m} \cdot \mathrm{K}$. While the TBC was not tested in an engine, its metal nature suggests that its CTE and ductility are well suited for engine conditions.

\subsubsection{Thermal Barrier Coating Research Opportunities}

The previous review of IC engine TBC research identifies numerous areas where additional study would be of benefit. Insulated diesel engines have been extensively researched, and further studies would add to the volume of performance and emissions data already collected. Work could also proceed on optimizing engine components, such as the fuel injector, and operational strategies, such as injection timing and intake temperature and pressure, to maximize efficiency gains.

Thermal barrier coatings in SI engines, conversely, have not been extensively researched and there are still significant opportunities for study. Further experimental data from a wide range of engine operating conditions would help to verify the performance and efficiency gains reported by the few earlier studies. Surface temperature 
and heat flux measurements would provide important information on the performance of the coating as a thermal barrier. Much more work is required to determine the optimum level of insulation to maximize performance gains without promoting knock. This optimization includes the type of coating used and its thickness.

There is also significant potential for additional research in the area of TBC materials. Commercialization of TBCs in engines requires that the coatings be extremely durable and still have desirable insulating properties. Durability improvements may be achieved by refinements to traditional ceramic materials such as YSZ and their application processes. Improvements may also come from entirely new TBC materials, such as metal-based coatings. Prior to being considered for a production engine, any coating will need to be rigorously tested to verify its durability and effect on engine performance.

\subsection{Research Program Objectives and Overview}

This thesis research program focused on two areas requiring further study: the use of TBCs in SI engines and the development of more durable coatings. A new metal-based TBC and conventional YSZ were tested in an SI engine to investigate the advantages of insulation and if the metal-based coating has potential to be a more durable substitute for YSZ.

The metal TBC was produced from a nanostructured iron-based refractory powder housed in a cored stainless steel wire (The Nanosteel Company Inc. proprietary product). The coating was applied by a wire arc technique, and the composition of the coating was a mixture of stainless steel and the nanostructured powder. The wire was $1.6 \mathrm{~mm}$ in diameter and the stainless steel walls were approximately $0.22 \mathrm{~mm}$ thick. From these dimensions, it was estimated that the coating composition was approximately 50 $\%$ stainless steel and $50 \%$ nanostructured powder. The approximate properties of the metal-based TBC are shown in Table 1.1. The values listed were measured from coating 
Table 1.1: Thermal barrier coating properties

\begin{tabular}{lcc}
\hline & Metal-Based TBC $[27]$ & YSZ $[26]$ \\
\hline Application Method & Wire Arc Thermal Spray & Plasma Spray \\
Thermal Diffusivity $\left(\mathrm{m}^{2} / \mathrm{s}\right)$ & $1.8 \mathrm{E}-6$ & $0.49 \mathrm{E}-6$ \\
Density $\left(\mathrm{kg} / \mathrm{m}^{3}\right)$ & 6400 & 4950 \\
Specific Heat Capacity $(\mathrm{kJ} / \mathrm{kg} \cdot \mathrm{K})$ & 0.43 & 0.49 \\
Thermal Conductivity $(\mathrm{W} / \mathrm{m} \cdot \mathrm{K})$ & 5.0 & 1.2 \\
Porosity $(\%)$ & 8.9 & 10.0 \\
Coefficient of Thermal Expansion $\left(\mathrm{K}^{-1}\right)$ & $15 \mathrm{E}-6$ & $9.8 \mathrm{E}-6[16]$ \\
\hline
\end{tabular}

samples, or in some cases estimated from measured values of coatings produced from the same raw material but different application method. The YSZ coating was applied by plasma spraying, and properties of a typical YSZ coating are also shown in Table 1.1.

The research program was divided into three main stages. The first stage was the preliminary cylinder wall tests, in which the metal coating was applied to the face of plugs that threaded into access ports in the cylinder wall. The plugs were instrumented with thermocouples to determine the coating's effect on substrate temperatures. Additional tests were run to determine if the coating's presence promoted knock.

The second stage involved development of a surface thermocouple. In the final stage it was desired to measure surface temperatures and heat flux, and a review of existing technology identified a lack of accurate thermocouples that are also simple to fabricate. An existing thermocouple developed for other applications was modified for engine use and optimized with Finite Element Analysis (FEA). The design was then engine tested to ensure that it performed as predicted. An in-depth thermocouple was also developed to measure temperatures within the substrate, as is required to calculate heat flux.

The final stage involved testing of both the metal and YSZ TBCs on the surface 
of a piston. The piston was instrumented with surface and in-depth thermocouples to measure heat flux. A mechanical linkage was used to route the thermocouple wires out of the piston and crank case for acquisition. Cylinder pressure was measured to determine peak pressure and Indicated Mean Effective Pressure (IMEP) and to monitor for knock. A number of other parameters were measured, including torque and exhaust temperature, to examine the coatings' effect on performance.

\subsection{Document Overview}

This document is divided into seven chapters including this introductory chapter. Chapter 2 describes the experimental setup and methodology common to all stages of the research program. Chapter 3 covers the preliminary cylinder wall tests, including setup and methodology unique to the tests and the results. Chapter 4 details the development processes for the surface and in-depth thermocouples that were required for the piston tests. The setup and methodology unique to the piston tests are described in Chapter 5, and the results of these tests are presented and discussed in Chapter 6. The conclusions and recommendations from the entire research program are presented in Chapter 7 . Additional information relevant to the research program but not suitable for the main text can be found in the appendices. 


\section{Chapter 2}

\section{General Experimental Setup and Methodology}

The experimental setup and methodology were varied for each stage in the research program to best meet specific test objectives. The aspects of the setup and methodology that remained constant throughout the full research program are described in this section. Experimental details specific to individual tests are described in subsequent sections when relevant.

\subsection{Engine Description}

A gasoline fueled, single cylinder Cooperative Fuels Research (CFR) engine was used for all tests. The engine utilizes a one-piece cylinder and head assembly with height adjustability relative to the crank shaft and piston. The clearance volume and compression ratio can be easily varied by raising or lowering the assembly. The one piece assembly also provides for easy replacement of the cylinder and head if a different geometry is desired. Multiple cylinder assembly configurations are available featuring a varying number of threaded access ports around the upper cylinder wall perimeter. The ports are fully in the clearance volume and therefore provide continuous access to the in-cylinder gases. 
Table 2.1: CFR engine specifications

\begin{tabular}{lc}
\hline Number of cylinders & 1 \\
Bore & $8.255 \mathrm{~cm}$ \\
Stroke & $11.43 \mathrm{~cm}$ \\
Displacement volume & $612 \mathrm{~cm}^{3}$ \\
Compression ratio & Variable \\
Spark timing & Variable \\
Fuel metering system & Carburetor \\
Load control & DC dynamometer \\
Cooling system & Evaporative with water-cooled condenser \\
Cooling Fluid & Water \\
\hline
\end{tabular}

Two different cylinder assemblies were used over the course of testing as described in subsequent sections. Important engine specifications are listed in Table 2.1, and further information can be found in the ASTM Manual of Engine Test Methods for Rating Fuels [28]. All tests used 87 octane regular pump gasoline and were run with a stoichiometric air fuel mixture.

\subsection{Data Acquisition and Processing}

Many temperature and pressure signals were measured and recorded electronically over the duration of testing. Three different National Instruments Data Acquisition (DAQ) boards were used depending on device availability and test requirements. The DAQ boards used are listed in Table 2.2 along with their corresponding termination blocks and key specifications. The DAQ boards were installed in a PC computer. Data were logged and processed with programs written in LabVIEW software, and when necessary additional processing was performed in MATLAB. Descriptions of these programs can 
Table 2.2: Data acquisition boards

\begin{tabular}{ccccc}
\hline $\begin{array}{c}\text { Data Acquisition } \\
\text { Board }\end{array}$ & $\begin{array}{c}\text { Termination } \\
\text { Block }\end{array}$ & $\begin{array}{c}\text { Double Ended } \\
\text { Analog Inputs }\end{array}$ & $\begin{array}{c}\text { Maximum Sampling } \\
\text { Rate (MS/s) }\end{array}$ & $\begin{array}{c}\text { Maximum Resolution } \\
(\mu \mathrm{V})\end{array}$ \\
\hline NI PCI-6220 & NI SCB-68 & 8 & 0.25 & 6 \\
NI PCI-6251 & NI SCB-68 & 8 & 1 & 3 \\
NI PCI-6071E & NI BNC-2080 & 8 & 1.25 & 24 \\
\hline
\end{tabular}

be found in Appendix A.

Data were measured either as a function of time or as a function of engine position. When using engine position, an encoder (BEI Encoder and Systems Company model no. H25D-SS-1800-ABZ-7407-LED-EM16) connected to the crank shaft provided the sampling time base at a frequency of 1800 samples per revolution, or one sample per $0.2^{\circ}$ Crank Angle (CA) rotation. The encoder also provided a once-per-revolution "Z" pulse which was used as a reference to determine exact crank shaft position.

\subsubsection{Error Bars}

Much of the data in the figures presented in this document are averages of multiple data points. When practical these figures contain error bars to indicate the $95 \%$ confidence interval for the given data set. The intervals were calculated with either $\mathrm{t}$ or $\mathrm{z}$ values depending on sample size.

\subsection{Cylinder Pressure Measurement}

A piezoelectric pressure transducer (Kistler Group model no. 6125B) was used to measure in-cylinder pressures during tests when such data were required. The transducer was installed in the cylinder wall access ports in a custom made adapter. The adapter was designed according to previous work by Randolph [29], and featured a slotted face to 
allow for accurate pressure measurement while preventing flame impingement on the transducer face. The transducer was connected by high impedance cable to a charge amplifier (Kistler Group model no. 5010) set with a one second time constant. The charge amplifier was connected to the PCI-6071E DAQ board through through the BNC-2080 termination block ${ }^{1}$. A $33 \mathrm{kHz}$ low pass filter (Kistler Group model no. 5311A) was used to remove signal noise due to the transducer's natural frequency and resonance in the slotted adapter. Cylinder pressure was measured as a function of crank angle position.

The pressure transducer was calibrated according to a procedure outlined by Burcar [30]. In short, the transducer was installed in a pressure bomb along with a slower response strain gauge pressure transducer (Schaevitz model no. PS10061-005). The bomb was fitted with a high flow rate ball valve to allow for fast pressure blowdown. The bomb was pressurized with nitrogen gas and then rapidly depressurized to atmospheric pressure. The fast voltage response of the piezoelectric transducer and the actual pressure drop indicated by the strain gauge transducer were recorded by the DAQ system. The blowdown test was repeated 10 times at pressures ranging from 0 to $9000 \mathrm{kPa}$. A linear curve fit to the data found that the piezoelectric transducer had a response of 908.9 $\mathrm{kPa} / \mathrm{V}$.

Piezoelectric pressure transducers measure pressure changes, not absolute pressures, and therefore a second pressure sensor was required for the piezoelectric sensor to be referenced to periodically. For this purpose, an absolute pressure sensor (General Motors model no. unknown) salvaged from a production vehicle was installed in the intake air line. The piezoelectric pressure signal was referenced to the intake pressure sensor every cycle at Bottom Centre (BC) at the end of the intake stroke.

MATLAB was used to process pressure data to calculate peak pressures and Indicated Mean Effective Pressures (IMEPs). IMEP is defined as the integral of pressure with

\footnotetext{
${ }^{1}$ The PCI-6071E failed near the end of the research program. It was replaced with a PCI-6251 DAQ board with an SCB-68 termination block. The accuracy of the new DAQ system was compared to the old and found to be accurate within $0.1 \%$.
} 
respect to volume over the full engine cycle. Cylinder pressure data were also used to identify and quantify knock as described in the following section.

\subsubsection{Knock Quantification}

The purpose of certain tests was to determine the effect of the TBCs on engine knock. To further promote knock during these tests, spark timing was advanced and a 1000 Watt heater was used to elevate intake air temperatures. Intake air temperatures were set with a temperature controller (Omega Engineering Inc. model no. CN9000A).

Knock was identified and quantified through analysis of cylinder pressure data. Knock intensity was defined as the peak-to-peak amplitude of the $3-33 \mathrm{kHz}$ band pass filtered pressure signal. Alternative knock indicators have been used; this method was chosen for its simplicity and it has previously been shown to be a good indicator [31]. The $3-33 \mathrm{kHz}$ range was chosen to capture the first three circumferential modes of acoustic vibration, which are the most dominant pressure wave frequencies during knock [32]. In the CFR engine, these modes should occur between 6 and $15 \mathrm{kHz}$ [33]. The $3 \mathrm{kHz}$ high pass filter was a software third order Butterworth type filter, and the $33 \mathrm{kHz}$ low pass filter was the Type 5311A filter previously described. Figure 2.1 provides two examples of filtered and unfiltered pressure signals for cycles with different levels of knock intensity.

\subsection{Visual Display Sensors}

The CFR engine was instrumented with a number of sensors with visual displays that were used to monitor performance and provide feedback to the operator. These sensors were not connected to a DAQ board for electronic recording but in some cases their values were recorded manually on paper. A Nernst cell oxygen sensor was located in the exhaust line. The voltage output was measured by a digital multimeter, which the operator monitored to ensure that the carburetor was delivering the desired air fuel mixture to the engine. 


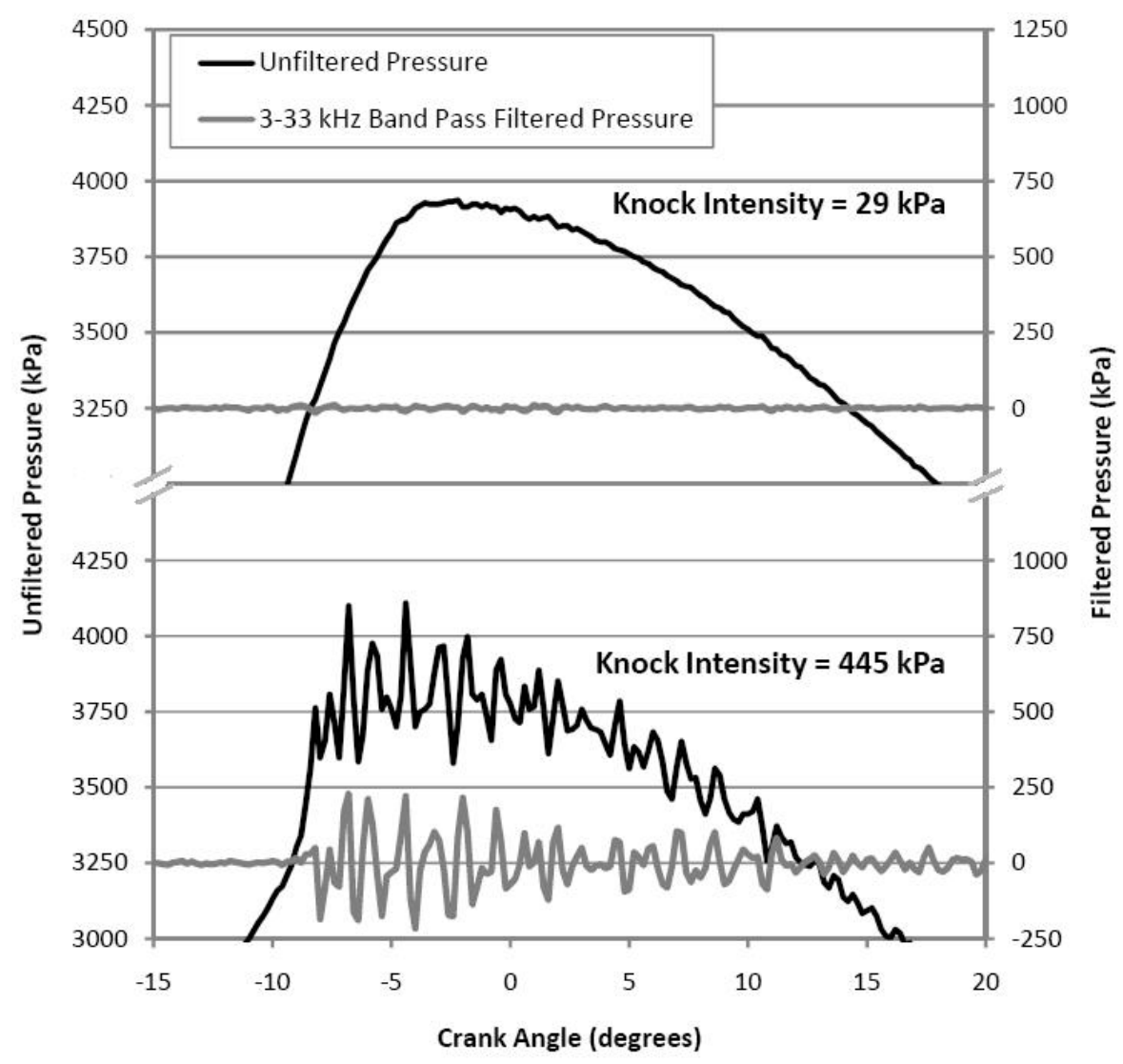

Figure 2.1: Sample cylinder pressure traces showing different knock intensities

Engine speed was measured off the dynamometer by a tachometer. A strain gauge load cell measured the force required to prevent rotation of the dynamometer, and torque was calculated from this force. Type $\mathrm{K}$ thermocouples were used to measure temperatures of the exhaust gas, intake air, cooling water and oil sump. 


\section{Chapter 3}

\section{Preliminary Cylinder Wall Tests}

The first stage in the research program was testing of the metal TBC in the cylinder wall. The objective of the tests was to obtain preliminary data on the effect of the coating on substrate temperatures and knock. This chapter describes the procedure used for these tests and presents the results.

\subsection{Setup and Methodology}

A cylinder assembly with three threaded access ports was used to provide for direct exposure of the coating to in-cylinder gases in multiple locations. A cross section of the cylinder assembly is shown in Figure 3.1. The cylinder bore was 0.020 inches oversize and a corresponding oversized cast iron piston was used to fit the cylinder. The metal TBC was applied in $0.5 \mathrm{~mm}$ thick layers to the face of plugs that threaded into the ports. The plugs were machined from an engine casting aluminum alloy cylinder head. The dimensions of the plugs are shown in Figure 3.2. Teflon tape was wrapped around the threads to minimize heat transfer in that direction.

Two holes were drilled in each plug to allow for insertion of type $\mathrm{K}$ thermocouples to depths of 3 and $11 \mathrm{~mm}$ from the face. The thermocouples were held in place with a gasket maker (Permatex model no. Ultra Blue), and a thermal joint compound (Wake- 


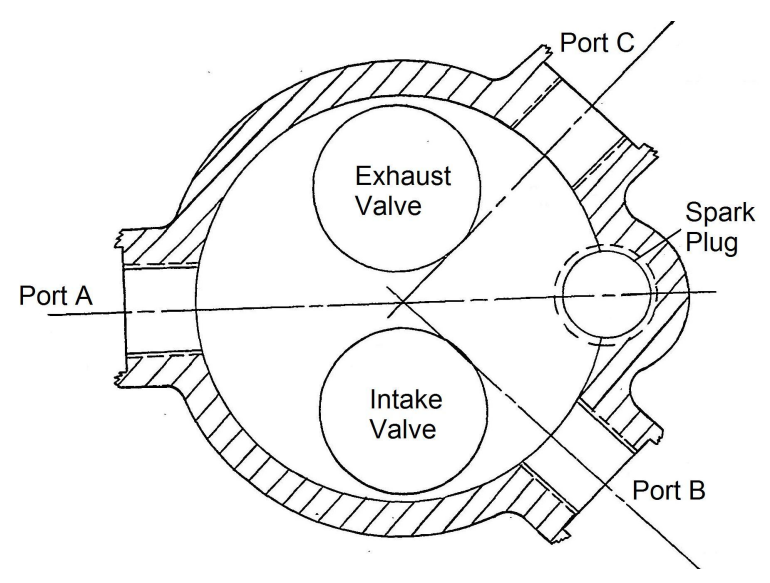

Figure 3.1: Cylinder wall tests cylinder assembly - cross section viewed from above, adapted from [34]

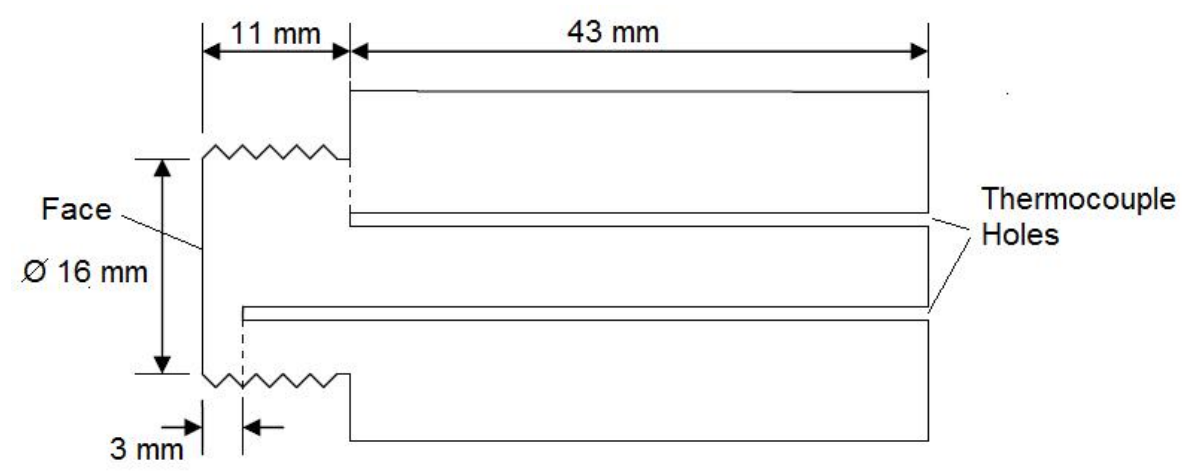

Figure 3.2: Plug dimensions

field Thermal Solutions model no. Type 126) was used to minimize contact resistance between the thermocouple junctions and the plug. In the following sections on test results, thermocouple locations are referred to by their access port and distance from the plug face. For example, the thermocouple in access port B that is $3 \mathrm{~mm}$ from the face will be referred to as "B3".

The plug thermocouples and the inlet air thermocouple were connected to the PCI6220 data acquisition board through an SCB-68 termination block. LabVIEW code was written to acquire the temperature data at a frequency of $1000 \mathrm{~Hz}$. The data were 
Table 3.1: Cylinder wall test engine operating parameters (BTC - Before Top Centre)

\begin{tabular}{lcc}
\hline Speed & & 1500 RPM \\
Load & & Full \\
& Temperature Tests & $20^{\circ}$ CA BTC \\
Spark Timing & Knock Tests & $40^{\circ}$ CA BTC \\
Compression Ratio & & $8.7: 1$ \\
Coolant & & Boiling Water \\
& Temperature Tests & Unheated \\
Intake Air Temperature & Knock Tests & $35 \& 65^{\circ} \mathrm{C}$ \\
\hline
\end{tabular}

subsequently filtered with a $100 \mathrm{~Hz}$ low pass filter and then averaged into one second intervals. The type $\mathrm{K}$ thermocouple calibration built into LabVIEW software was used to generate temperature data from the raw thermocouple voltages. The calibration of all thermocouples was checked against a physical ice point and against boiling water; both checks provided satisfactory agreement. A description of the LabVIEW program, named "Prelim_Temp.vi", can be found in Appendix A.

All data presented in the results were recorded after a warm-up of at least five minutes at idle and seven minutes at Wide Open Throttle (WOT). By this time, the cooling water had stabilized at its boiling point and plug temperatures were approximately steady. It was attempted to perform every test under similar conditions, although this was impossible due to changes in ambient conditions, oil temperature, etc. To provide a universal measure of test conditions, a control plug was left in port A throughout all tests except the knock test. This control plug was uncoated for all tests. Table 3.1 provides a summary of the engine operating parameters used for the cylinder wall test. For clarity, a few additional setup and methodology details specific to the knock test are provided at the start of Section 3.3. 


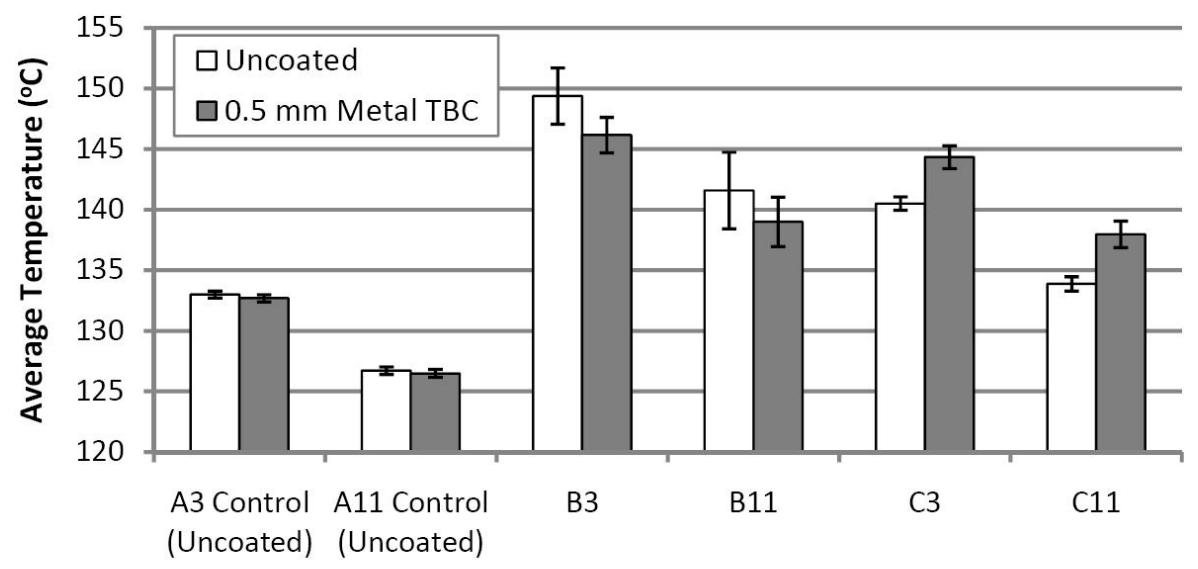

Thermocouple

Figure 3.3: Average plug temperatures before and after coating

\subsection{Temperature Test Results and Discussion}

The first preliminary tests compared temperatures in the plugs before and after coating, the results of which are shown in Figure 3.3. The same plugs were installed in the same ports before and after coating to eliminate uncertainty about whether temperature differences were due to variation between plugs.

During fabrication of one of the plugs, an error was made in the threading process that resulted in shallow threads. When installed in the cylinder wall, this plug ran up to $15^{\circ} \mathrm{C}$ hotter than the other plugs with good threads. This difference was likely due to increased contact resistance reducing heat transfer from the plug to the engine block. To investigate the coating's performance on a hotter substrate, the damaged plug was also tested and the results are shown in Figure 3.4. The damaged plug was tested before and after coating in both ports B and C.

Figures 3.3 and 3.4 on balance show higher temperatures in the coated plugs, suggesting the TBC actually increased net heat flux. Only thermocouples B3 and B11 in Figure 3.3 show reduced temperatures after coating, and these differences are not statistically significant to a $95 \%$ confidence level when checked with a Student's t-Test. On the other hand, the thermocouple data that show temperature increases after coating are all 


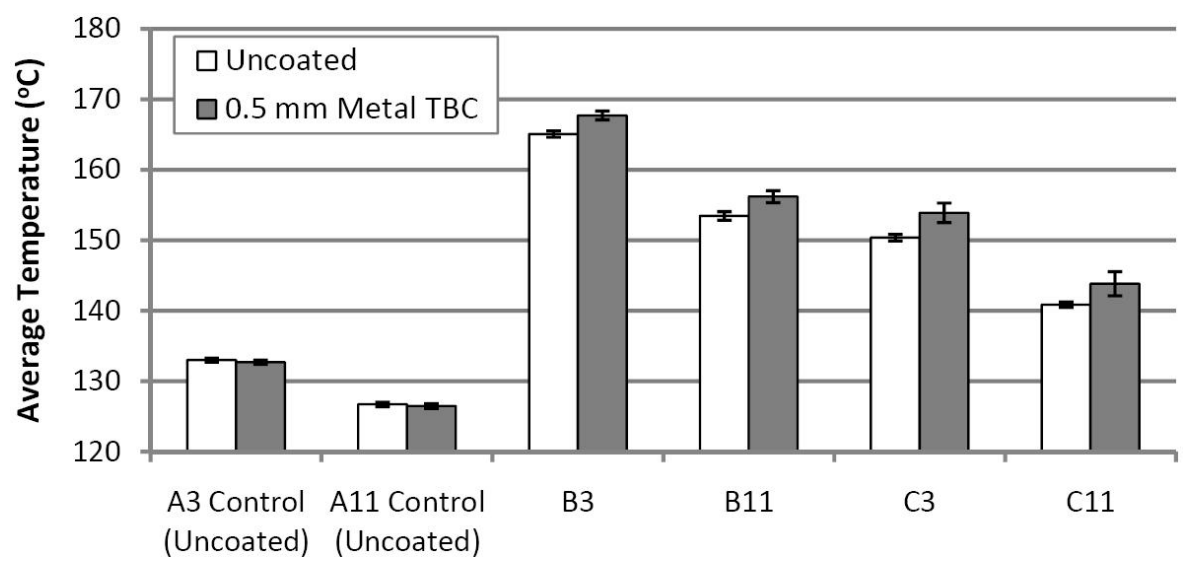

Thermocouple

Figure 3.4: Average damaged plug temperatures before and after coating

statistically significant. This result is unexpected, but there are possible explanations for the temperature increases.

During late intake and early compression, heat is transferred from the combustion chamber surfaces to the cooler intake gas. It is possible that the TBC reduces heat flow in this direction more than it reduces heat flow in the primary direction from the gas to the wall. This would effectively increase net heat transfer and plug temperatures.

A second explanation is that surface roughness increases convective heat transfer by changing the effective area available for heat transfer. This effect was observed by Tsutsumi et al., who found that applying a mirror finish to combustion chamber surfaces reduces component temperatures and overall heat transfer [35]. In the present study, the metal TBC had a very rough finish, while the uncoated plug face had a much smoother machined finish. The effect of surface roughness was explored in more detail as is described in Sub-Section 3.2.1.

A point of interest in Figures 3.3 and 3.4 is the temperature difference between ports $\mathrm{B}$ and $\mathrm{C}$, which are near the inlet valve and exhaust valve respectively. The difference is likely because of variation in proximity to coolant passages and coolant circulation patterns. 


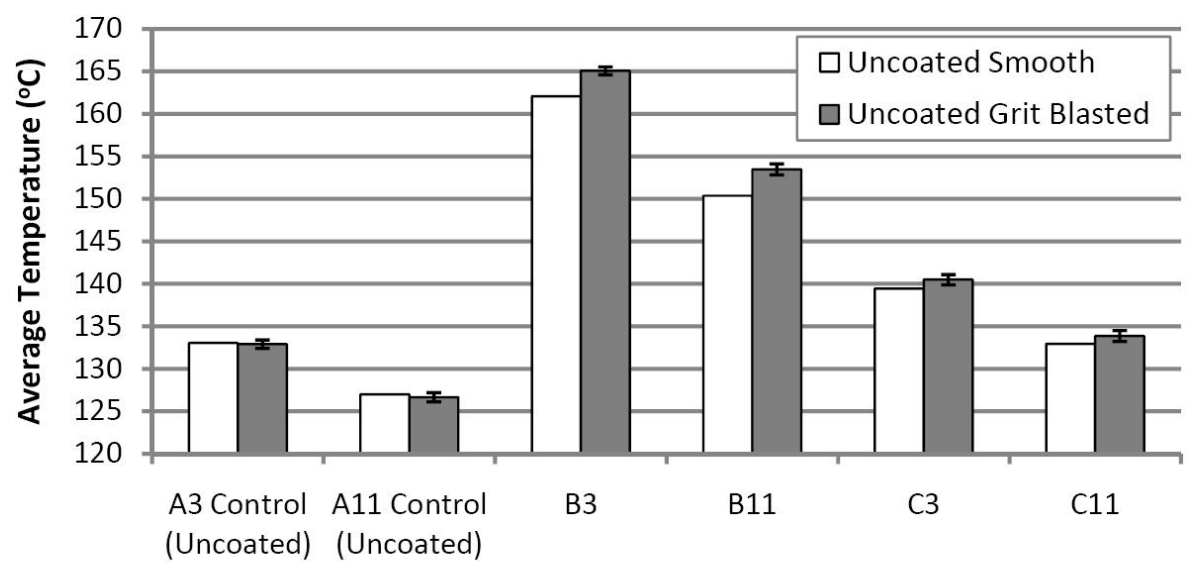

Thermocouple

Figure 3.5: Average uncoated plug temperatures before and after grit blasting

\subsubsection{Effect of Surface Roughness}

Two experiments were performed to investigate the effect of surface roughness on substrate temperatures. The first experiment measured temperatures of uncoated plugs before and after grit blasting was performed to increase roughness. The results are shown in Figure 3.5. It should be noted that the uncoated smooth finish experienced only one testing cycle before grit blasting, and therefore no error bars are shown on those temperatures. Also, the plug with damaged threads was used in port B, and is the reason for the considerably higher temperatures measured there.

The second experiment on surface roughness measured temperatures in a coated plug before and after polishing to a mirror finish. The results are shown in Figure 3.6.

Figures 3.5 and 3.6 both show that plug temperatures were higher with the rougher surface finish, suggesting that roughness does increase heat transfer.

\subsection{Knock Test Results and Discussion}

Preliminary knock tests were conducted to determine if the presence of the metal TBC increased the incidence of knock. Details about the pressure measurement system and 


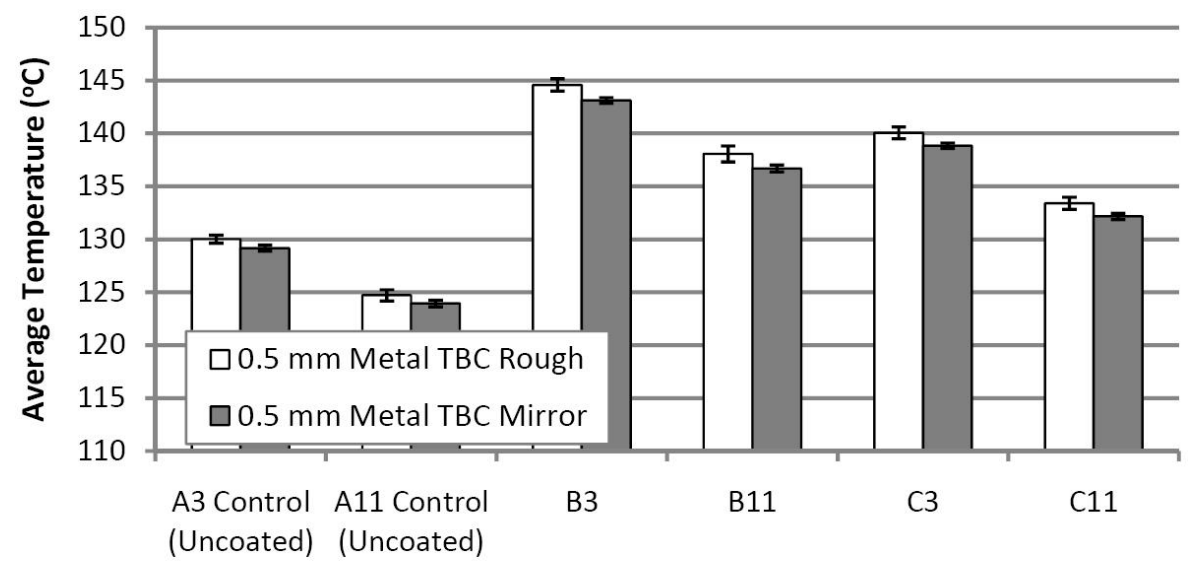

Thermocouple

Figure 3.6: Average metal TBC coated plug temperatures before and after polishing

knock quantification method are provided in Section 2.3. The LabVIEW program used for these tests was named "Prelim_Knock.vi", and further processing was performed by the MATLAB program "Prelim_Knock.m". Details on both of these programs can be found in Appendix A. New plugs were used for these tests to minimize the influence of deposits. The plugs were installed in ports $\mathrm{A}$ and $\mathrm{C}$ and the pressure transducer was installed in port B.

The results of the knock tests are shown in Figure 3.7. Each bar represents the average of approximately 600 cycles, and knock intensity values for individual cycles were between 20 and $1250 \mathrm{kPa}$. The results show that average knock intensity levels were slightly lower with the coated plugs installed. However, this result should not be interpreted as a reduction in knock because the coated area was only a small fraction of the total combustion chamber surface area. Rather, it should be concluded that the TBC did not promote knock during these tests. Tests with a larger coated surface area are required to more rigorously investigate the coating's effect on knock levels. These tests could show an increase in knock due to higher surface temperatures or a decrease in knock if deposit accumulation is reduced. 


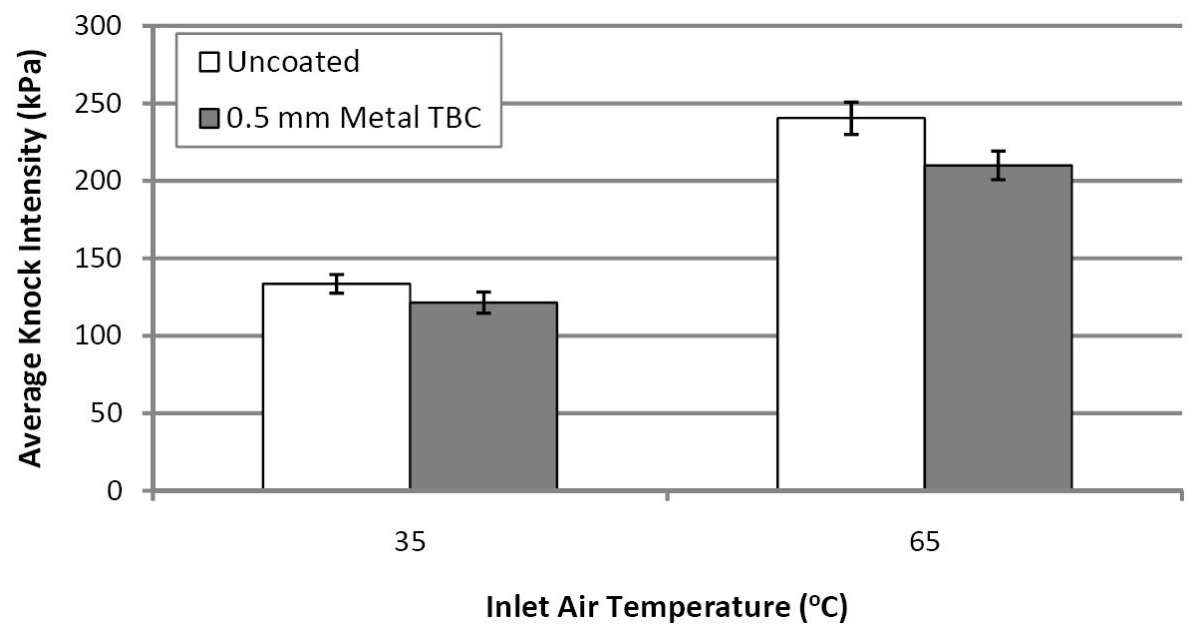

Figure 3.7: Average knock intensity

\subsection{Preliminary Cylinder Wall Test Summary}

In these preliminary tests, the metal TBC was applied to the face of aluminum plugs, which were installed in ports around the cylinder wall. Temperatures were measured within the plugs and in-cylinder pressure data were analyzed to identify and quantify knock. The following points summarize the results:

1. The metal TBC did not significantly reduce and more likely increased net heat transfer. In some tests the TBC reduced plug temperatures, but more often it increased plug temperatures.

2. Reducing surface roughness appeared to reduce heat transfer through the TBC, as demonstrated by a reduction of plug temperatures after the coating was polished to a mirror finish. A similar effect was observed with uncoated plugs that increased in temperature after being grit blasted.

3. The presence of the TBC in the end gas region did not increase knock.

These preliminary results justified the need for further study of TBCs on the piston crown as described in Chapters 5 and 6 . For the piston tests it was desirable to have 
accurate heat flux and surface temperature data. For this purpose, a fast response surface thermocouple and an in-depth thermocouple were developed, as is described in the next chapter. 


\section{Chapter 4}

\section{Thermocouple Development}

For the piston tests, it was desired to measure instantaneous surface temperatures and heat flux in the piston crown. These tasks required surface thermocouples paired with "indepth" thermocouples within the substrate approximately five millimeters behind the surface. Existing thermocouples did not meet this study's needs for accuracy and cost effectiveness, and therefore surface and in-depth thermocouples were developed. This chapter describes the development process.

\subsection{Surface Thermocouple Development}

Measurement of combustion chamber surface temperatures is necessary for many areas of engine research, and for many years the thermocouple has been the sensor most commonly used for this purpose. However, there is no consensus about the optimal thermocouple design or even general configuration that best suits fast response engine applications.

The primary consideration when selecting or designing a surface thermocouple is accuracy at measuring "true" temperatures, being the temperatures that would exist if the thermocouple was not present. Indeed, this criterion embodies the experimenter's age-old challenge of taking measurements without changing what is being measured. For

the surface thermocouple, this includes accurate measurement of average temperatures 
and temperature swings, while minimizing delays in response time. Additionally, the thermocouple should be robust and simple to fabricate and install. Finally, it is necessary that it fits within a researcher's budget.

The accuracy issue was explored in 1989 by Assanis and Badillo [36], who used FEA to model a $0.452 \mathrm{~mm}$ diameter coaxial thermocouple embedded in an aluminum piston. A coaxial thermocouple is essentially an insulated wire of one thermocouple element housed within a tube of a second element. A thin metal junction forms the electrical connection between the wire and tube at the thermocouple tip. Assanis and Badillo's analysis found that type $\mathrm{K}$ and type $\mathrm{J}$ thermocouples overestimate the magnitude of true temperature swings by 59 and $69 \%$, respectively. This difference is due to the substantially different thermal properties of the aluminum substrate compared to the thermocouple materials. Aluminum's thermal conductivity is at least three times greater than that of every metal in type $\mathrm{K}$ and type $\mathrm{J}$ thermocouples, and aluminum's thermal diffusivity is at least four times greater than that of the thermocouple metals. As such, heat does not diffuse as readily through the thermocouple and its junction experiences larger temperature swings than the more conductive aluminum substrate. This difference in thermal properties also introduces lateral heat conduction between the thermocouple and the substrate. Similar coaxial thermocouples have been used in recent engine heat transfer studies [37, 38].

Furuhama and Enomoto developed a different coaxial thermocouple which their analysis found to be very accurate at measuring temperature swings [4]. The design featured a $3 \mathrm{~mm}$ aluminum cylinder with a $0.17 \mathrm{~mm}$ hole drilled through to house an insulated constantan wire. Interestingly, copper was used to form the junction and its thickness was optimized to provide sufficient heat conduction from the wire tip to the aluminum to allow for temperature equalization. The optimal copper thickness was found to be 7 - $10 \mu \mathrm{m}$. However, the $0.17 \mathrm{~mm}$ diameter hole is too small to be drilled in a standard machine shop and therefore this exact design was not feasible for the present study.

The eroding thermocouple is another style of thermocouple that is frequently used 


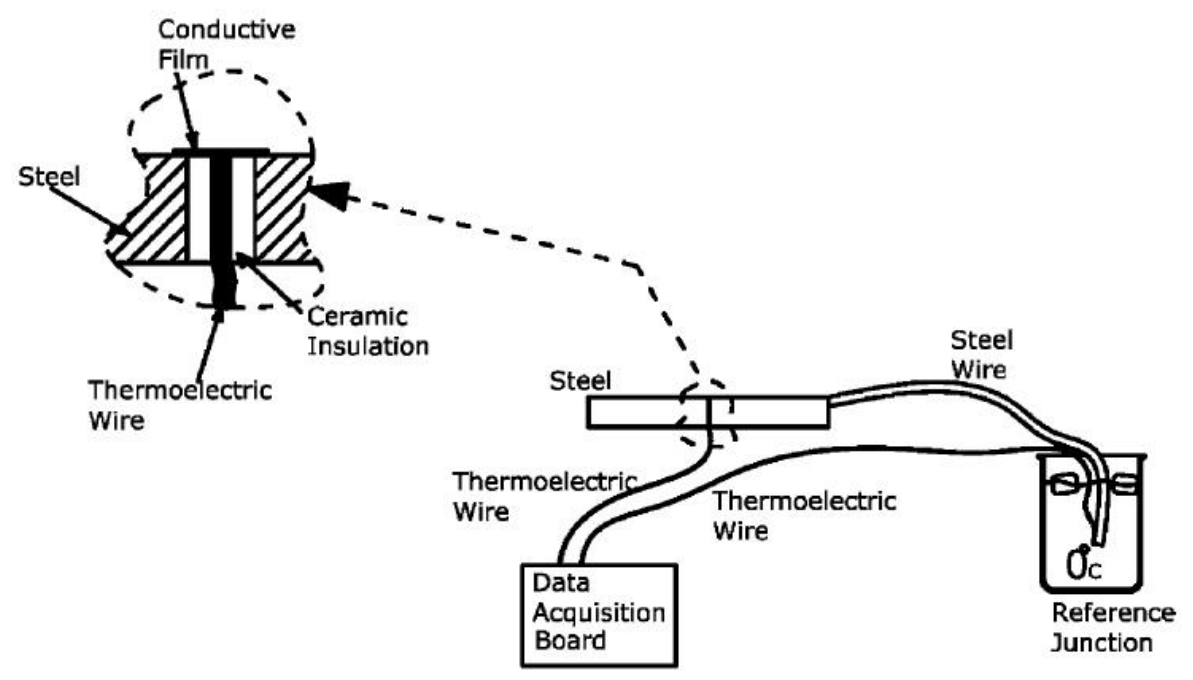

Figure 4.1: Heichal et al. surface thermocouple [40]

for engine measurements. The design utilizes two thin ribbons of thermocouple element, insulated and housed within a metal sheath. The electrical connection between the two elements is formed by abrading the surface. Yet despite the small size of the thermocouple elements, FEA by Buttsworth [39] showed that the temperature at the junction is significantly higher than that of the sheath during transient heat flux.

An alternative surface thermocouple (Figure 4.1) was developed by Heichal et al. [40] to measure temperatures of liquid droplets impacting a metal surface. The steel substrate was used as one of the thermocouple elements, and a $0.25 \mathrm{~mm}$ diameter constantan wire was the second element. The wire was cemented in a $0.57 \mathrm{~mm}$ diameter hole through the steel, and the junction was formed at the surface with an electrically conductive film.

As the substrate is one of the elements, the Heichal et al. design has the potential to produce accurate true surface temperature measurements. Additionally, it is simple enough to be fabricated in a typical machine shop. However, it was found that modifications were required to improve its robustness and accuracy for engine use.

This section describes the modifications made to the Heichal et al. thermocouple to improve it for measuring temperatures of aluminum combustion chamber surfaces. The process included the use of FEA to optimize and evaluate the design. Ultimately the 
FEA optimized thermocouple was engine tested to verify its effectiveness before being used in the piston tests.

\subsubsection{Surface Thermocouple Design}

The modified thermocouple is illustrated in Figure 4.2. The position of the cold junction shown in Figure 4.2 was chosen arbitrarily as an example. In the piston tests the cold junction was located on the piston where it was convenient to measure its temperature, as will be described in Section 5.2. In the engine testing of the thermocouple itself, as described in Sub-Section 4.1.3, the cold junction was positioned in an ice bath to eliminate the need for an additional temperature sensor.

The first change from the Heichal et al. design was the addition of the Teflon coating on the wire, which is simply the standard insulator sold with the wire (Omega product number TFCI-010-XX). The Teflon coating was left on as otherwise electrical isolation between the wire and the substrate could not be achieved consistently with cement alone. It should be noted that while Teflon's melting temperature is $327^{\circ} \mathrm{C}$, it is only rated to $260^{\circ} \mathrm{C}$ and the thermocouple may not be suitable for temperatures above this. The ceramic cement (Omega product number CC HIGH TEMP) is the same type used by Heichal et al.

The second significant modification was the addition of a thick copper layer applied by a wire arc spray coating technique. The copper performs the same function as it did with the Furuhama and Enomoto thermocouple [4], that being to conduct heat away from the tip of the constantan wire to the aluminum substrate. Thus, the copper helps to equalize the temperature of the constantan and the aluminum substrate, allowing the thermocouple to measure true temperatures much more accurately. The negative consequence of the copper layer is that it delays the thermocouple's response time. However, as will be shown in Sub-Section 4.1.2, this delay is small and acceptable when considering the accuracy improvements the copper layer provides. The copper also forms the 


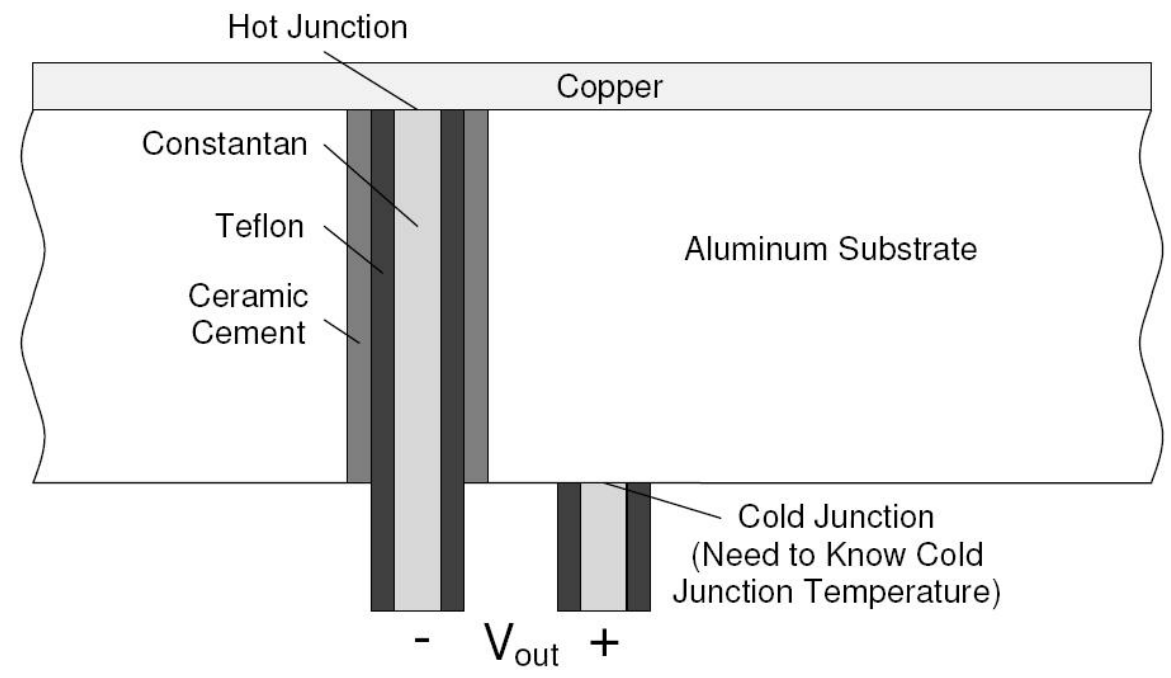

Figure 4.2: Surface thermocouple schematic

electrical connection between the aluminum and the constantan. The thickness of the junction was optimized using FEA.

\subsubsection{Surface Thermocouple Finite Element Analysis}

COMSOL Multiphysics FEA software was used to model the surface thermocouple under typical SI engine heat transfer conditions. The geometry and boundary conditions used for the analysis are shown in Figure 4.3, and relevant material properties are listed in Table 4.1. The model was two-dimensional axially symmetric in cylindrical coordinates to provide a three-dimensional equivalent output. To simplify the analysis, temperature differences across the copper between the aluminum and constantan were ignored by considering the tip of the constantan as the hot junction. This is a reasonable assumption because the temperature differences were generally small, and copper and aluminum have similar thermoelectric powers, which are considerably smaller in magnitude than constantan's. For example, at $100^{\circ} \mathrm{C}$ the thermoelectric voltages of copper, aluminum and constantan are approximately 1.0, 0.5 and $-4.0 \mathrm{mV}$ respectively when paired with platinum with the reference junction at $0^{\circ} \mathrm{C}[41]$. 


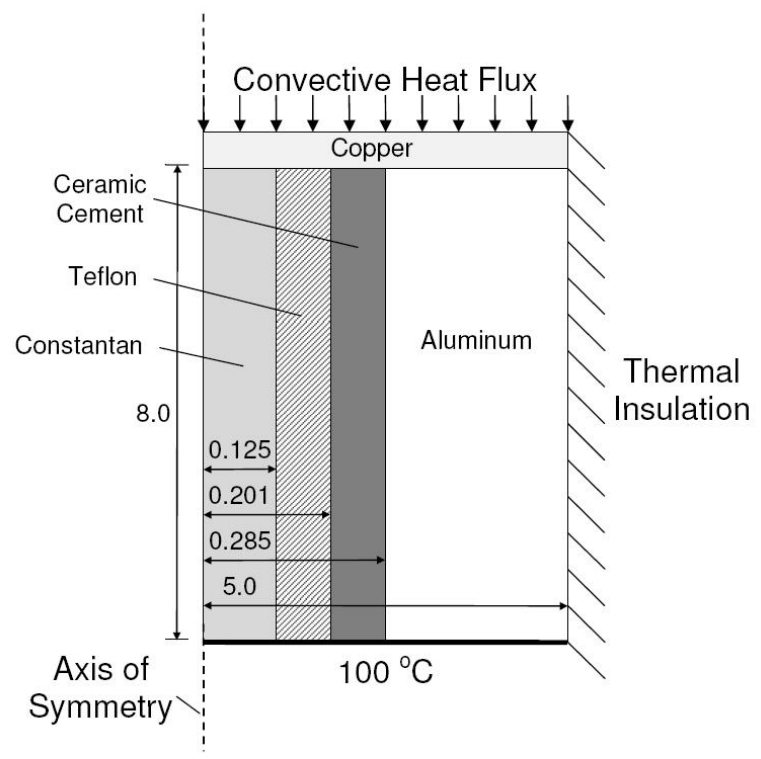

Figure 4.3: Surface thermocouple FEA model geometry and boundary conditions (all dimensions in $\mathrm{mm}$, not to scale)

The time varying boundary condition for the upper surface was convective heat flux as shown in Figure 4.4. These data were taken from measurements by Alkidas and Myers [42] in the cylinder head of a propane-fueled SI engine running slightly lean at part load and $1500 \mathrm{RPM}$. The lower boundary condition was set at $100^{\circ} \mathrm{C}$, and the aluminum side wall was modeled as thermally insulated.

The geometry was meshed by COMSOL with variable spacing with the highest density around the hot junction. The time step was set at $0.1 \mathrm{~ms}$. Trials found that further refinement of the mesh or time step did not substantially alter the FEA output.

Figure 4.5 shows FEA computed hot junction temperatures for a range of copper thicknesses. True temperatures were determined by removing the copper and changing all other materials to aluminum.

Most striking about Figure 4.5 is the No Copper curve, which has an average temperature and temperature swing significantly greater than True values. This demonstrates the importance of the copper layer for removing heat from the hot junction to equalize its temperature with the substrate. 
Table 4.1: Surface thermocouple FEA material properties

\begin{tabular}{lccc}
\hline Material & $\mathrm{k}$ & $\rho$ & $\mathrm{C}$ \\
& $(\mathrm{W} / \mathrm{m} \cdot \mathrm{K})$ & $\left(\mathrm{kg} / \mathrm{m}^{3}\right)$ & $(\mathrm{J} / \mathrm{kg} \cdot \mathrm{K})$ \\
\hline Constantan & 19.5 & 8900 & 390 \\
Teflon & 0.23 & 2190 & 1010 \\
Ceramic Cement & 1.2 & 2260 & 1000 \\
Aluminum & 155 & 2750 & 915 \\
Copper & 400 & 8700 & 385 \\
\hline
\end{tabular}

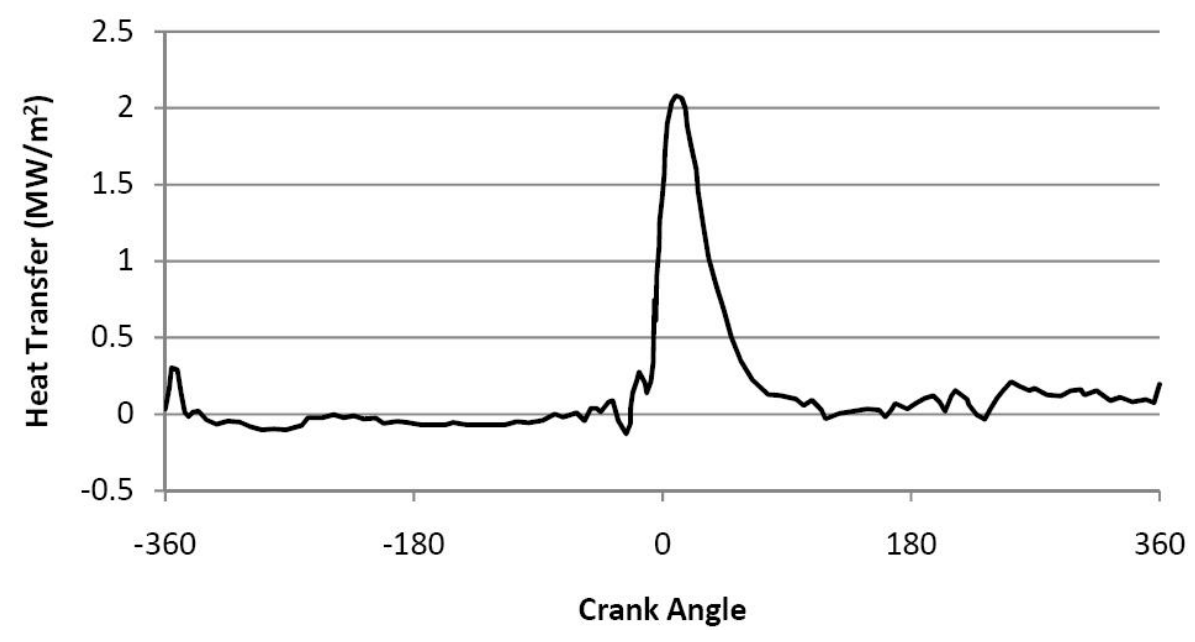

Figure 4.4: Convective heat flux data from Alkidas and Myers [42]

The thermocouple is highly accurate at measuring cycle averaged temperatures over a wide range of copper layer thicknesses. The range of thicknesses shown in Figure 4.5, 75 to $400 \mu \mathrm{m}$, all measure the average temperature within $0.23^{\circ} \mathrm{C}$ of the true average temperature. If copper thickness is reduced to $10 \mu \mathrm{m}$, the thermocouple would still measure an average temperature within $0.8^{\circ} \mathrm{C}$ of the true value.

When measuring the magnitude of surface temperature swings, the specific thickness of the copper layer is more important. In Figure 4.5 , the $75 \mu \mathrm{m}$ case overestimates the true temperature swing by $11 \%$, while the $400 \mu \mathrm{m}$ case underestimates it by $44 \%$. 


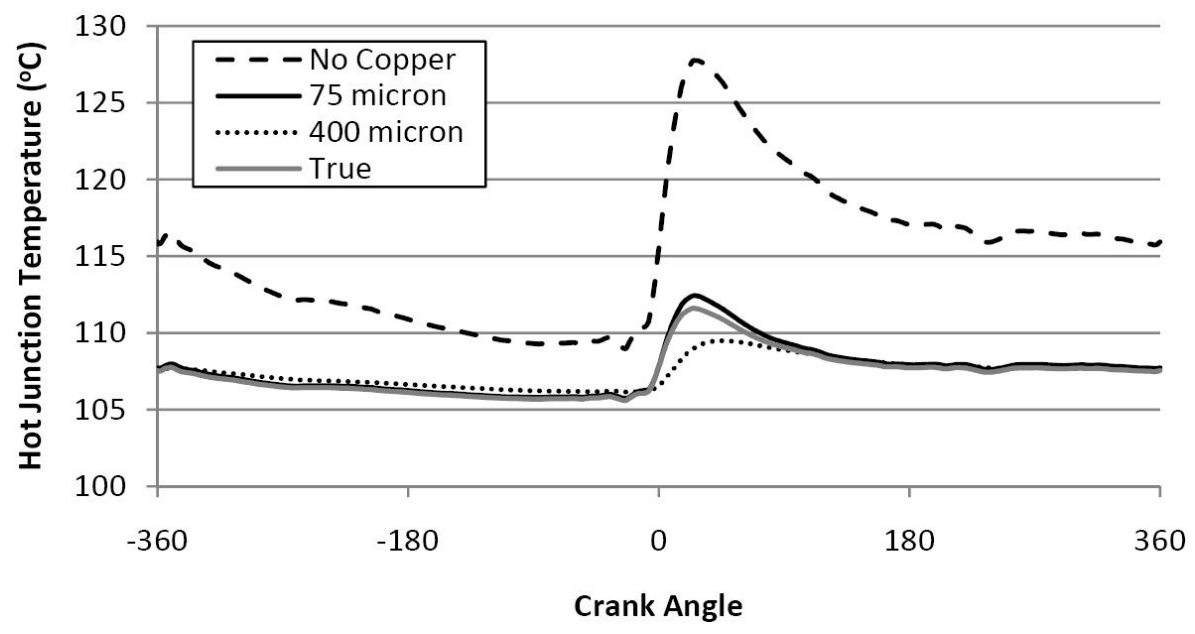

Figure 4.5: Hot junction temperature with varied copper thickness

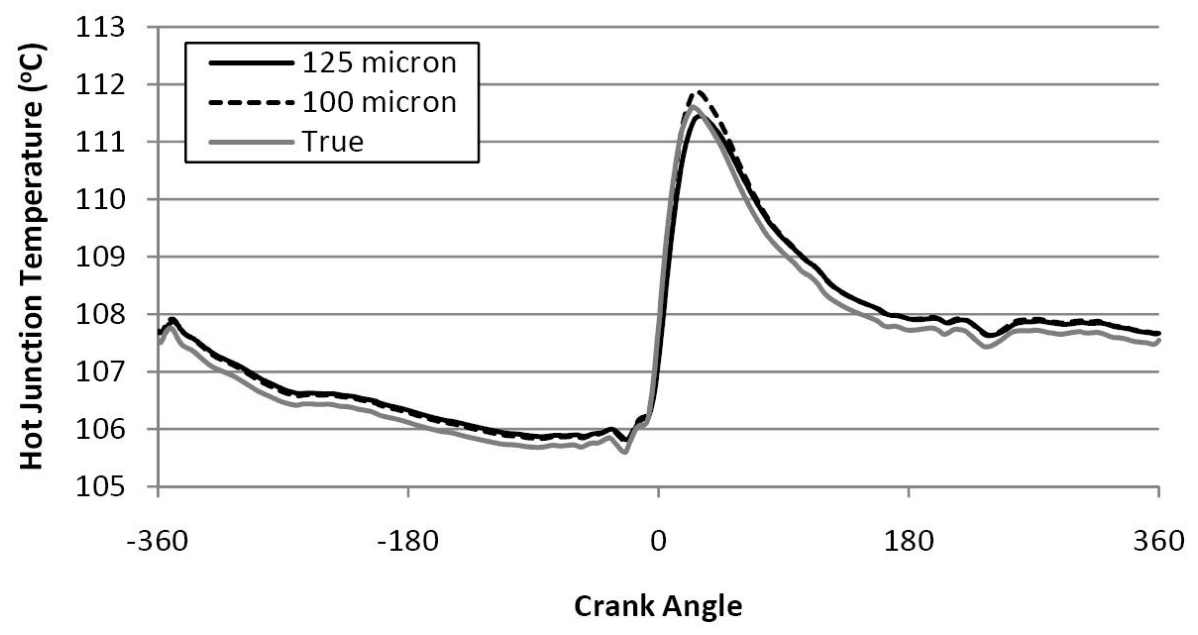

Figure 4.6: Hot junction temperature with 100 and $125 \mu \mathrm{m}$ copper layers

The optimal thickness of the copper layer was found to be between 100 and $125 \mu \mathrm{m}$, as shown in Figure 4.6. These thicknesses will measure the true temperature swing within 2 and $6 \%$ accuracy, respectively. Furthermore, in this thickness range the delay in peak temperature occurance from the true value is less than $5^{\circ}$ Crank Angle (CA).

To confirm the thermocouple's accuracy over a range of heat transfer conditions, the analysis was repeated twice using different convective heat transfer boundary conditions. First, the model was run using twice the Alkidas and Myers convective heat flux, the results of which are shown in Figure 4.7. Second, the analysis was performed with 


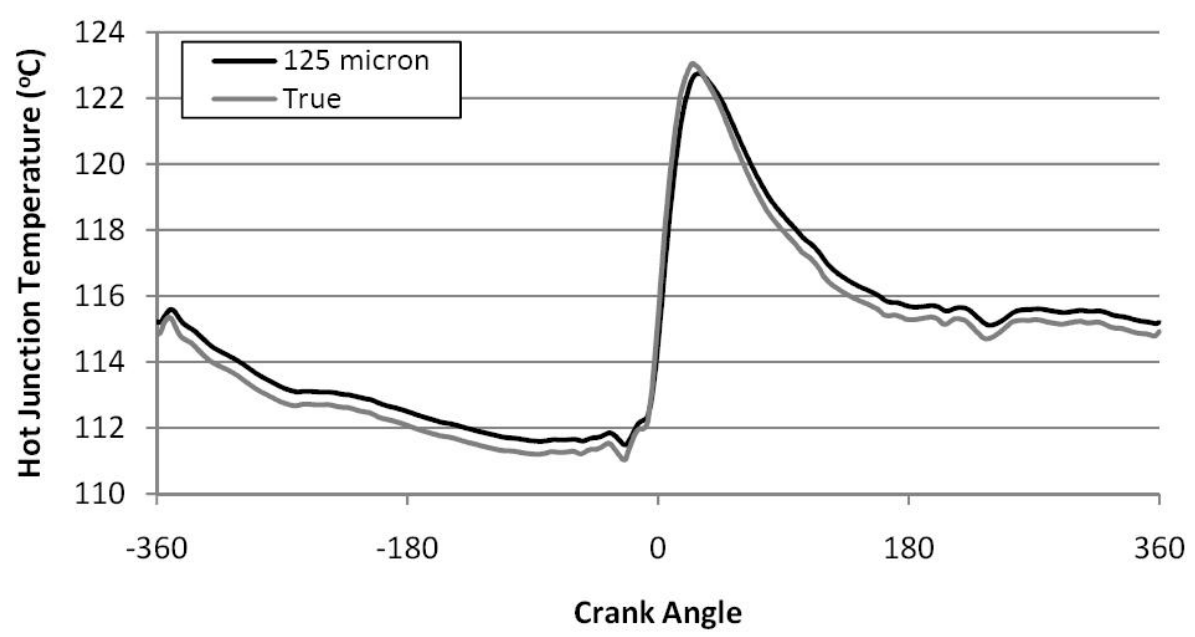

Figure 4.7: Hot junction temperature with 2X Alkidas and Myers convective heat flux

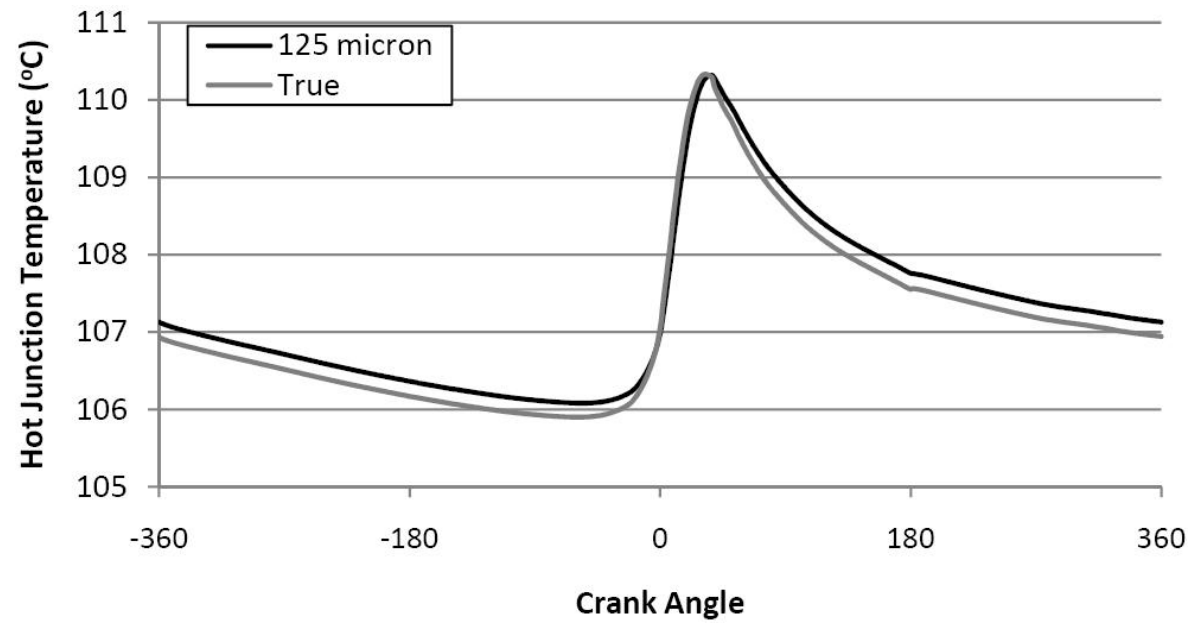

Figure 4.8: Hot junction temperature with Woschni heat transfer coefficient

heat flux calculated from in-cylinder gas temperatures and a heat transfer coefficient. Gas temperatures were taken from previous SI engine work by Enomoto and Furuhama [43], and the heat transfer coefficient was calculated with the Woschni equation [44] using temperature and pressure data from Enomoto and Furuhama. Hot junction temperatures from the analysis with the Woschni equation are shown in Figure 4.8.

Figures 4.7 and 4.8 confirm that, with a $125 \mu \mathrm{m}$ copper layer, the thermocouple should produce highly accurate temperature measurements.

Finally, as the thermocouple was to be used to study TBCs, the FEA was performed 


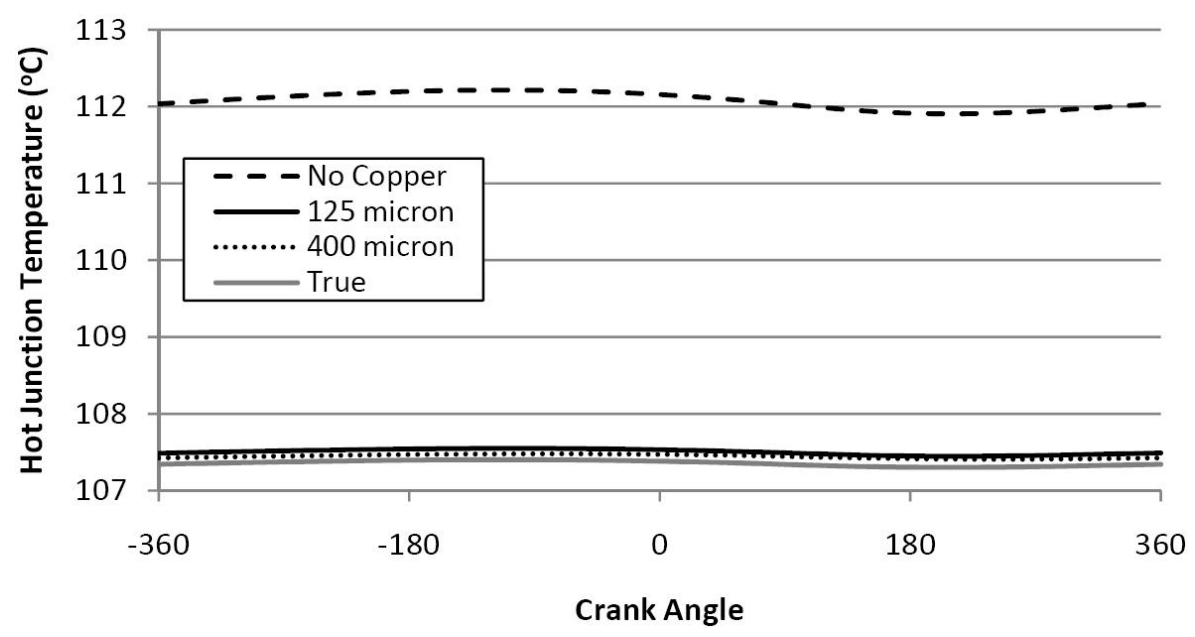

Figure 4.9: Hot junction temperature with $0.5 \mathrm{~mm}$ YSZ TBC

with the thermocouple behind a layer of Yttria-Stabilized Zirconia (YSZ). The geometry shown in Figure 4.3 was again used, except a $0.5 \mathrm{~mm}$ thick layer of $\mathrm{YSZ}(\mathrm{k}=2 \mathrm{~W} / \mathrm{m} \cdot \mathrm{K}, \rho$ $\left.=5100 \mathrm{~kg} / \mathrm{m}^{3}, \mathrm{C}=590 \mathrm{~J} / \mathrm{kg} \cdot \mathrm{K}\right)$ was added on top of the copper layer. The TBC results are shown in Figure 4.9. Without the copper layer, the thermocouple overestimates true temperatures by $4-5^{\circ} \mathrm{C}$. However, with 125 and $400 \mu \mathrm{m}$ copper layers, hot junction temperatures are within $0.2^{\circ} \mathrm{C}$ of true values. Temperature swings are minimal under the TBC, and therefore a wide range of copper thicknesses can be used while still producing accurate measurements.

\subsubsection{Surface Thermocouple Engine Testing}

The same cylinder assembly used for the cylinder wall tests (see Figure 3.1) was used for engine testing of the surface thermocouple. Three thermocouples were built in a single aluminum plug that could be threaded into either Port B or Port C. The thermocouples were spaced $4.5 \mathrm{~mm}$ apart along a line that oriented vertically when the plug was installed in the engine. To label the thermocouples, Thermocouple 1 was highest (closest to the cylinder head), Thermocouple 2 was in the middle and Thermocouple 3 at the lowest position. To complete the thermocouple loop, an aluminum wire was clamped to the 


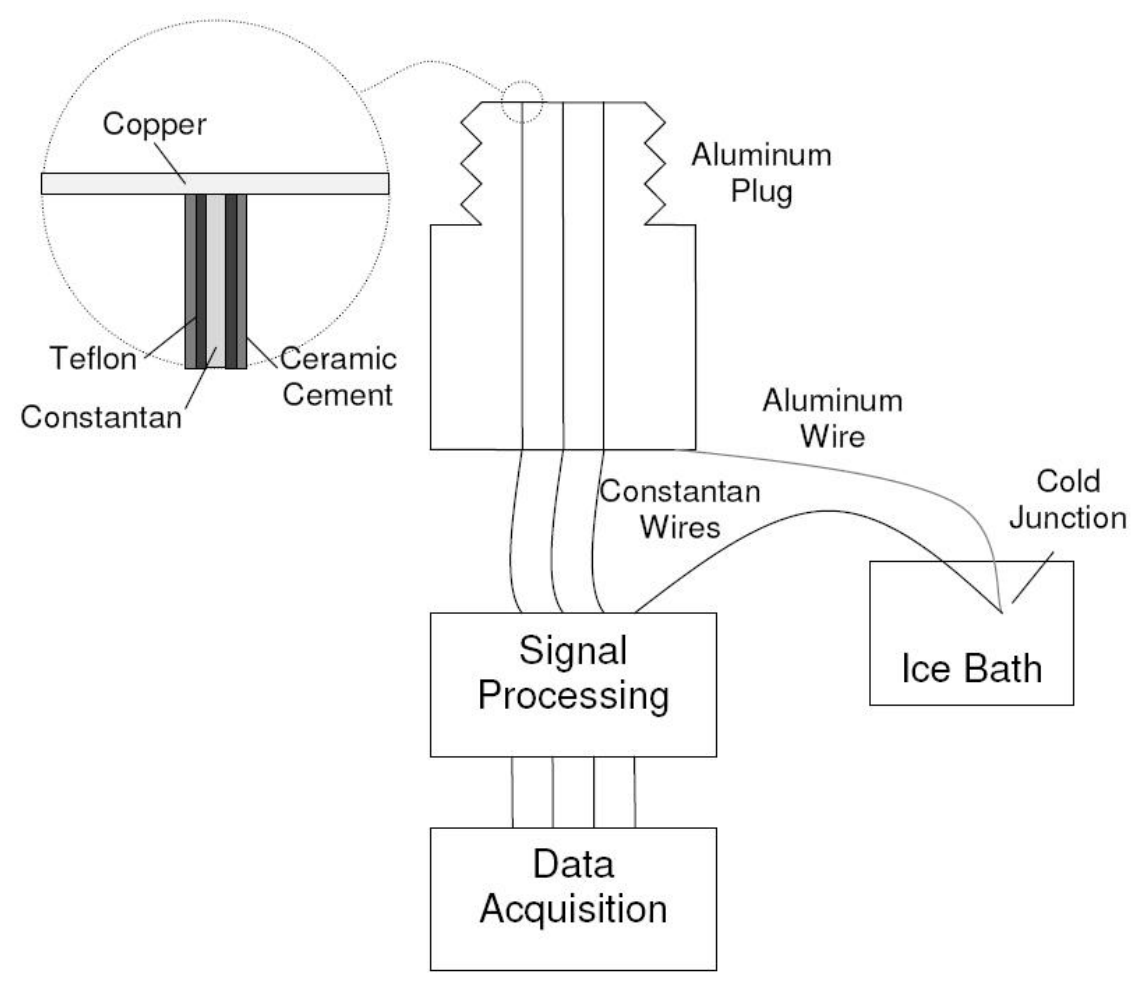

Figure 4.10: Surface thermocouple setup for engine testing

plug and joined with another constantan wire in an ice bath to form the cold junction. A schematic of the thermocouple setup used for the engine testing is shown in Figure 4.10. A control plug was fabricated with a type $\mathrm{K}$ thermocouple embedded $3 \mathrm{~mm}$ from the face. The control plug was installed in port A for all tests to provide an indication of the consistency of test conditions.

The constantan-aluminum thermocouple metal combination was calibrated against a type $\mathrm{J}$ thermocouple in an oven. Both pairs of thermocouple wires were embedded in an aluminum block to avoid fast temperature changes. Calibration voltage data were recorded from room temperature to $250^{\circ} \mathrm{C}$ during both heating and cooling. A third-order polynomial was fitted to the calibration data to find the temperature-voltage relationship, which averaged $44 \mu \mathrm{V} /{ }^{\circ} \mathrm{C}$ over that temperature range.

Due to the noisy test environment and the low magnitude of the output, analog signal conditioning was required prior to measurement with the DAQ board. First the 
raw voltages were amplified by a factor of 100 by a differential amplifier (Analog Devices product number AD626). Subsequently the amplified signals were passed through an active two-pole low-pass Butterworth filter with a cut-off frequency of $200 \mathrm{~Hz}$. This cutoff frequency provided high noise reduction with minimal damping of the signal. The filters were built following the modified Sallen-Key circuit design [45]. Three parallel amplifier-filter modules were built to permit sampling of all three surface thermocouples simultaneously.

The conditioned thermocouple signals were acquired with the PCI-6251 DAQ board through an SCB-68 termination block. During testing, average temperatures were measured continuously in one second intervals and instantaneous temperatures were measured intermittently in packets of 10 consecutive cycles. LabVIEW code named "TC_Dev_Temp.vi" was written to acquire the signals and convert voltage readings to temperatures.

MATLAB code named "TC_Dev_Temp.m" was used to further process the instantaneous temperature data. A 25 point $\left(5^{\circ} \mathrm{CA}\right)$ moving average smoothing algorithm was applied to damp remaining random noise, and temperatures were shifted $1 \mathrm{~ms}$ to offset the delay introduced by the analog filter. Additionally, the code removed the occasional large noise spike transmitted through the analog filter. These spikes were only found around spark and exhaust valve closure. Finally, the code identified the minimum and maximum temperatures of each cycle and the crank angle position of the maximum. More details about the LabVIEW and MATLAB programs can be found in Appendix A.

The thermocouple plug was tested with five surface conditions applied in the following sequence as described:

1. 400 micron - A coating of copper was applied by wire arc spray to the face of the surface thermocouple plug. The copper was machined on a lathe to a thickness of $400 \mu \mathrm{m}$.

2. $\underline{\text { YSZ }}$ - The copper layer was removed and a new copper layer approximately 400 
Table 4.2: Surface thermocouple engine tests operating parameters

\begin{tabular}{lc}
\hline Speed & 1500 RPM \\
Load & Full \\
Spark Timing & $20^{\circ}$ CA BTC \\
Compression Ratio & $8.7: 1$ \\
Coolant & Boiling Water \\
Intake Air Temperature & Unheated \\
\hline
\end{tabular}

$\mu \mathrm{m}$ thick was applied. A $400 \mu \mathrm{m}$ coating of YSZ was applied by plasma spray on top of the copper.

3. 237 micron - The YSZ was removed and the copper underneath was machined to a thickness of $237 \mu \mathrm{m}$.

4. 125 micron - The copper was further machined to a thickness of $125 \mu \mathrm{m}$.

5. 75 micron - The copper was removed and a new layer was applied and machined to a thickness $75 \mu \mathrm{m}$.

It should be noted that copper was applied three times in the above sequence, and since there were three thermocouples in the plug, the thermocouple was essentially fabricated nine times. The thickness of the copper layer was determined by measuring the overall length of the plug with a micrometer before coating and then after coating and machining. Thicknesses were verified after engine testing by measuring before and after removing the coating with the lathe. It is estimated that the thickness values listed are accurate within $25 \mu \mathrm{m}$.

The engine was operated according to the parameters listed in Table 4.2. A 12 minute warm-up was performed before measurements were taken. By this time, the cooling water 
Table 4.3: Surface thermocouple engine testing results - summary table

\begin{tabular}{|c|c|c|c|c|c|c|c|c|c|c|c|}
\hline \multirow{4}{*}{ Port } & \multirow{4}{*}{$\begin{array}{c}\text { Copper } \\
\text { Thick- } \\
\text { ness } \\
(\mu \mathrm{m})\end{array}$} & \multirow{4}{*}{$\begin{array}{c}\text { Control } \\
\text { Temp }\end{array}$} & \multicolumn{3}{|c|}{ Thermocouple 1} & \multicolumn{3}{|c|}{ Thermocouple 2} & \multicolumn{3}{|c|}{ Thermocouple 3} \\
\hline & & & Avg & Temp & Peak & Avg & Temp & Peak & Avg & Temp & Peak \\
\hline & & & Temp & Swing & & Temp & Swing & & Temp & Swing & \\
\hline & & & $\left({ }^{\circ} \mathrm{C}\right)$ & $\left({ }^{\circ} \mathrm{C}\right)$ & $\left({ }^{\circ} \mathrm{CA}\right)$ & $\left({ }^{\circ} \mathrm{C}\right)$ & $\left({ }^{\circ} \mathrm{C}\right)$ & $\left({ }^{\circ} \mathrm{CA}\right)$ & $\left({ }^{\circ} \mathrm{C}\right)$ & $\left({ }^{\circ} \mathrm{C}\right)$ & $\left({ }^{\circ} \mathrm{CA}\right)$ \\
\hline \multirow{4}{*}{ B } & 400 & 131.4 & 157.5 & 2.8 & 146.4 & 156.4 & 3.5 & 137.4 & 155.0 & 2.9 & 145.5 \\
\hline & 237 & 130.0 & 152.2 & 5.2 & 85.0 & 151.7 & 5.1 & 95.1 & 151.0 & 4.3 & 93.5 \\
\hline & 125 & 129.6 & 153.9 & 6.8 & 63.5 & 153.7 & 6.2 & 69.6 & 153.2 & 5.0 & 69.7 \\
\hline & 75 & 129.7 & 154.2 & 5.9 & 62.6 & 154.5 & 7.9 & 53.6 & 154.1 & 6.2 & 69.8 \\
\hline \multirow{4}{*}{$\mathrm{C}$} & 400 & 131.2 & 153.4 & 2.3 & 152.6 & 153.1 & 2.8 & 147.1 & 151.9 & 2.3 & 148.4 \\
\hline & 237 & 129.5 & 150.0 & 4.1 & 94.0 & 149.3 & 4.0 & 101.4 & 148.2 & 3.5 & 95.4 \\
\hline & 125 & 129.9 & 150.7 & 5.1 & 69.7 & 150.2 & 5.0 & 73.9 & 149.4 & 3.9 & 70.2 \\
\hline & 75 & 129.8 & 152.7 & 4.5 & 70.5 & 152.3 & 6.3 & 59.0 & 151.4 & 5.2 & 74.0 \\
\hline
\end{tabular}

temperature had stabilized at its boiling point and plug temperatures were approximately steady. At least 300 cycles of instantaneous data were collected for each surface condition.

The results from the engine tests are summarized in Table 4.3. Examples of representative instantaneous temperature profiles are shown in Figures 4.11 and 4.12. In the plots, instantaneous temperatures are shifted to produce an average temperature of $0^{\circ}$ C.

For all but one copper thickness and port combination in Table $4.3(75 \mu \mathrm{m}$ in Port B being the exception), Thermocouple 1 has the highest average temperature, followed by Thermocouples 2 and 3 respectively. This consistency supports the accuracy of the thermocouple at reading average temperatures.

The temperature swing values in Table 4.3 and the temperature profiles in Figures 4.11 and 4.12 generally show the same trends as suggested by the FEA. To make this clearer, Figure 4.13 shows the ratios of average temperature swing to the average temperature swing at $400 \mu \mathrm{m}$ copper layer thickness. The FEA ratios are indicated with black lines. Thermocouples 2 and 3 follow the FEA trend with all copper thicknesses, 


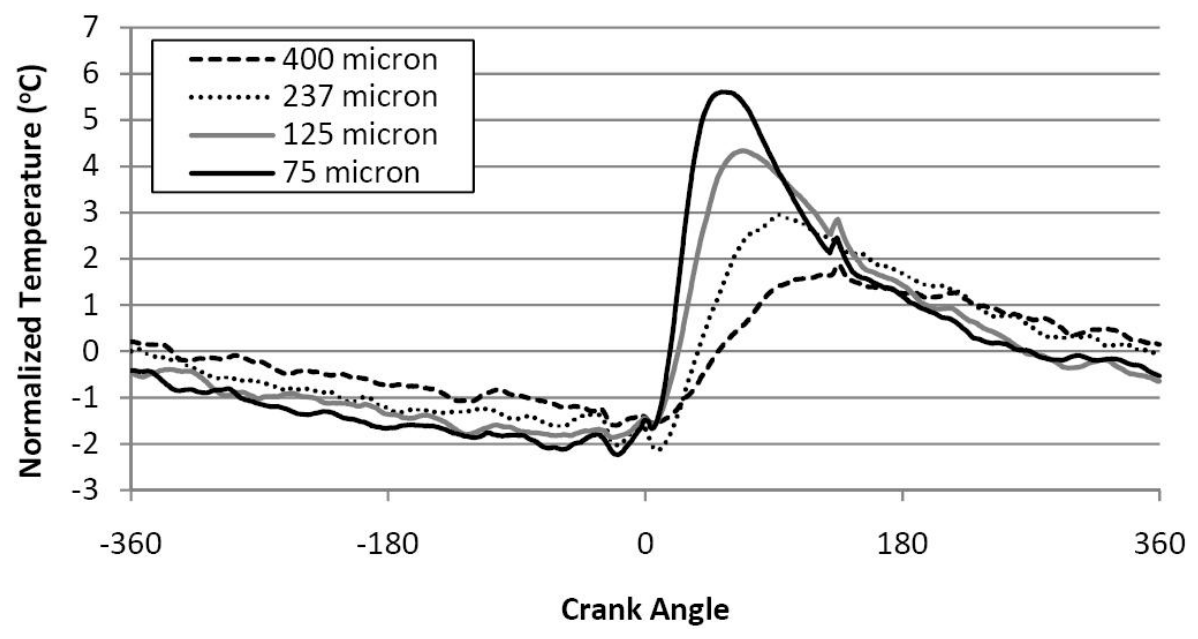

Figure 4.11: Representative cycles of Thermocouple 2 in Port B (temperatures shifted to provide an average temperature of $0^{\circ} \mathrm{C}$ )

but Thermocouple 1 has a substantially higher ratio with both the 125 and $237 \mu \mathrm{m}$ copper layer thicknesses. These thicknesses had the same copper application, suggesting the possibility that an irregularity during coating or pre-coating preparation resulted in an imperfect copper layer around Thermocouple 1's hot junction.

It is impossible to know the true magnitude of the temperature swings the thermocouples were measuring. The consistency between the FEA and experimental results suggests that the thermocouples were accurate. The irregularities displayed by Thermocouple 1 with 125 and $237 \mu$ m copper layer thickness were effectively a one in nine occurrence. Additional care during fabrication could reduce this frequency. Moreover, improvements in measuring copper thickness and machining to the specified thickness would further increase accuracy.

While the results of the tests with the surface thermocouples under the YSZ coating were not explored in detail, a sample temperature profile is presented in Figure 4.14. The coating damps the temperature swing to the point where it is no longer visible to the human eye. This level of damping is consistent with the results of the FEA run with the YSZ coating, as shown in Figure 4.9. 


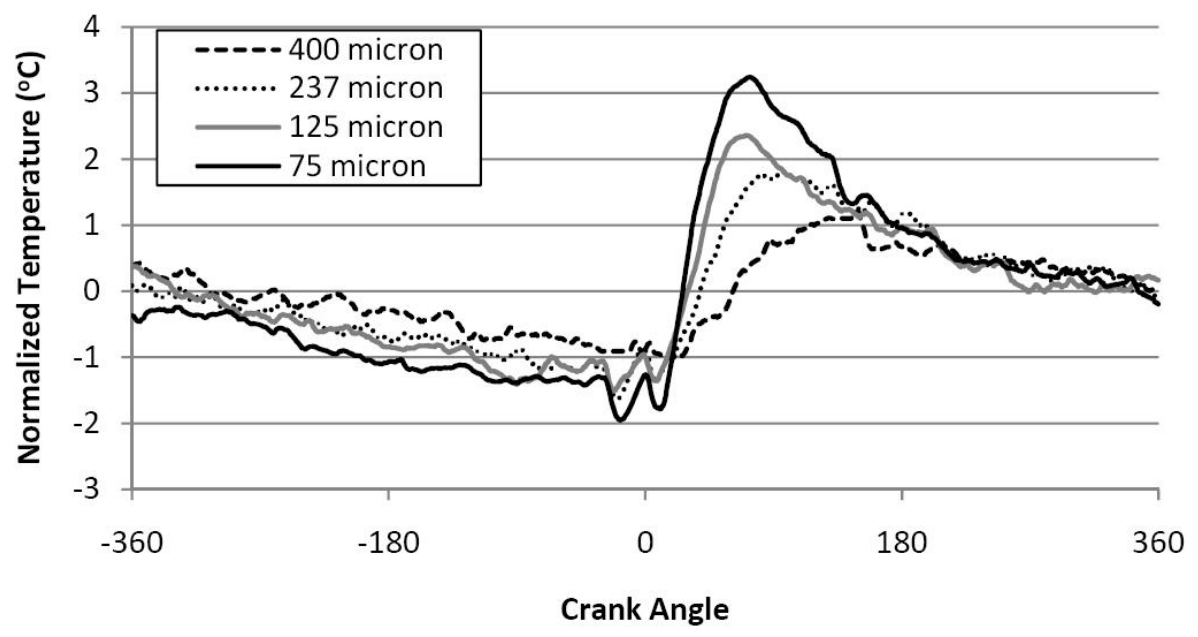

Figure 4.12: Representative cycles of Thermocouple 3 in Port C

\subsubsection{Surface Thermocouple Development Summary}

The thermocouple developed by Heichal et al. was successfully modified to measure accurate surface temperatures in aluminum engine components such as the piston. The primary modification was the addition of a thick copper layer at the surface to conduct heat away from the constantan wire. Using FEA, the optimal thickness of the copper layer was found to be between 100 and $125 \mu \mathrm{m}$ for accurately measuring the true temperature swing. The addition of this layer will introduce a modest delay in peak temperature occurrence of less than $5^{\circ} \mathrm{CA}$. The thermocouple is very accurate at measuring average temperatures, a task that is less sensitive to copper thickness compared to the measurement of temperature swings. If the thermocouple is used to measure temperatures under a TBC, a wide range of copper thicknesses can be tolerated while still producing accurate measurements.

Experimental engine testing of the thermocouple displayed the trends predicted by the FEA. The results suggest that the thermocouple is accurate at measuring average temperatures and temperature swings. Therefore, the recommendation for the piston tests was to have a copper layer thickness of $125 \mu \mathrm{m}$ when uncoated, and a copper layer thickness in the range of 125 to $400 \mu \mathrm{m}$ when coated. 


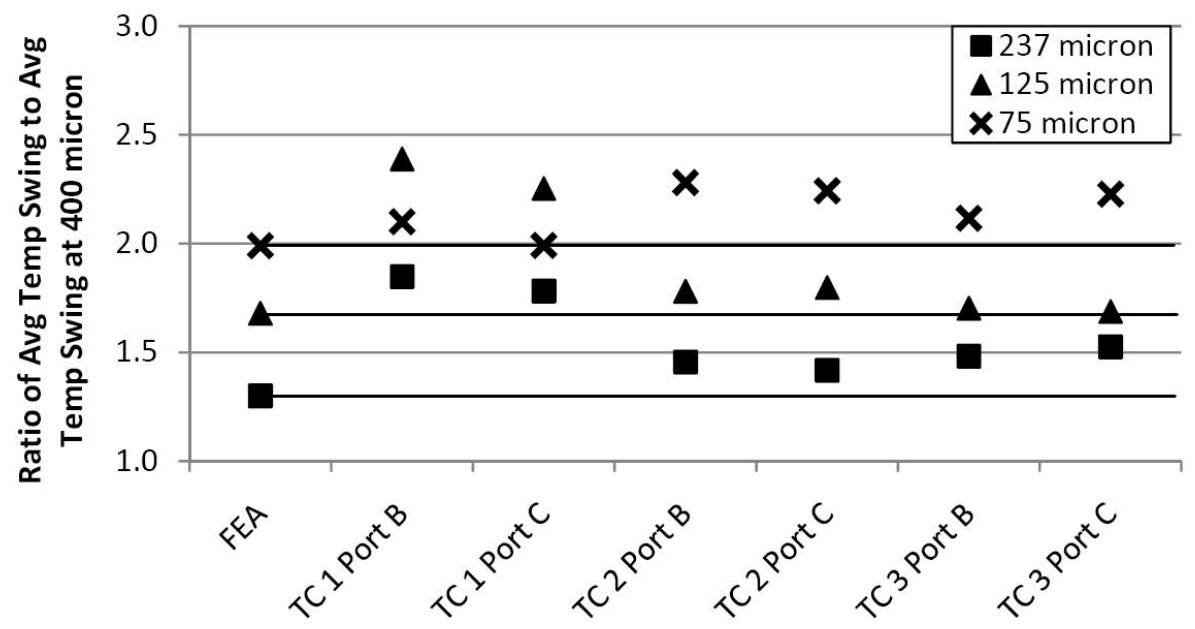

Figure 4.13: Ratios of average temperature swing to average temperature swing at 400 $\mu \mathrm{m}$ copper layer thickness - black lines indicate FEA ratios

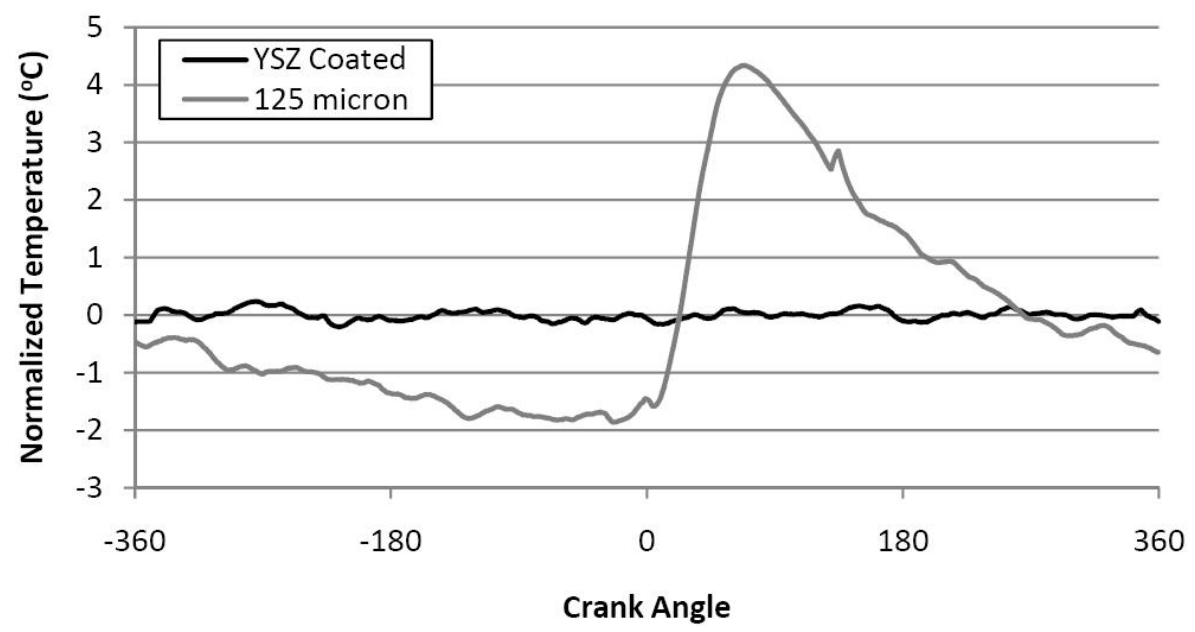

Figure 4.14: Sample cycle of Thermocouple 3 with YSZ coating in Port C 


\subsection{In-Depth Thermocouple Development}

Development of the in-depth thermocouple was considerably less challenging than development of the surface thermocouple for two reasons. First, the in-depth thermocouples are embedded within the substrate at a depth where cyclic temperature fluctuations are negligible, so response time is not a concern. Second, temperature equalization between the hot junction and the surrounding substrate will occur readily without any special design features. The surface thermocouple required the copper layer for this purpose, but the highly conductive aluminum substrate will inherently perform this task for the in-depth thermocouple. Nonetheless, work was still required to produce a functional and accurate in-depth thermocouple. The following sub-sections describe the development process, starting with design of a functional thermocouple followed by verification of its accuracy with FEA.

\subsubsection{In-Depth Thermocouple Design}

A schematic of the in-depth thermocouple is shown in Figure 4.15. To fabricate the thermocouple, a hole is drilled mid way through the substrate and bottom tapped for a \#2-56 thread. A Teflon-insulated constantan wire (Omega product number TFCI-010$\mathrm{XX}$ ) is fed through a vented screw and a small piece of Teflon tube. The tip of the wire is stripped of insulation and formed into a ball small enough to fit into the threaded hole but larger than the Teflon tube inner diameter. The wire, tube and screw assembly is then threaded into the hole until tight. The tube presses against the constantan wire ball, holding it in continuous contact with the aluminum to form the hot junction. Similarly to the surface thermocouple, a cold junction is required at a second location where temperatures can be accurately measured. 


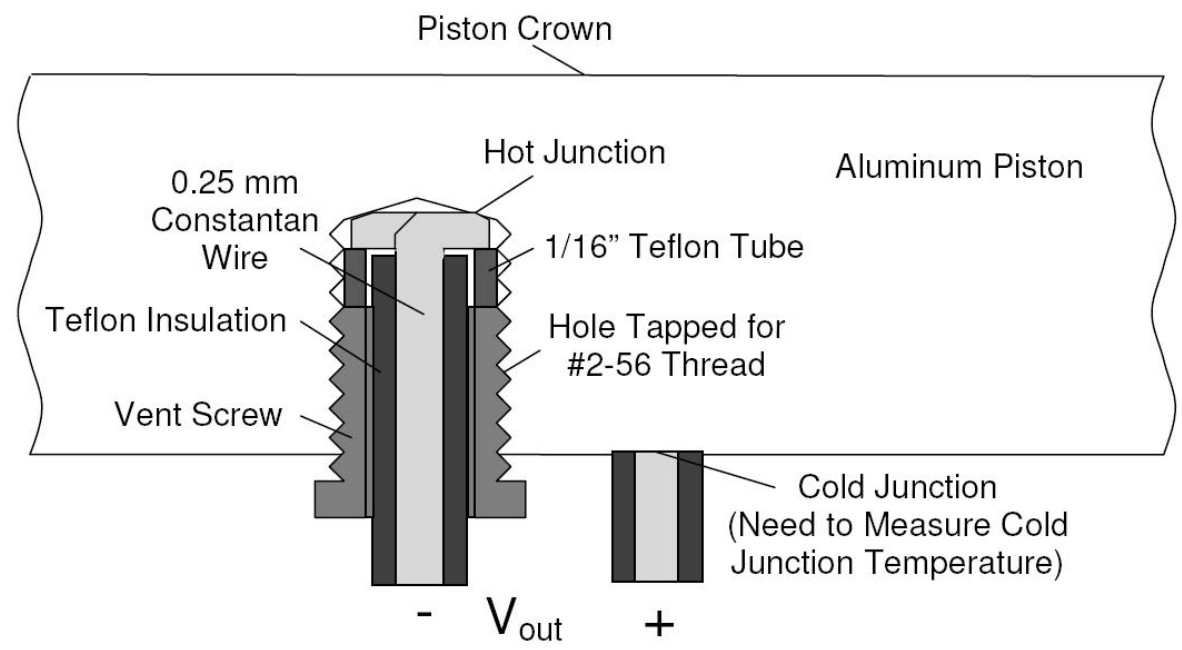

Figure 4.15: In-depth thermocouple schematic

\subsubsection{In-Depth Thermocouple Finite Element Analysis}

Finite element analysis was used first to determine a suitable depth for the in-depth thermocouple and then to verify the design's accuracy. The in-depth thermocouple should be located deep enough within the substrate that temperature fluctuations are essentially damped out. However, if it is too far from the surface, heat conduction becomes less onedimensional, which increases the error associated with calculating heat flux (discussed in Sub-Section 5.2.2). A suitable depth was chosen to be where the full cycle temperature swing is less than one percent of the temperature swing at the surface.

Using the True FEA model, described in Sub-Section 4.1.2 (that shown in Figure 4.3 with no copper layer and all other materials set to aluminum), along with the convective heat transfer boundary condition shown in Figure 4.4, temperature swings at various depths were computed. Figure 4.16 shows the ratio of temperature swing to the temperature swing at the surface for a range of depths. At approximately $5 \mathrm{~mm}$ below the surface, the temperature swing becomes less than one percent of the surface swing, and therefore this was selected as a suitable depth. However, referring to Figure 4.15, it can be seen that the bottom of the hole is conical due to the drill bit, and the constantan is not likely contacting the aluminum at the very tip of the hole. Therefore it was decided 


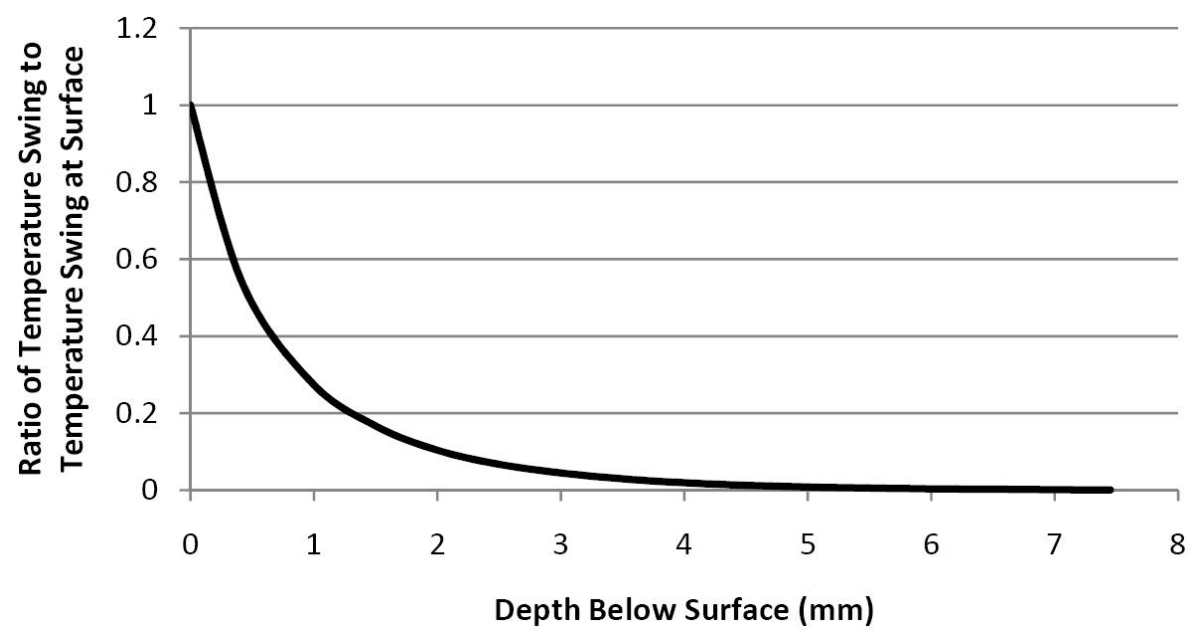

Figure 4.16: Ratio of temperature swing to surface temperature swing

to drill the tip of the hole to a depth of $4.8 \mathrm{~mm}$ from the surface.

Verification of the in-depth thermocouple accuracy was performed with the simplified FEA model shown in Figure 4.17. The entire thermocouple was modeled with the thermal properties of Teflon for simplicity and to provide a worst case scenario. Convective heat flux data were taken from Figure 4.4 and material properties were taken from Table 4.1. Other details about the FEA procedure are the same as described in Sub-Section 4.1.2. The results from the in-depth thermocouple FEA analysis are shown in Figure 4.18. To calculate the true temperatures, the model was run with all materials set as aluminum.

The average in-depth thermocouple temperature is $0.42^{\circ} \mathrm{C}$ higher than the average true temperature. These results show that the in-depth thermocouple is actually slightly less accurate than the surface thermocouple, but still acceptable.

\subsubsection{In-Depth Thermocouple Development Summary}

An in-depth thermocouple was developed to accurately measure temperatures within the aluminum piston. Through FEA it was determined that $5 \mathrm{~mm}$ below the surface is the optimum depth to locate the thermocouple. The accuracy of the design was also verified with FEA, which found that the thermocouple would be accurate within $0.42^{\circ} \mathrm{C}$ of true 


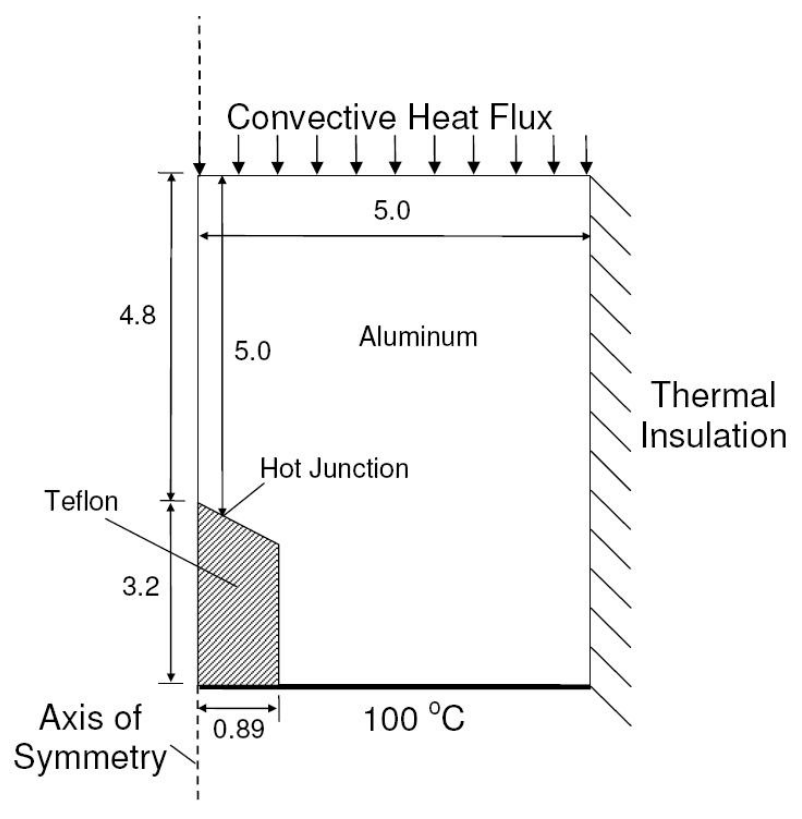

Figure 4.17: In-depth thermocouple FEA model geometry and boundary conditions (all dimensions in $\mathrm{mm}$, not to scale)

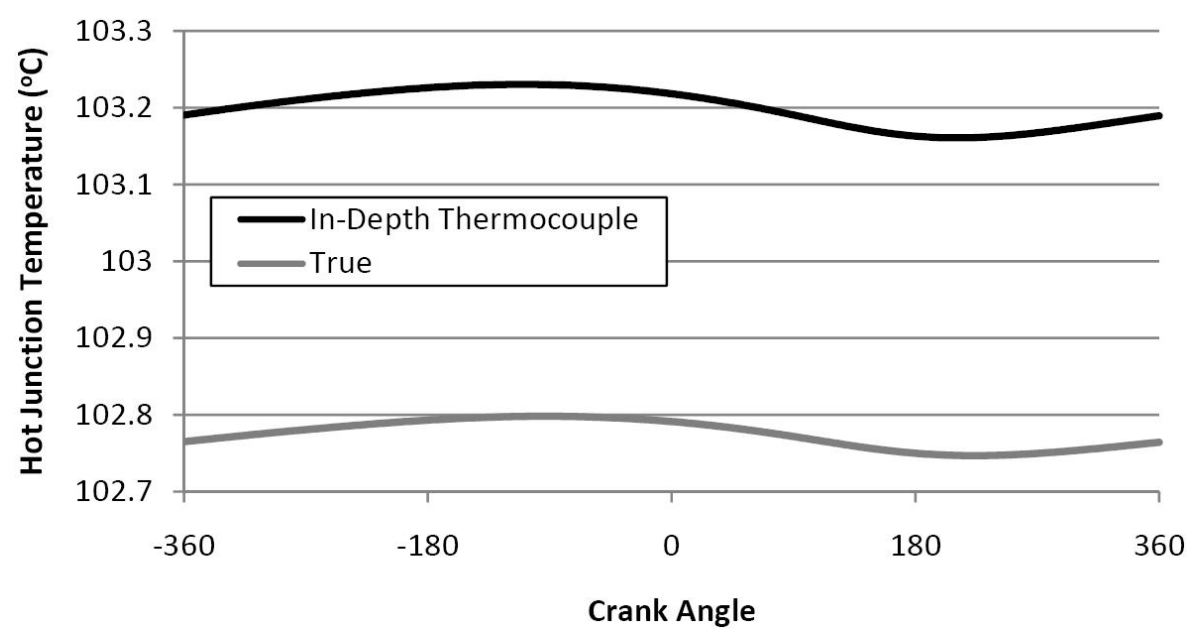

Figure 4.18: In-depth thermocouple FEA results

temperatures under typical SI engine heat flux conditions. 


\section{Chapter 5}

\section{Piston Test Setup and Methodology}

This chapter describes the experimental setup and methodology used for the piston tests. A primary objective of the tests was to measure piston temperatures and heat flux into the crown when coated with the different TBCs and when uncoated. Accordingly, much of this chapter is devoted to the instrumentation of the piston. The piston crown was the only surface in the combustion chamber that was coated. Only one piston was instrumented and was used for all tests with the different coatings.

\subsection{Engine}

The cylinder assembly used for the cylinder wall tests and thermocouple development was removed and replaced with a standard bore size assembly with only one access port, shown in Figure 5.1. The switch to the new cylinder assembly was necessary because it fit the standard size aluminum piston that was to be tested. An aluminum piston was used as it is the material of choice in the modern SI engine. All other engine specifications were the same as described in Section 2.1. 


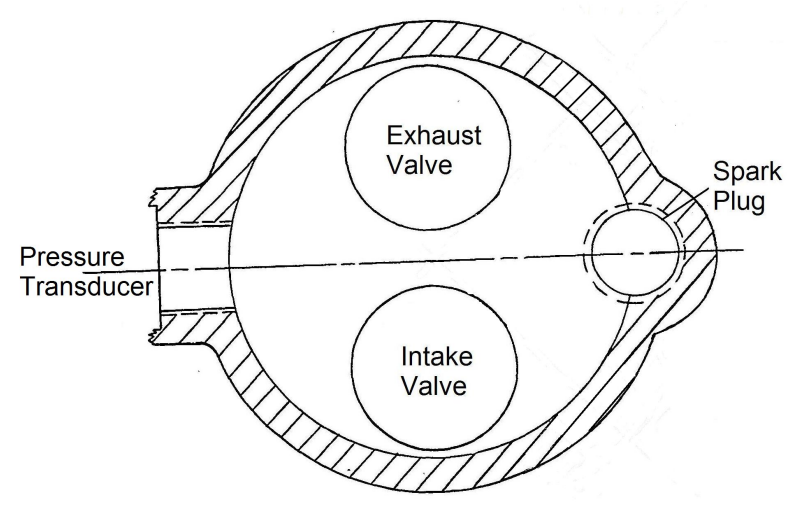

Figure 5.1: Piston test cylinder assembly - cross section viewed from above, adapted from $[34]$

\subsection{Piston Instrumentation}

Four pairs of surface and in-depth thermocouples were installed in the piston crown to enable heat flux measurements at four locations, as illustrated in Figure 5.2. However, due to DAQ system limitations, it was only possible to measure the voltages of two pairs, for which pairs 1 and 3 were selected. The spacing of a surface and in-depth thermocouple pair is shown in Figure 5.3, and details on the thermocouples are in Chapter 4. The TBCs were applied on top of the copper layer that forms the surface thermocouples' hot junction, which means the surface thermocouples were actually measuring temperatures behind the TBC at the substrate surface. When the crown was uncoated, the actual surface temperatures were being measured.

Each of the surface and in-depth thermocouples required a cold junction to complete their thermocouple loop (see Figures 4.2 and 4.15). For the surface thermocouples, the corresponding in-depth thermocouple served as their cold junction. The in-depth thermocouples required an additional constantan wire in contact with the aluminum for the cold junction. For this purpose, a single constantan wire was pressed into the aluminum near the bottom of the piston skirt. This single wire served as the cold junction for both in-depth thermocouples. To determine the temperature of the cold junction, as 


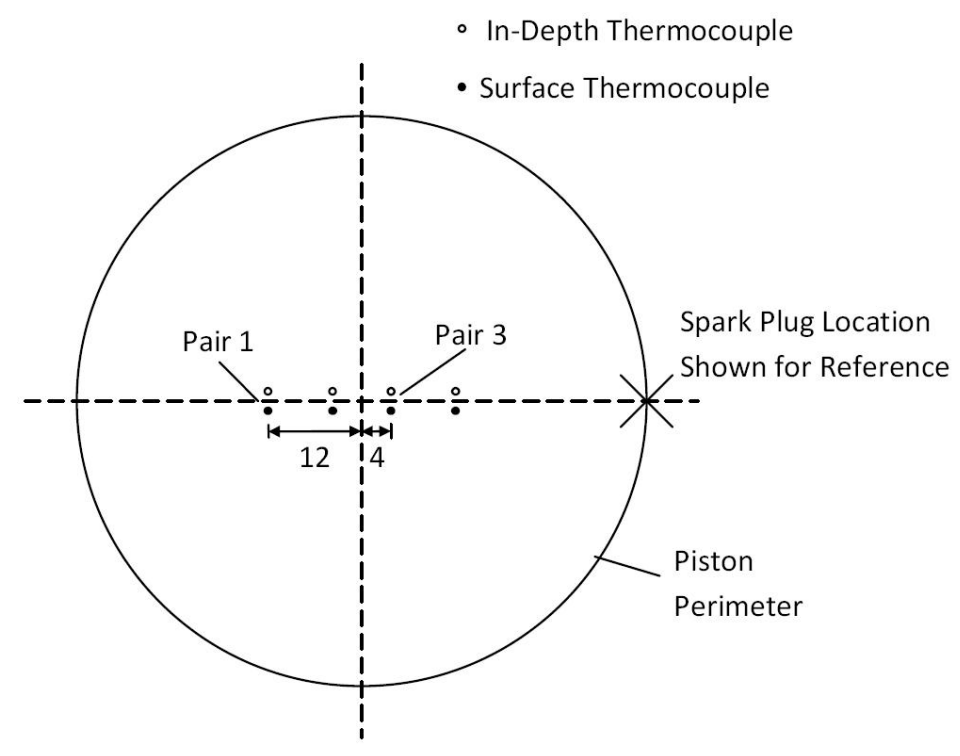

Figure 5.2: Thermocouple position in piston crown (not to scale, all dimensions mm)

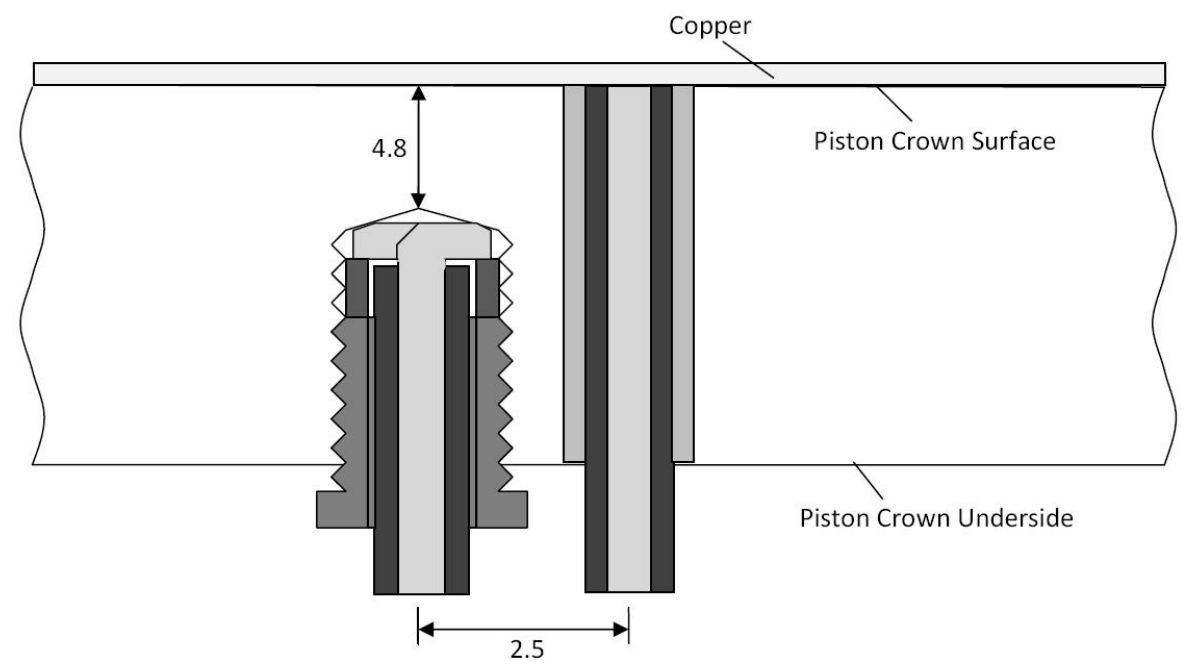

Figure 5.3: Thermocouple pair spacing (not to scale, all dimensions mm) 


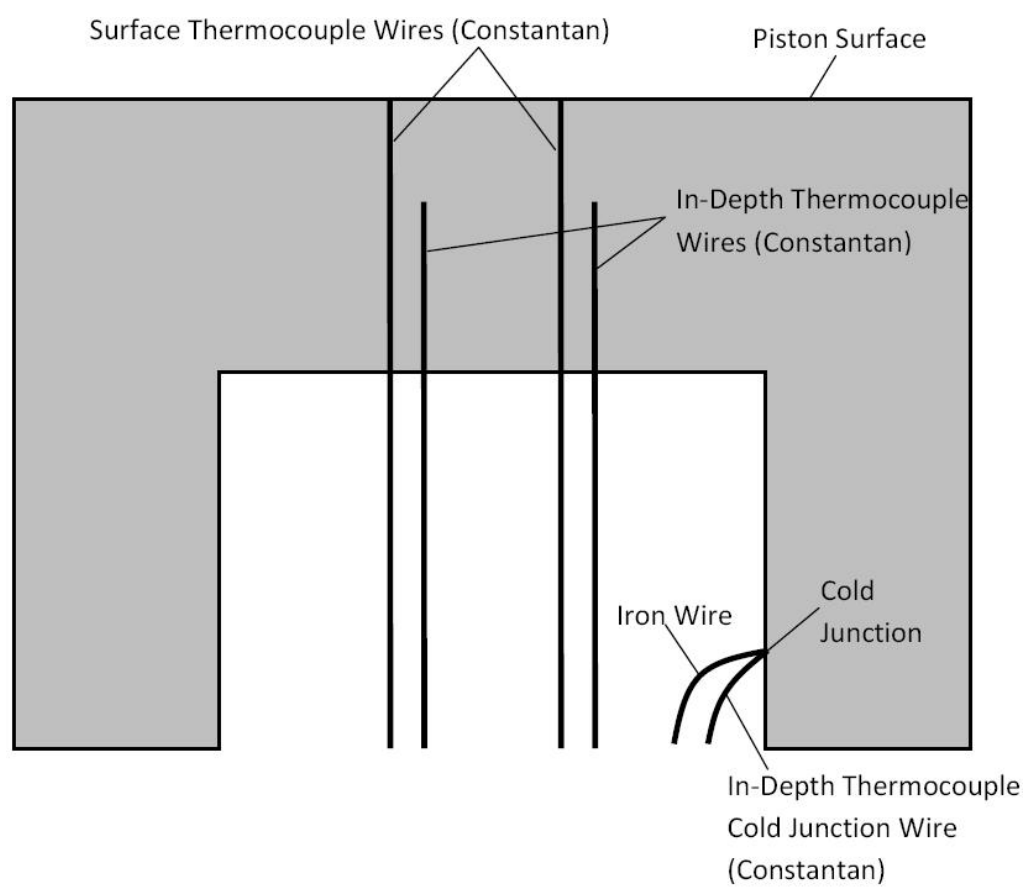

Figure 5.4: Piston thermocouple wiring schematic

is necessary for calculating hot junction temperatures, an iron wire was pressed in contact with the aluminum directly beside the single constantan wire. Iron and constantan form a type $\mathrm{J}$ thermocouple, so these wires allowed for measurement of the cold junction temperature. A schematic clarifying the thermocouple wiring in the piston is shown in Figure 5.4.

\subsubsection{Thermocouple Wire Routing}

The thermocouples wires were routed from the piston down to the big end of the connecting rod and then along a mechanical telemetry linkage out of the crank case and to the DAQ system.

Figure 5.5 illustrates the wire path within the piston and the transfer to the connecting rod. The piston required modification to accommodate the wires, and drawings of the modified piston are in Appendix B. Aluminum plates were used to protect the wires and 
route them around the piston. A custom made connector was used to connect the 30 gauge wires used to make the thermocouples to more durable 24 gauge stranded wires (Omega product numbers TFIR-24S and TFCI-24S). The connector was also used to press the constantan and iron cold junction wires into contact with the piston. High temperature gasket maker (Permatex product number Sensor-Safe Ultra Blue) was used to seal the connector perimeter and mitigate short circuiting. The wires were transferred to the connecting rod along a spring steel strap in a manner similar to that used by Nakic [19]. The purpose of the strap was to reduce wire bending and fatigue. The wires were held against the strap with room temperature vulcanizing sealant (Dow Corning product number 736 Heat Resistant Sealant) and unshrunk heat shrink Teflon tubing. A custom built clamp fastened the end of the strap and the wires to the connecting rod. Heli-Coil@ screw thread inserts were installed in all screw holes in the piston, and drilled head screws with wire wrapping were used to ensure the screws would not loosen over the course of testing. Figure 5.6 shows pictures of the piston at different stages in the modification and wiring process.

At the bottom of the connecting rod, the wires were transferred to the mechanical telemetry linkage illustrated in Figure 5.7. The linkage was developed by Memme [46] specifically for these tests. The linkage connector attached to the bottom of the big end of the connecting rod as shown in Figure 5.8. At each pin joint, the wires were fed through a hole through the joint to minimize bending and fatigue. The wires were clamped at multiple places to the side of the links. Where the potential of rubbing existed, heat shrink tubing was used to protect the wires. A steel housing for the linkage, shown in Figure 5.9, was installed on the side of the crank case. The linkage was mounted to the upper inside surface of the housing, and the wires were routed through a hole drilled in the housing to the DAQ system. A picture of the wired linkage is shown in Figure 5.10. 


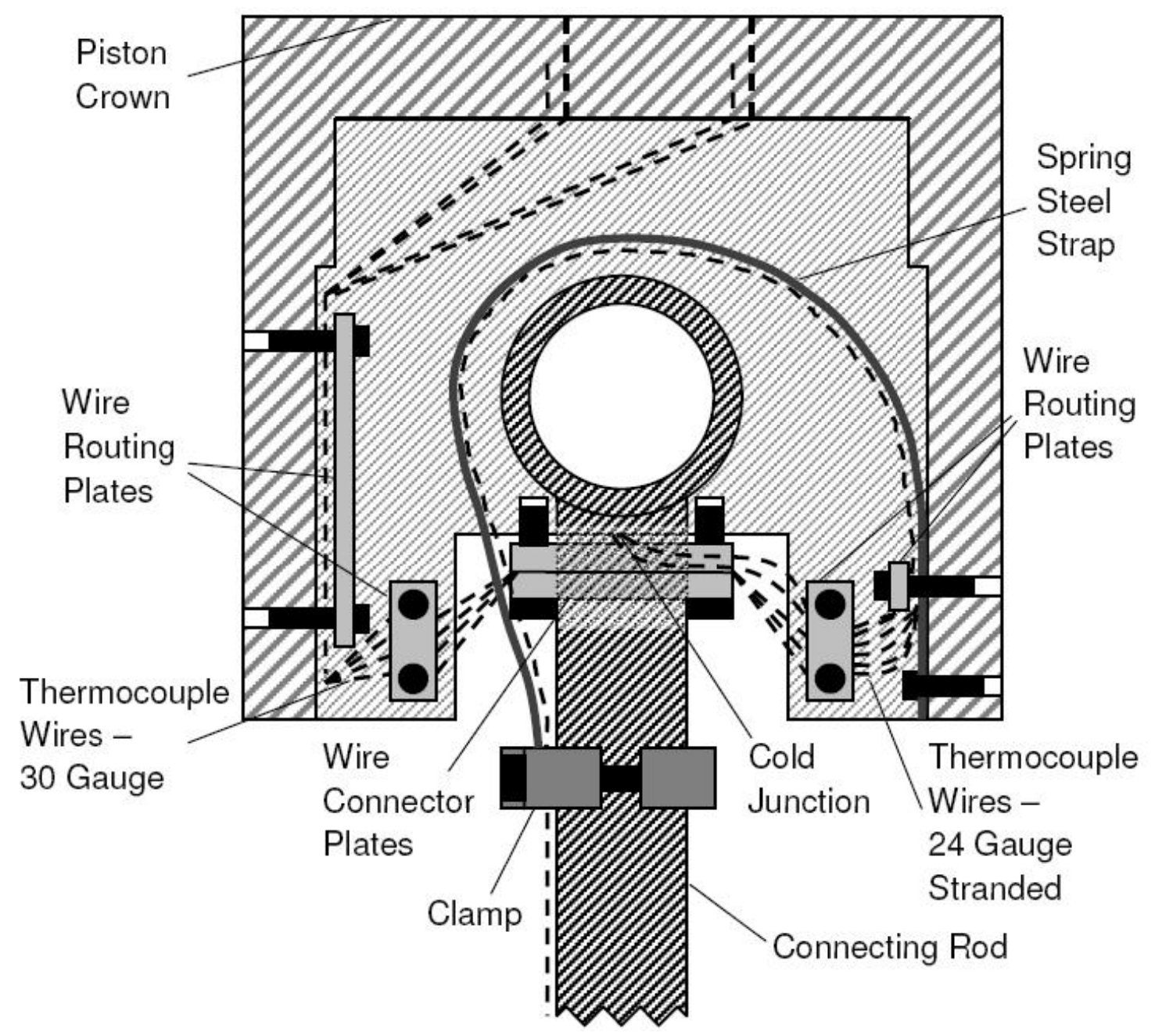

Figure 5.5: Wire routing from piston crown to connecting rod
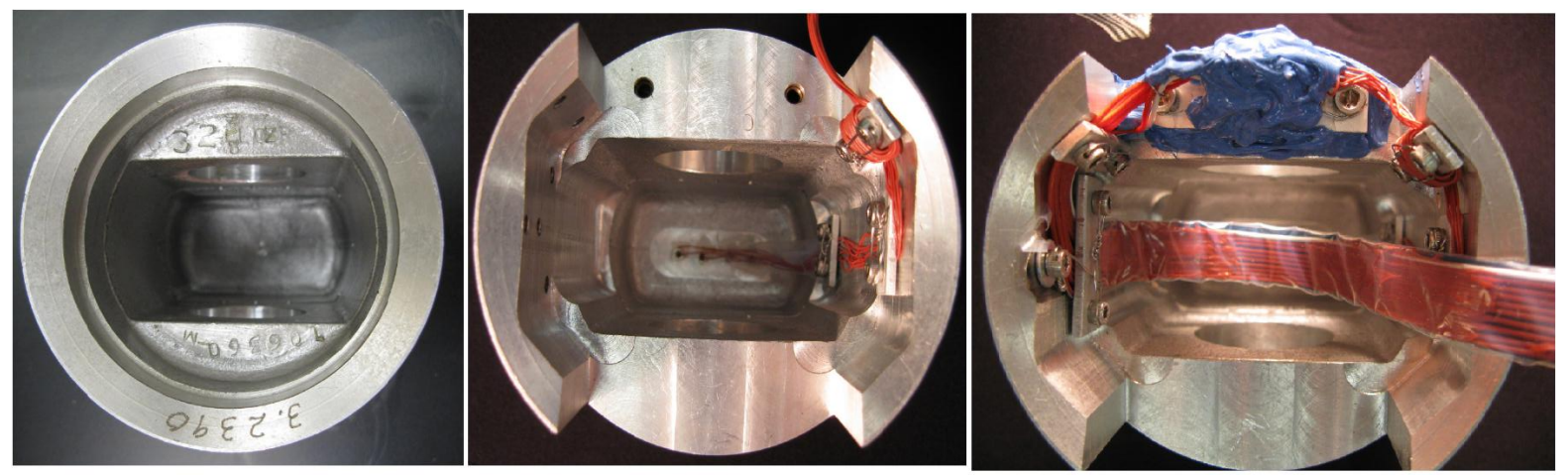

Figure 5.6: Pictures of the piston at different stages in the instrumentation process (left - before modification; middle - thermocouples installed; right - fully wired) 


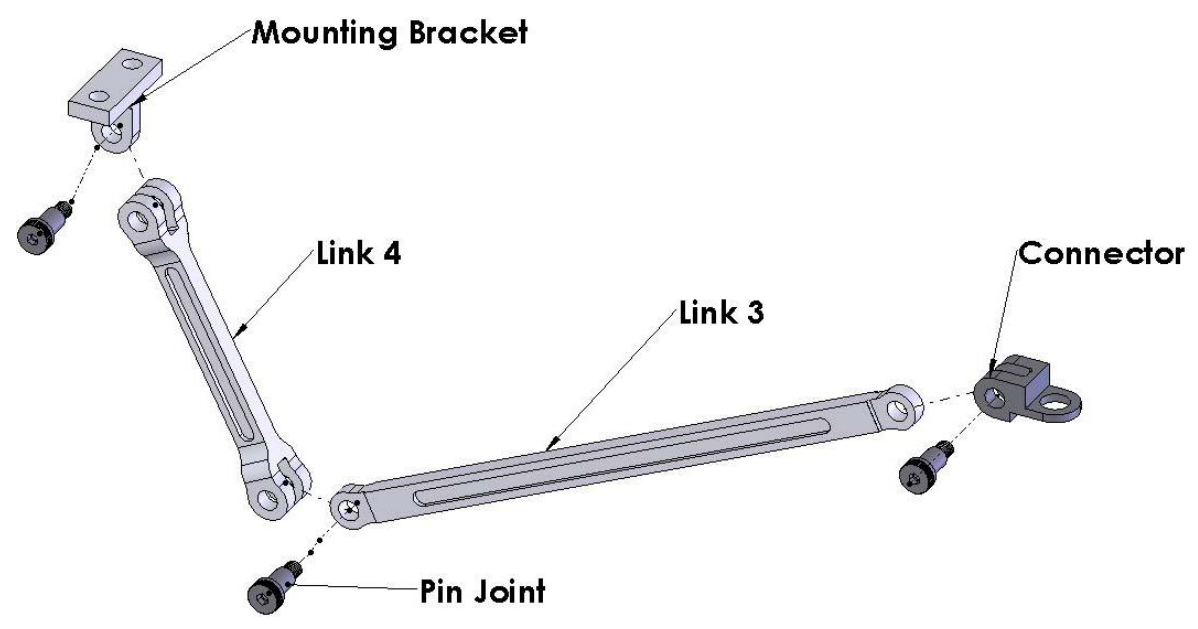

Figure 5.7: Mechanical telemetry linkage [46]

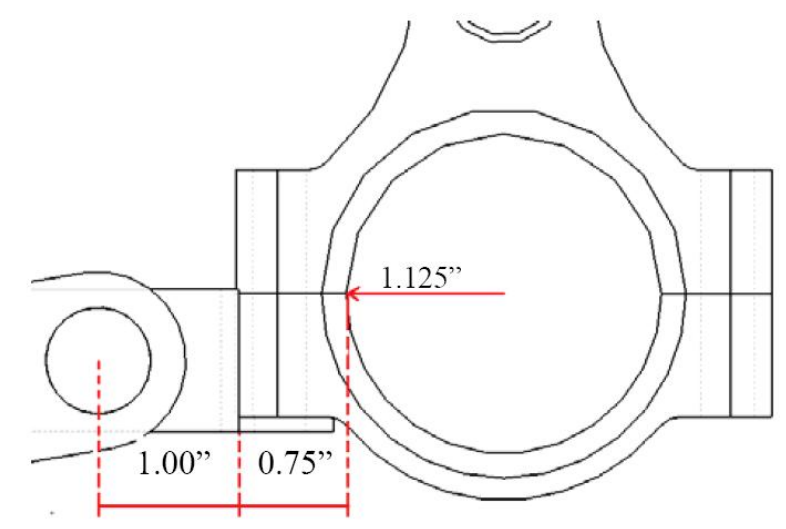

Figure 5.8: Linkage connection to connecting rod big end [46]

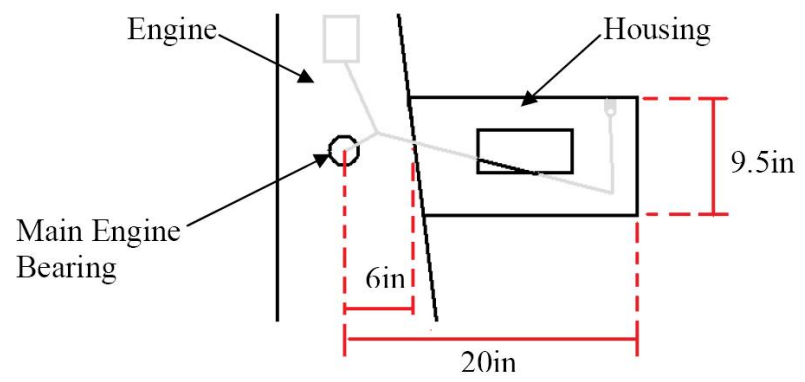

Figure 5.9: Linkage housing [46] 


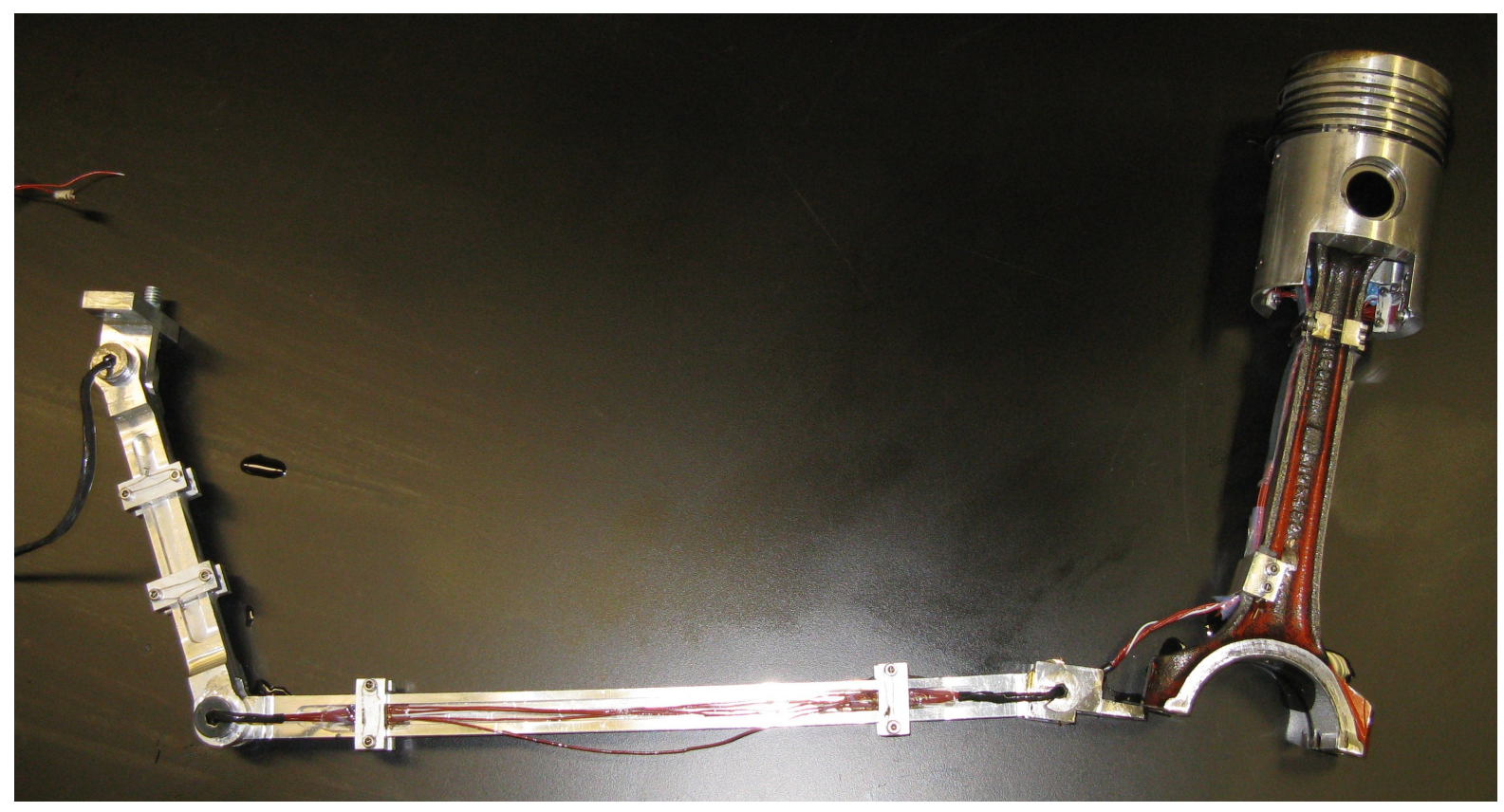

Figure 5.10: Wired linkage, connecting rod and piston

\subsubsection{Thermocouple Signal Conditioning, Acquisition and Pro- cessing}

The DAQ system had capacity to measure five temperatures in the piston: two surface temperatures, two in-depth temperatures and the cold junction temperature. The signals for these five temperatures were carried by six wires. As the signal processing and DAQ system worked with double ended signals, the six wires needed to be appropriately split and shared by ten signal wires, or two for each temperature. Figure 5.11 illustrates the splitting process.

Analog conditioning of the double ended signals was required due to the noisy test environment and the low magnitude of the thermocouple voltages. The same amplifierfilter modules used for the thermocouple development, described in Sub-Section 4.1.3, were used for this purpose. The modules consisted of a 100X differential amplifier (Analog Devices product number AD626) and a $200 \mathrm{~Hz}$ cut-off low-pass, two-pole Butterworth filter built according to the modified Sallen-Key circuit design [45]. The filters ampli- 


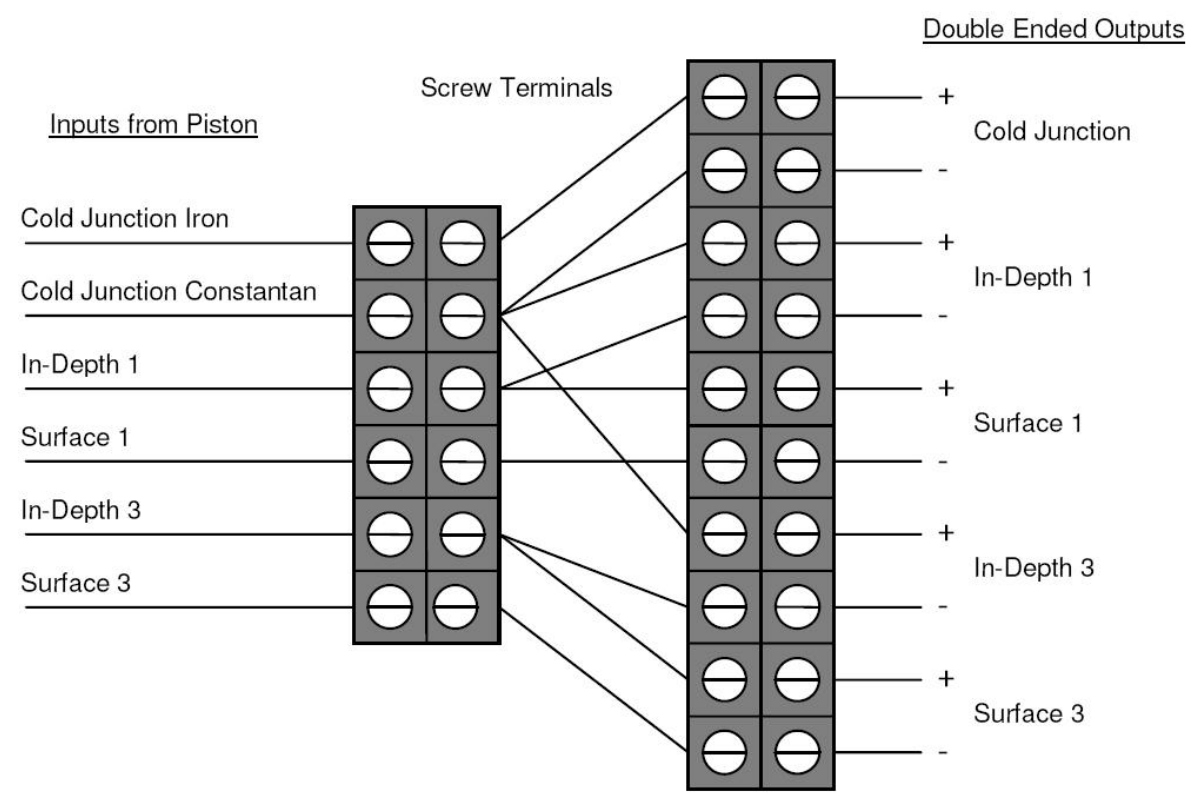

Figure 5.11: Thermocouple wire splitting

fied the signal by 1.59, making total signal amplification a factor of 159. Five parallel amplifier-filter modules were built to permit sampling of all five thermocouples simultaneously.

The conditioned thermocouple signals were acquired with the PCI-6251 DAQ board through an SCB-68 termination block. The exhaust gas thermocouple, the SCB-68's reference temperature and the encoder's Z pulse were also acquired with the same DAQ system. LabVIEW code named "Piston_T\&P.vi" was written to acquire the temperature voltages at a frequency of $1000 \mathrm{~Hz}$, average them into 1, second intervals and convert the voltages into temperatures. The code could also acquire instantaneous voltages as a function of crank angle when desired. These voltages were converted subsequently to temperatures by the MATLAB program "Piston_T\&HF.m". More details on both programs can be found in Appendix A. Both programs converted voltages to temperatures according to the thermocouple calibration and conversion algorithm described below. 


\section{Thermocouple Calibration}

In Sub-Section 4.1.3, the surface thermocouples had their cold junction in an ice bath, which greatly simplified the calibration process. The piston thermocouples had their cold junction in the piston, and therefore a different calibration method was used. As the calibration is of the aluminum-constantan metal combination, it was performed prior to installation of the thermocouples. One pair of iron and constantan wires was clamped to the outside of the piston near the crown, and a second pair was clamped to the outside near the bottom of the piston skirt. The insulation was stripped of the wires at the very tip so that the metals were pressed into contact with the aluminum. The wire tips were insulated from the clamps to ensure that the electrical connection was completely through the aluminum piston.

LabVIEW code was written to measure the voltage difference between the two constantan wires and the temperatures of both constantan-aluminum junctions from the voltage difference produced by each iron-constantan pair. To calibrate, the piston was placed crown side down on a hot plate to develop a temperature difference between the junctions. The piston was heated until the hotter junction reached $260^{\circ} \mathrm{C}$ and then cooled naturally. This process was repeated three times. During calibration, the temperature difference between the junctions was between 15 and $30^{\circ} \mathrm{C}$. The calibration data are presented in Figure 5.12, which shows the temperature-voltage slope versus the average temperature of the two junctions. A third-order polynomial was fitted to the data to determine the following relationship:

$$
\text { Slope }\left({ }^{\circ} \mathrm{C} / \mathrm{mV}\right)=29.131-6.1861 E-2 * T_{\text {ave }}+1.4124 E-4 * T_{\text {ave }}^{2}-1.4935 E-7 * T_{\text {ave }}^{3}
$$




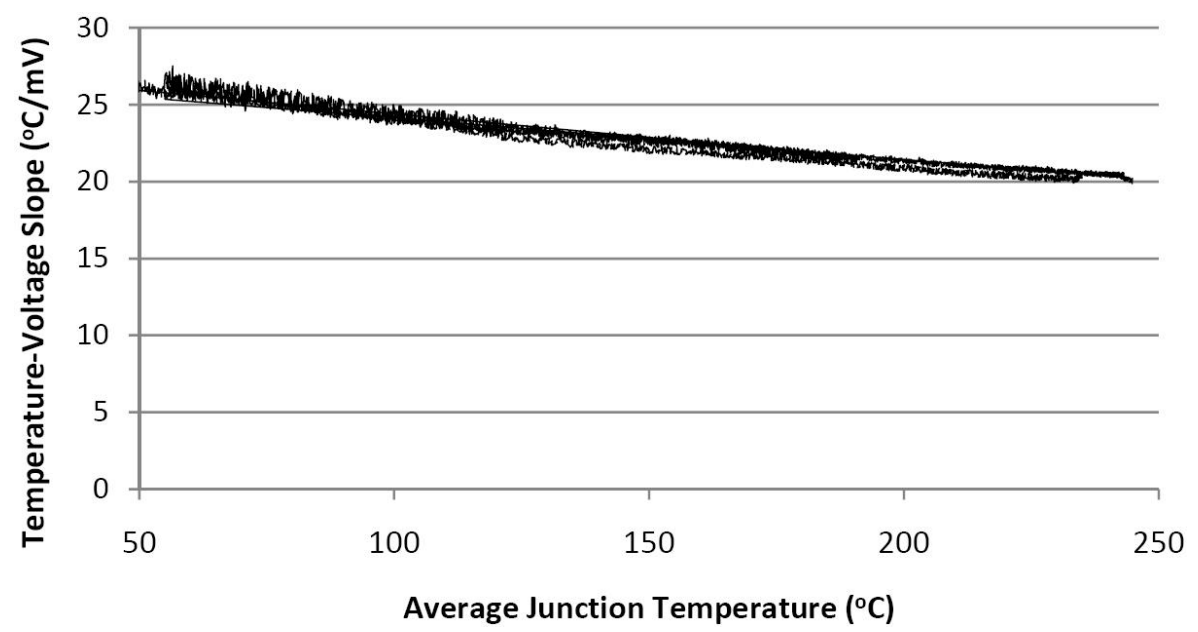

Figure 5.12: Piston aluminum-constantan calibration data

\section{Voltage to Temperature Conversion Algorithm}

The following steps describe the algorithm used by "Piston_T\&P.vi" and "Piston_T\&HF.m" to convert the piston thermocouple voltages to temperatures:

1. Multiply the raw thermocouple voltages by 1000 to convert to $\mathrm{mV}$ and divide by 159 offset the amplification introduced by the amplifier-filter modules.

2. Calculate the cold junction temperature from the voltage and the National Institute of Standards and Testing (NIST) type J thermocouple coefficients [47]. The SCB68's built-in temperature sensor provided the reference temperature needed for the calculation.

3. Calculate the in-depth thermocouple temperatures from their voltages and the cold junction temperature. Plugging the cold junction temperature into Equation 5.1, a first guess was made for the temperature-voltage slope which was then used to make an accurate estimate of $T_{\text {ave }}$ for both in-depth thermocouples. Equation 5.1 was run again with the new values of $T_{\text {ave }}$ to produce more refined temperature-voltage slopes. The in-depth temperatures were calculated by multiplying the in-depth voltages by their corresponding slopes and adding to the cold junction temperature. 
4. Calculate the surface thermocouple temperatures from their voltages and paired in-depth temperatures. Plugging the in-depth temperatures into Equation 5.1, first guesses were made for the temperature-voltage slope, which were then used to make an accurate estimate of $T_{\text {ave }}$ for both surface thermocouples. Equation 5.1 was run again with the new values of $T_{\text {ave }}$ to produce more refined temperaturevoltage slopes. The surface temperatures were calculated by multiplying the surface voltages by their corresponding slopes and adding to their paired in-depth temperatures.

\section{Instantaneous Temperature Data Processing}

Even after analog amplifying and filtering, the in-depth thermocouple signals contained considerable noise with a frequency equal to the engine speed and a magnitude of approximately $2^{\circ} \mathrm{C}$. As the actual temperatures at these depths should be nearly constant, "Piston_T\&HF.m" averaged the in-depth temperatures into single values for each engine cycle. This averaging was performed prior to calculating the surface temperatures to eliminate any noise compounding effects.

The surface temperature signals were less noisy than the in-depth signals, but still contained random noise with magnitude of approximately $0.5^{\circ} \mathrm{C}$. To minimize this noise, "Piston_T\&HF.m" applied a moving average filter to the instantaneous temperature data. A 51 point $\left(10^{\circ} \mathrm{CA}\right)$ filter was used for the uncoated temperatures, as any larger filter would overly damp the sharp peak experienced during combustion. A 251 point (50 $\mathrm{CA}$ ) filter was used for the coated data because they did not contain such sharp temperature changes. Additionally, the coated data had smaller signal-to-noise ratios because of their smaller temperature swings, and therefore more smoothing was necessary. 


\section{Heat Flux Calculation}

"Piston_T\&HF.m" also calculated heat flux from the instantaneous temperature data. Instantaneous heat flux through the piston surface was calculated from the one-dimensional, unsteady heat conduction equation:

$$
\frac{\partial T}{\partial t}=\alpha \frac{\partial^{2} T}{\partial^{2} x}
$$

In the equation, $\alpha$ is the thermal diffusivity of the substrate. The solution to Equation (5.2) by Fourier Analysis is shown in Appendix C. The solution requires temperature data for boundary conditions, which are provided by the pairs of surface and in-depth thermocouples. Within this range, the one-dimensional assumption can be considered valid because cyclically varying temperature gradients into the wall are large relative to those in directions parallel to the wall [48].

Steady state heat flux was calculated simply from Equation 5.3.

$$
\dot{q}_{s, m}=\frac{k}{l}\left(T_{s, m}-T_{i}\right)
$$

In the equation, $\dot{q}_{s, m}$ is mean heat flux into the surface, $l$ is the depth of the in-depth thermocouple, $T_{s, m}$ is the average surface temperature and $T_{i}$ is the average in-depth thermocouple temperature, which should be approximately steady, as can be seen in Figure 4.16.

\subsection{Additional Sensors}

In addition the thermocouples in the piston, a number of other sensors were used during testing. The piezoelectric pressure transducer was installed in the cylinder assembly port as shown in Figure 5.1. Cylinder pressure was measured according to the procedure in Section 2.3, and knock was identified when desired according to the procedure outlined in Sub-Section 2.3.1. The previously mentioned LabVIEW program "Piston_T\&P.vi" was 
Table 5.1: Piston test coating thicknesses

\begin{tabular}{lccc}
\hline & Metal TBC & YSZ & Uncoated \\
\hline Copper Thickness $(\mu \mathrm{m})$ & 400 & 400 & 125 \\
TBC Thickness $(\mu \mathrm{m})$ & 400 & 200 & N/A \\
\hline
\end{tabular}

also used to acquire the necessary signals. The MATLAB program "Piston_P.m" was used to process the raw pressure data to determine pressure and knock statistics.

The visual display sensors listed in Section 2.4 were also used for the piston tests. Exhaust temperature was measured along with the piston thermocouples by the PCI6251 DAQ board and engine speed, torque, and intake air, coolant and oil temperatures were recorded manually approximately every minute.

\subsection{Test Procedure}

The full surface of the piston crown was coated for the tests, and the thicknesses of the TBCs and intermediate copper layers are listed in Table 5.1. The YSZ thickness of 200 $\mu \mathrm{m}$ was chosen to approximately match the level of thermal insulation used by Assanis and Mathur [2] for their insulated SI engine tests. The thickness of the metal TBC was chosen to provide approximately half the thermal insulation of the YSZ coating. As only one piston was instrumented, it was necessary that the TBCs be tested sequentially. First the metal TBC was tested, followed by YSZ, and finally the piston was tested uncoated with just the copper layer needed for the surface thermocouples. The properties of the TBCs are listed in Table 1.1. The engine compression ratio was maintained constant for all tests by adjusting the height of the cylinder assembly.

Each coating was put through five temperature test cycles followed by one knock test cycle. The engine operating parameters are listed in Table 5.2, and the test cycles are described below. 
Table 5.2: Piston test engine operating parameters

\begin{tabular}{lcc}
\hline Speed & & $1200 \mathrm{RPM}$ \\
Load & & Full \\
& Temperature Tests & $20^{\circ} \mathrm{CA}$ BTC \\
Spark Timing & Knock Tests & $30{ }^{\circ} \mathrm{CA}$ BTC \\
Compression Ratio & & $8.7: 1$ \\
Coolant & & Boiling Water \\
& Temperature Tests & Unheated \\
Intake Air Temperature & Knock Tests & $60{ }^{\circ} \mathrm{C}$ \\
\hline
\end{tabular}

\section{Temperature Test Cycle}

0-3 Minutes Idle at $1000 \mathrm{RPM}$

3-16 Minutes WOT at $1200 \mathrm{RPM}$

\section{6-17 Minutes Motor at 800 RPM}

One second averaged temperatures were recorded over the full test cycle, and 90 engine cycles of instantaneous temperature and pressure data were recorded between 10 and 15 minutes.

\section{Knock Test Cycle}

0-3 Minutes Idle at 1000 RPM

3-18 Minutes WOT at 1200 RPM

\section{8-19 Minutes Motor at 800 RPM}

One second averaged temperatures were recorded over the full test cycle, and 600 engine cycles of instantaneous pressure data were recorded between 10 and 17 minutes. 
Testing cycles for each coating were spread out over at least five days to minimize the influence of ambient weather conditions on the results.

\subsection{Piston Test Setup and Methodology Summary}

The piston tests were designed to evaluate the metal TBC and YSZ coatings on the surface of an aluminum piston. The piston was instrumented with surface thermocouples at the aluminum surface and with in-depth thermocouples $5 \mathrm{~mm}$ behind the surface to measure temperature and heat flux into the crown. The thermocouple wires were routed from the piston to the DAQ system along a mechanical linkage. Cylinder pressure was measured and was used to calculate peak pressure and IMEP and to quantify knock. Engine torque and speed and a number of temperatures throughout the engine were also measured. Each TBC was run through five temperature test cycles under normal operating conditions and one knock test cycle under extreme conditions intended to promote knock. The tests were also run with an uncoated piston to establish the baseline. The results of the piston tests are presented and discussed in the next chapter. 


\section{Chapter 6}

\section{Piston Test Results and Discussion}

This chapter presents and discusses the results of the piston tests, which consisted of temperature and knock tests. First though, it is beneficial to discuss the condition of the TBCs after completion of their five temperature and one knock test cycles. The poor oil control of the engine was evident, as both TBCs and the uncoated surface were covered with substantial oil deposits. Appendix D contains pictures of the piston crown with each coating after testing. Some of the oil solidified into a viscous black sludge or hardened deposit, while some of it remained as liquid oil. It is not clear if the oil control problem became worse over the course of testing, which would mean it was worst for the uncoated tests.

Oil control was a particular issue for the uncoated tests because deposits greatly damp the temperature swings measured by the surface thermocouples. To minimize this issue and obtain temperature data more representative of a modern engine, the uncoated piston surface was cleaned between each test cycle. The picture in Figure D.1, however, was taken after the uncoated piston was run through the five temperature and one knock test cycles without cleaning. Data were not recorded during these cycles; they were run simply to accumulate oil. Oil control also posed a challenge for the uncoated piston's knock tests, as is discussed in Section 6.2. The metal TBC and YSZ were not cleaned in 
between tests.

The TBCs were visually inspected after testing for signs of failure. The metal TBC appeared completely intact with no signs of cracking or delamination. The YSZ coating also appeared to be in good condition except for one chip on the perimeter. The chip is visible in Figure D.3 in the 4 o'clock position. It is not clear whether the chipping occurred during testing or accidentally during engine assembly or disassembly.

\subsection{Temperature Tests}

The primary objective of the temperature tests was to measure temperatures in the piston. Heat fluxes into the piston crown were then calculated from these values. Cylinder pressure, torque and exhaust gas temperature were also measured.

\subsubsection{Piston Temperature and Heat Flux}

Table 6.1 summarizes the main temperature and heat flux results from the temperature tests. The average temperatures were measured during the 15th minute of the testing cycle, and the average heat fluxes were calculated from these temperatures. Five tests were run with each coating, so these average temperature and heat flux values are the mean of five packets of 60 seconds of data sampled at $1000 \mathrm{~Hz}$. The surface temperature swing, peak temperature occurrence and peak heat flux values were determined from instantaneous data sampled as a function of crank angle. Ninety engine cycles of instantaneous data were measured each test between the 10 and 15 minute mark, so the instantaneous data derived values in the table are the averages from 450 cycles. Figures 6.1 to 6.6 elaborate on the values in Table 6.1 .

Surface Thermocouple 1 had a loose connection and only functioned properly during portions of some tests. Accordingly, the values in Table 6.1 derived from this thermocou-

ple were calculated only from the measurements taken when it was functioning properly. 
Table 6.1: Piston test temperature and heat flux results - summary of average values

\begin{tabular}{|c|c|c|c|c|}
\hline $\begin{array}{c}\text { Thermocouple } \\
\text { Pair }\end{array}$ & & Uncoated & $\begin{array}{c}0.4 \mathrm{~mm} \\
\text { Metal TBC }\end{array}$ & $\begin{array}{c}0.2 \mathrm{~mm} \\
\mathrm{YSZ}\end{array}$ \\
\hline \multirow{6}{*}{1} & Average Surface Temp $\left({ }^{\circ} \mathrm{C}\right)$ & 168.4 & 174.9 & 170.9 \\
\hline & Surface Temp Swing $\left({ }^{\circ} \mathrm{C}\right)$ & 2.13 & 0.74 & 1.27 \\
\hline & Peak Temp Occurrence $\left({ }^{\circ} \mathrm{CA}\right)$ & 227.1 & 311.8 & 327.1 \\
\hline & Average In-Depth Temp $\left({ }^{\circ} \mathrm{C}\right)$ & 166.2 & 172.2 & 168.3 \\
\hline & Average Heat Flux $\left(\mathrm{kW} / \mathrm{m}^{2}\right)$ & 64.2 & 82.8 & 59.2 \\
\hline & Peak Heat Flux $\left(\mathrm{kW} / \mathrm{m}^{2}\right)$ & 342 & 179 & 191 \\
\hline \multirow{6}{*}{3} & Average Surface Temp $\left({ }^{\circ} \mathrm{C}\right)$ & 173.7 & 180.7 & 176.1 \\
\hline & Surface Temp Swing $\left({ }^{\circ} \mathrm{C}\right)$ & 4.44 & 1.97 & 1.27 \\
\hline & Peak Temp Occurrence $\left({ }^{\circ} \mathrm{CA}\right)$ & 71.0 & 257.3 & 326.7 \\
\hline & Average In-Depth Temp $\left({ }^{\circ} \mathrm{C}\right)$ & 170.1 & 175.8 & 172.5 \\
\hline & Average Heat Flux $\left(\mathrm{kW} / \mathrm{m}^{2}\right)$ & 94.9 & 126.8 & 95.4 \\
\hline & Peak Heat Flux $\left(\mathrm{kW} / \mathrm{m}^{2}\right)$ & 1045 & 325 & 240 \\
\hline
\end{tabular}

Additionally, oil tended to accumulate more readily on the piston crown above Surface Thermocouple 1, rendering its data unrepresentative of modern engines where oil control is better. Oil accumulation was much less above Surface Thermocouple 3 and therefore the subsequent analysis focuses on the results obtained with this thermocouple.

Figure 6.1 shows the average temperatures during the 15th minute of each test. Surface Thermocouple 1 is not shown for the tests in which it never worked properly. These results were not analyzed in detail because much of the variation is due to uncontrolled changes in ambient conditions. However, the temperatures with the metal TBC were all higher than those during the YSZ and uncoated tests.

Figure 6.2 shows sample instantaneous temperature cycles measured by Surface Ther- 


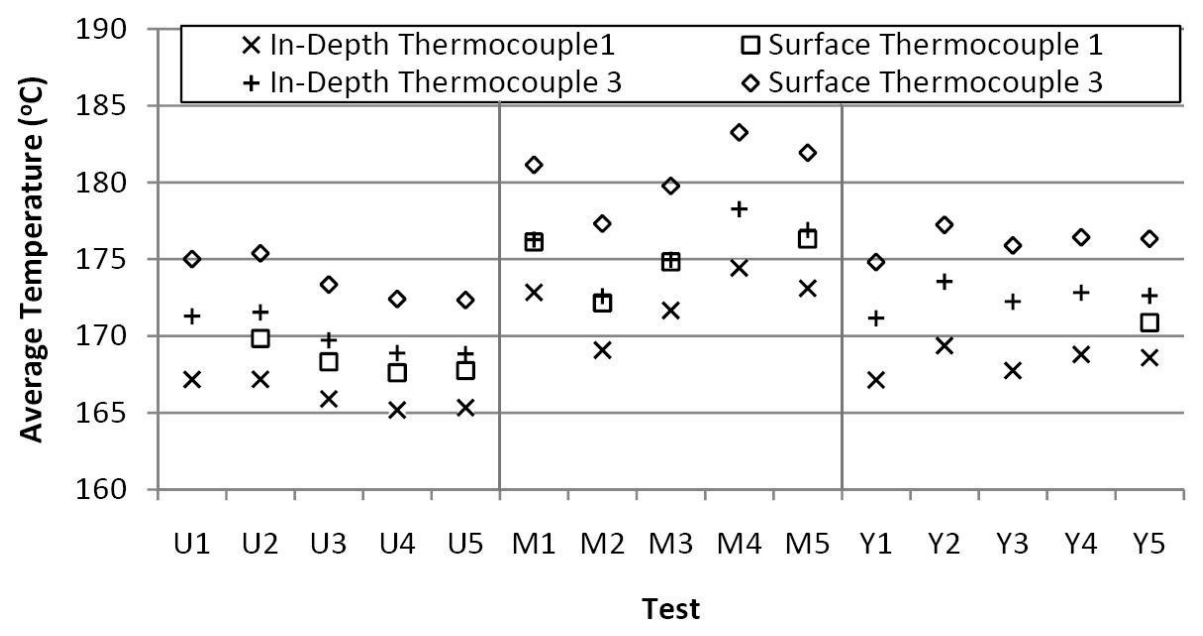

Figure 6.1: Average piston temperatures (U - Uncoated, M - $0.4 \mathrm{~mm}$ Metal TBC, Y $0.2 \mathrm{~mm}$ YSZ)

mocouple 3. These cycles were selected for presentation because they are representative of the typical sample. The curves are normalized to have a cycle average temperature of $0^{\circ} \mathrm{C}$. The uncoated curve has the largest temperature swing, steepest rise during the expansion stroke, and the earliest peak. The metal TBC has a larger temperature swing and earlier peak compared to YSZ.

Figure 6.3 shows representative temperatures in the uncoated piston as measured by both in-depth and both surface thermocouples for the same engine cycle. It was hoped to gain information on flame progression from this figure, but oil deposits severely damped and delayed the temperature swing at surface thermocouple 1.

Representative curves for instantaneous heat flux into the piston crown are shown in Figure 6.4. These curves were calculated from the temperature data in Figure 6.2 (before normalizing) and their corresponding in-depth temperatures. Noise in the temperature data is amplified during the heat flux calculation, and hence the curves contain considerable noise. To obtain a clearer picture, 40 cycles of heat flux data were averaged into into the single curves shown in Figure 6.5. All temperature data were first processed with a 


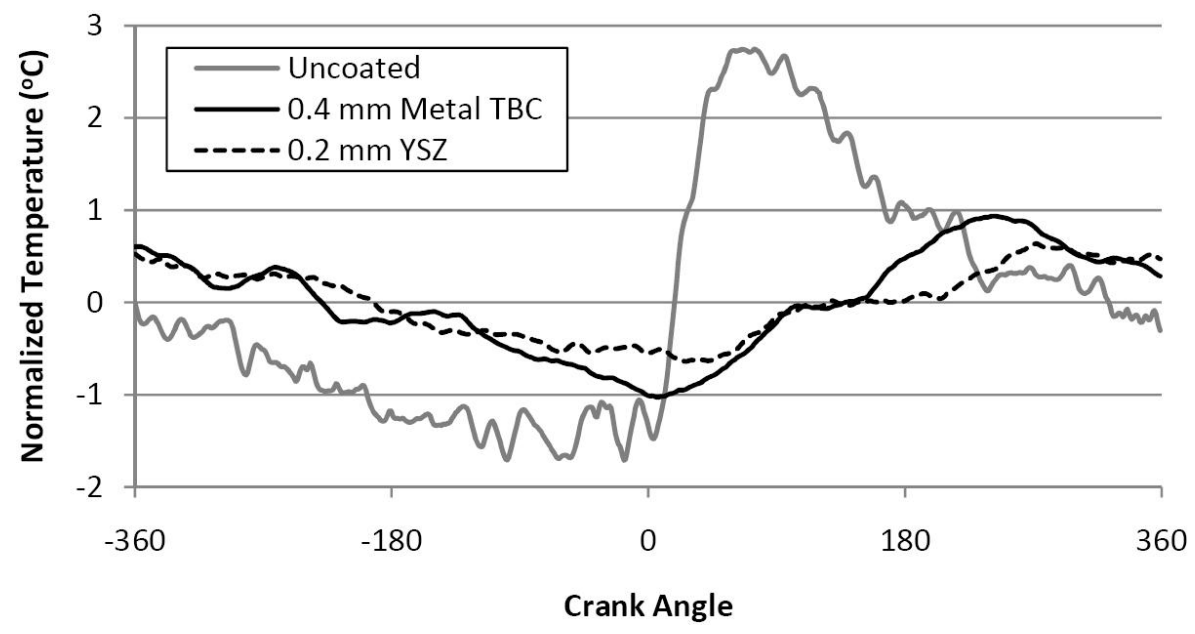

Figure 6.2: Surface Thermocouple 3 representative temperature cycles - normalized to average temperature of $0^{\circ} \mathrm{C}$

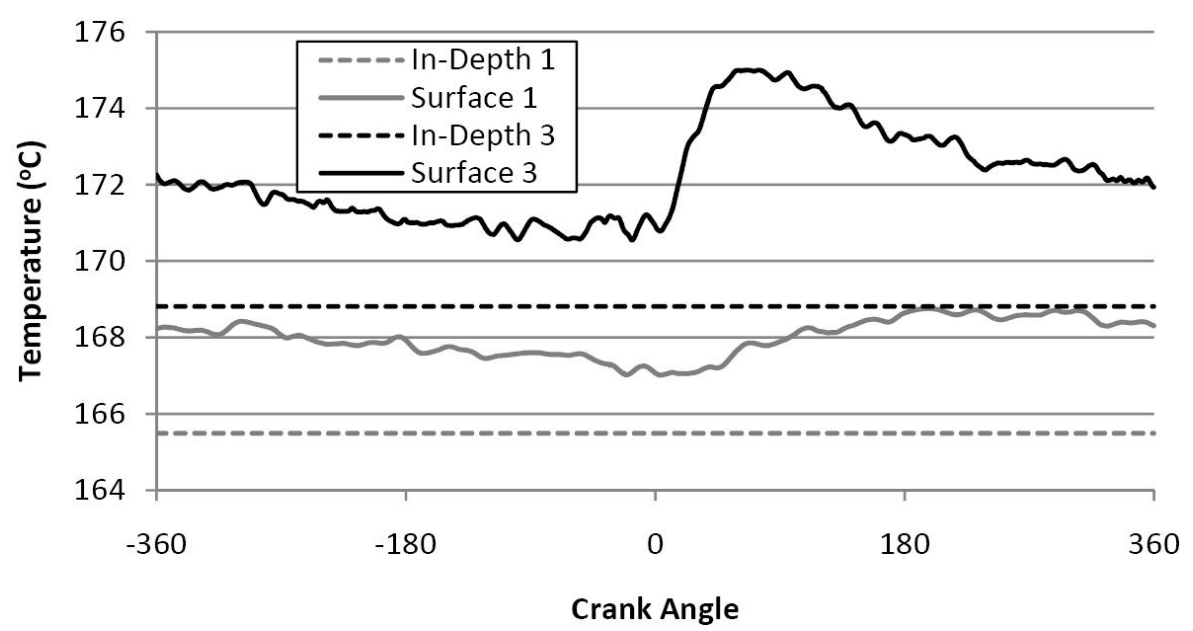

Figure 6.3: Representative uncoated piston temperature cycles - all thermocouples 


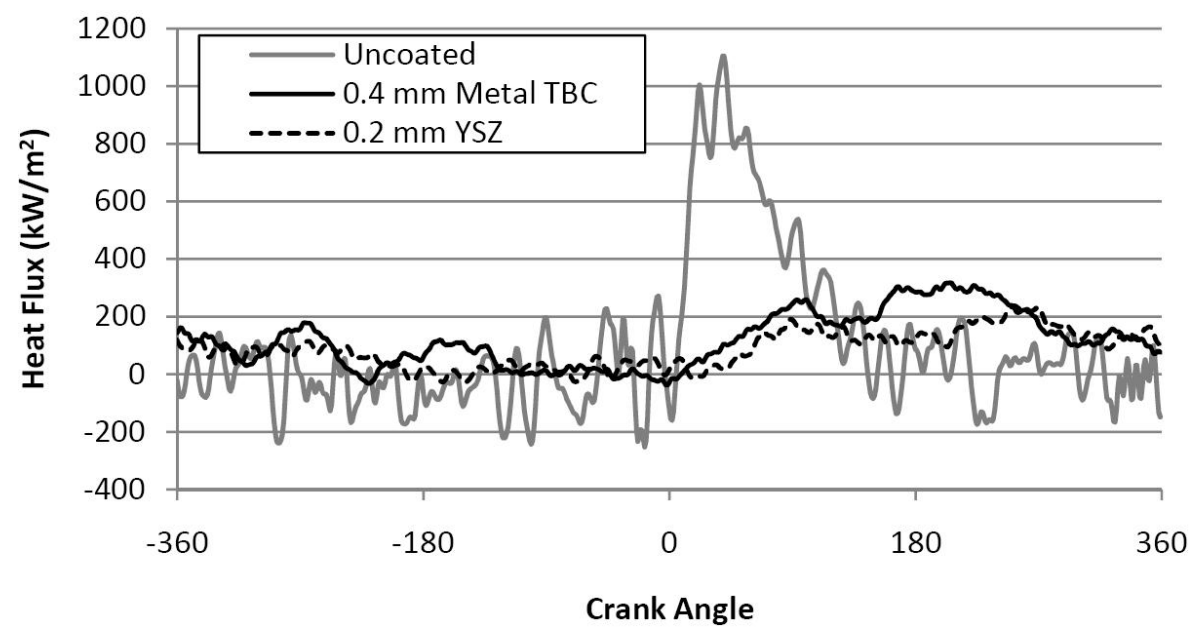

Figure 6.4: Thermocouple Pair 3 representative instantaneous heat flux - calculated from temperature data in Figure 6.2

251 point moving average filter prior to heat flux calculations ${ }^{1}$.

The uncoated curve in Figure 6.5 shows that heat flux is small relative to combustion and expansion in all other parts of the cycle. Heat flux is negative at the end of intake and start of compression, indicating that heat is being transfered from wall to gas. The metal TBC and YSZ curves are more damped than the uncoated curve as would be expected. Heat flux is always positive under the TBCs except around $0^{\circ} \mathrm{CA}$ when it nears zero and becomes slightly negative, although this negative segment could actually be lingering noise. A discussion of the errors associated with the instantaneous heat flux results is presented in Appendix Section E.2.

Figure 6.6 presents cycle average heat fluxes into the piston crown. The missing error bar indicates that Surface Thermocouple 1 was functioning properly for only one testing cycle with the YSZ coating. Average heat flux through the YSZ coating was comparable to that through the uncoated surface, with no statistical difference, as shown

\footnotetext{
${ }^{1}$ Previously presented metal TBC and YSZ instantaneous data were also processed with 251 point filters, though only a 51 point filter was used on the uncoated data. As such, the peak in the uncoated curve in Figure 6.5 is lower than the value listed in Table 6.1.
} 


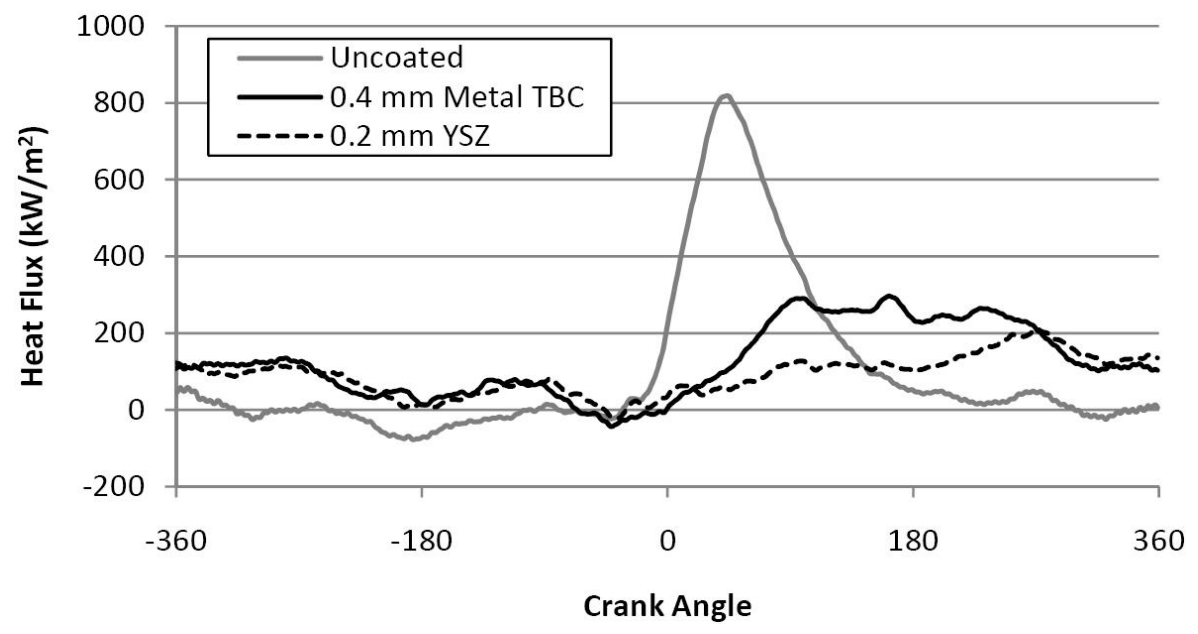

Figure 6.5: Thermocouple Pair 3 instantaneous heat flux - average of 40 cycles

by the error bars. Average heat flux through the metal TBC, on the other hand, was approximately $33 \%$ higher than it was into the uncoated or YSZ coated piston. A more detailed error analysis of the average heat flux results is presented in Appendix Section E.1.1. This analysis included shifting the results in Figure 6.6 in an attempt to correct for thermocouple errors. This shift did not change the general results presented in Figure 6.6. That is, average heat fluxes into the YSZ coated and uncoated surfaces were still the same within statistical limits, while average heat flux through the metal TBC was approximately $30 \%$ higher.

The result of higher heat flux into the piston crown when coated with the metal TBC is consistent with the results of the preliminary cylinder wall tests described in Chapter 3. That similarly high heat flux was not measured under the YSZ coating suggests that surface roughness significantly increases heat transfer. Research by Tsutsumi et al. found surface roughness increases heat transfer in engines, a result the authors attributed to an increase effective surface area [35]. A typical wire arc applied metal coating has an Average Roughness (Ra) of 12-20 $\mu \mathrm{m}$, while a typical plasma spray applied YSZ coating has an Ra of 7-12 $\mu \mathrm{m}$ [49]. A standard milling machine finish would have an Ra in the range of 0.8-6.3 $\mu \mathrm{m}[50]$. Average Roughness is the average of a surface's deviation from 


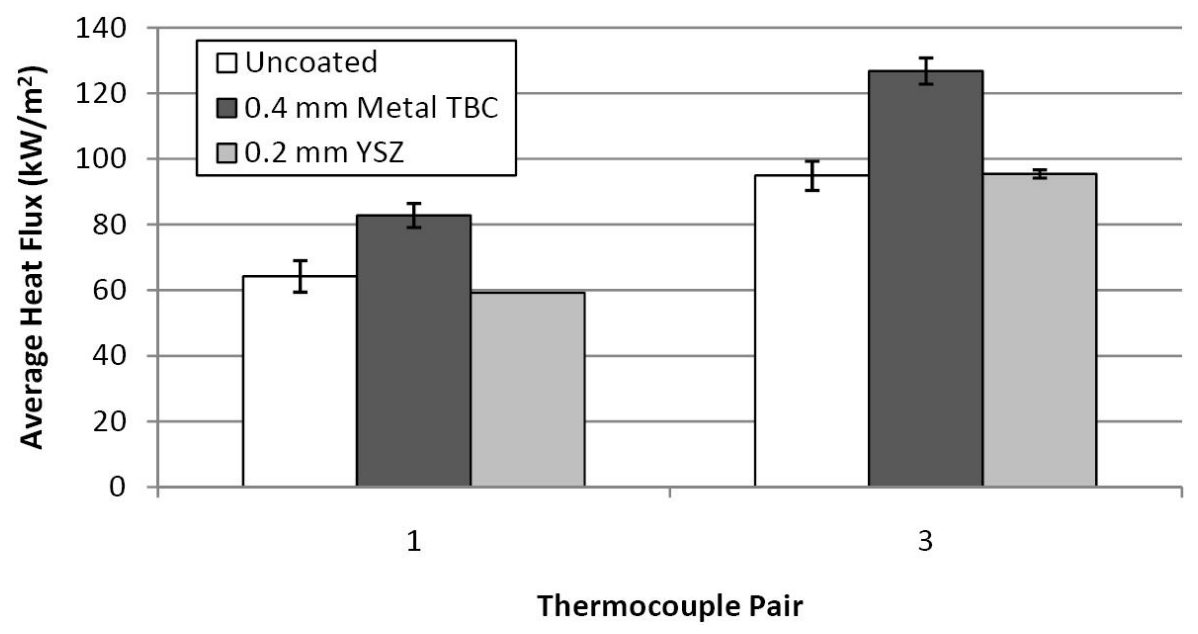

Figure 6.6: Average heat flux into piston crown

its mean surface height. Pictures of each TBC prior to testing, shown in Figure 6.7, also convey the roughness of the metal TBC. The YSZ coating, while substantially smoother than the metal TBC, was still rougher than the uncoated surface. This roughness could partially explain why net heat flux through the YSZ coating was not reduced compared to the uncoated surface.

In addition to surface roughness, there are at least two other possible explanations for why the TBCs did not reduce overall heat transfer. First, as suggested by Furuhama and Enomoto [4] and Woschni et al. [6], higher temperatures at the coating surface may increase the convective heat transfer coefficient because of thinning of the thermal boundary layer. A higher coefficient could increase heat transfer despite a smaller temperature difference between the gas and wall. Further investigation of this effect is beyond the scope of this thesis project. The second possible explanation, as mentioned in Section 3.2 , is that the TBC blocks heat flow from the wall to the gas during the portion of the cycle when the in-cylinder gases are cooler than the wall, effectively increasing overall heat transfer. Finite Element Analysis was used to investigate if this second explanation could be a factor with the coatings used for the piston tests. 


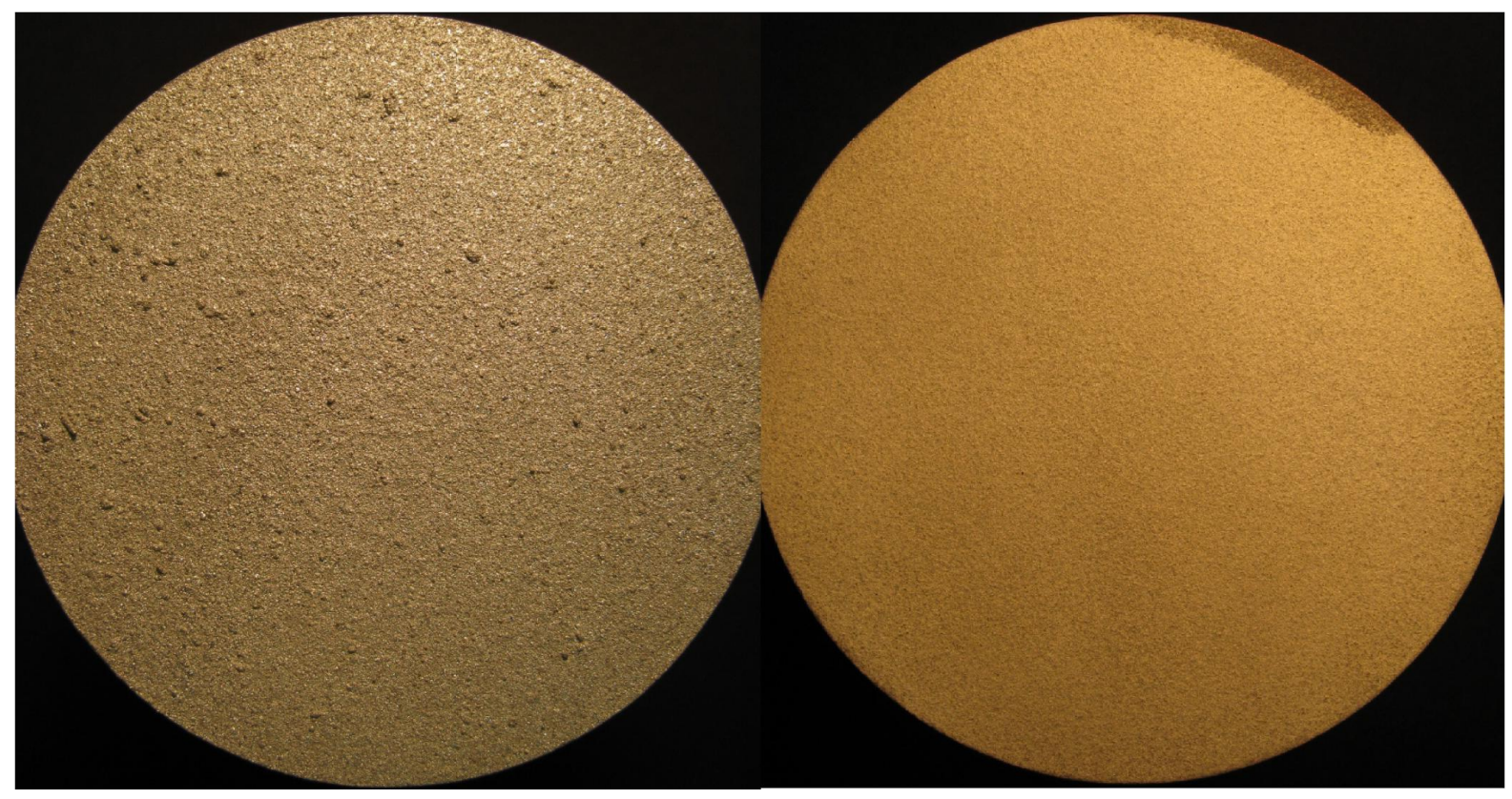

Figure 6.7: Pictures of TBCs prior to testing (left - metal TBC, right - YSZ)

\section{Finite Element Analysis Surface Temperature and Heat Flux Modeling}

A simple FEA was performed to model temperatures at the surface of the different TBCs to predict whether they were blocking heat transfer from the wall to the gas during any portion of the cycle. The only variables changed were the TBCs' thicknesses and thermal properties; the analysis ignored surface roughness and the possibility of the heat transfer coefficient varying with surface temperature. The FEA procedure was similar to that used in Chapter 4. The geometry and boundary conditions used for the present analysis are shown in Figure 6.8, and the material properties listed in Table 1.1 were used for the TBCs. The convective heat flux boundary condition inputs were in-cylinder gas temperatures and a heat transfer coefficient. Gas temperatures were taken from previous SI engine work by Enomoto and Furuhama [43], and the heat transfer coefficient was calculated with the Woschni equation [44] using temperature and pressure data from Enomoto and Furuhama.

Figure 6.9 shows the FEA results for temperatures at the surface of the TBCs. The TBC surface temperatures are always higher than that of the uncoated aluminum surface, 


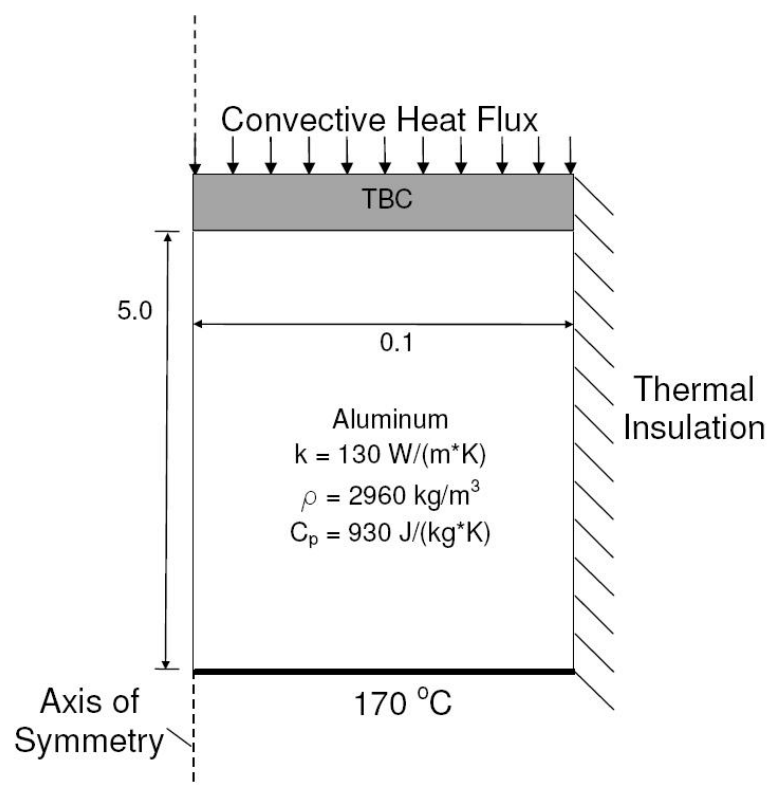

Figure 6.8: TBC surface temperature FEA model geometry and boundary conditions (all dimensions in $\mathrm{mm}$, not to scale)

so the TBCs are never blocking heat flow from the wall to the gas. In fact, the result shows that the TBCs should be increasing heat transfer to the gas when it is colder than the walls. Therefore, the explanation that the TBCs increase overall heat transfer by reducing heat transfer from the walls to the gas is likely incorrect.

The FEA was also used to model heat flux into the substrate surface as would be measured by the thermocouple pairs installed in the piston. This FEA predicted heat flux is shown in Figure 6.10. As mentioned earlier, the only variables changed were the TBC thicknesses and material properties. The FEA results show that the metal TBC and YSZ should have very similar heat flux curves at the substrate surface. The FEA results differ from the experimental heat flux results, shown in Figures 6.4 and 6.5, which show the metal TBC having much higher heat flux during the expansion and exhaust strokes. This difference may be attributable to the roughness of the metal TBC.

Another important point about Figure 6.10 is that the average of the YSZ heat flux curve is only $3.6 \%$ less than the average of the uncoated heat flux curve. This difference 


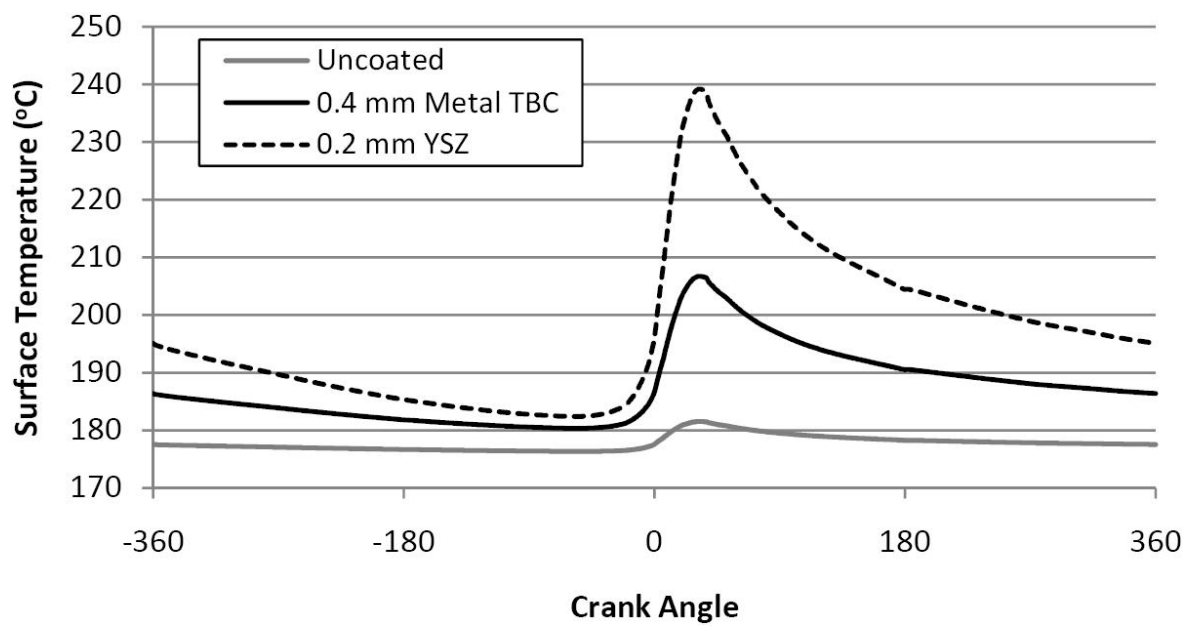

Figure 6.9: FEA predicted surface temperatures

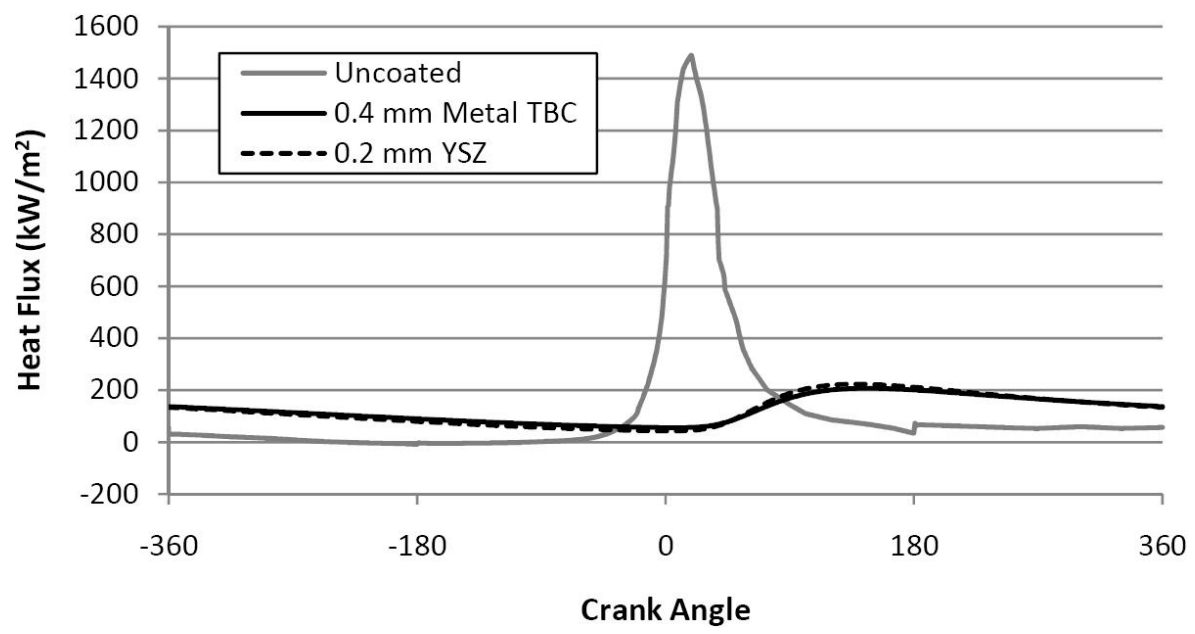

Figure 6.10: FEA predicted heat flux at substrate surface 
is within the error limits of the average experimental heat fluxes in Figure 6.6. Therefore it can not be determined from the experimental results if the YSZ was reducing heat flux as would be expected based upon its thermal properties or if other phenomena such as surface roughness were increasing heat flux.

To summarize, the previous discussion considered three effects that could increase heat transfer into a piston crown insulated with a TBC. First, roughness likely increased heat transfer through the metal TBC and possibly the YSZ to a lesser extent by increasing effective surface area. Second, the notion that higher surface temperatures increase the convective heat transfer coefficient was considered but not explored in further detail. Finally, FEA was used to explore the possibility that the TBCs were blocking heat transfer back to the in-cylinder gases when the gases were cooler than the walls. It was found that the coated walls should always be hotter at the gas interface than the uncoated wall and therefore this effect was not likely occurring.

\subsubsection{Cylinder Pressure, Torque and Exhaust Temperature}

In addition to piston temperatures and heat flux, a number of other parameters were measured during the temperature tests. Ninety cycles of instantaneous cylinder pressure data were measured each test between 10 and 15 minutes. Figure 6.11 shows the average peak pressures measured each test, Figure 6.12 shows the average angle of peak pressure occurrence, and Figure 6.13 shows the average IMEPs. Average IMEP, a good indicator of engine performance, varied by less than $3 \%$ over the course of testing. Close inspection of the three figures reveals that IMEPs and peak pressures generally decreased as angle of peak pressure occurrence increased. While not presented here, angle of peak pressure occurrence generally increased with ambient air temperature. As such, the variation in the pressure data is likely due more to changes in ambient conditions than the TBCs. However, the data do show that the coatings did not have a drastic negative impact on performance. 


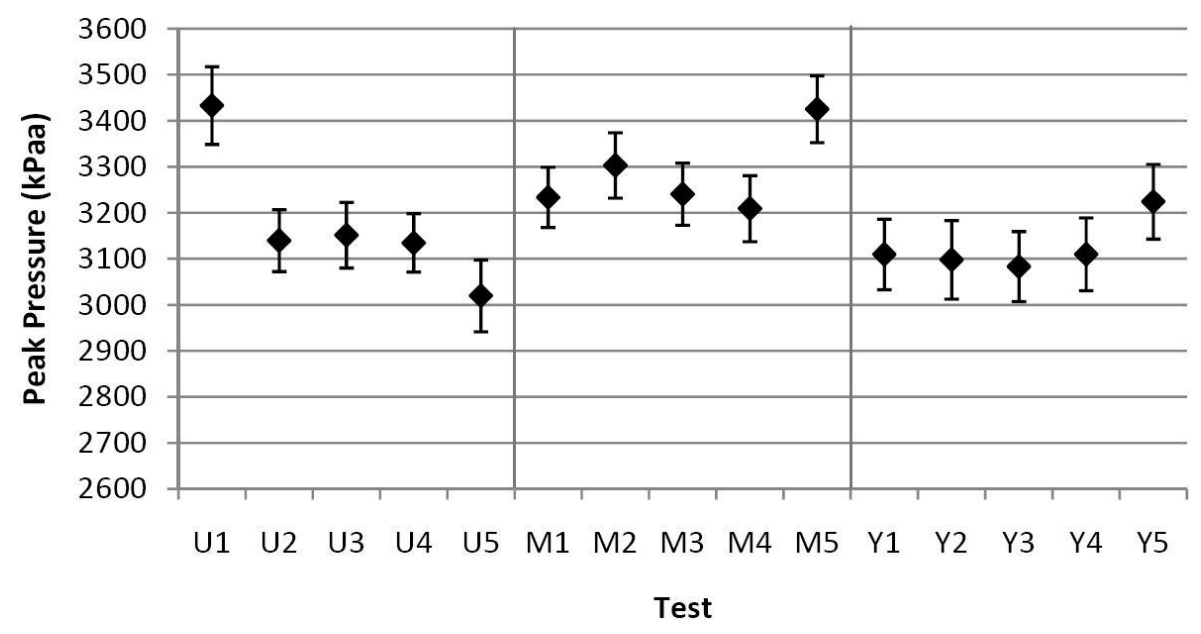

Figure 6.11: Average peak pressure

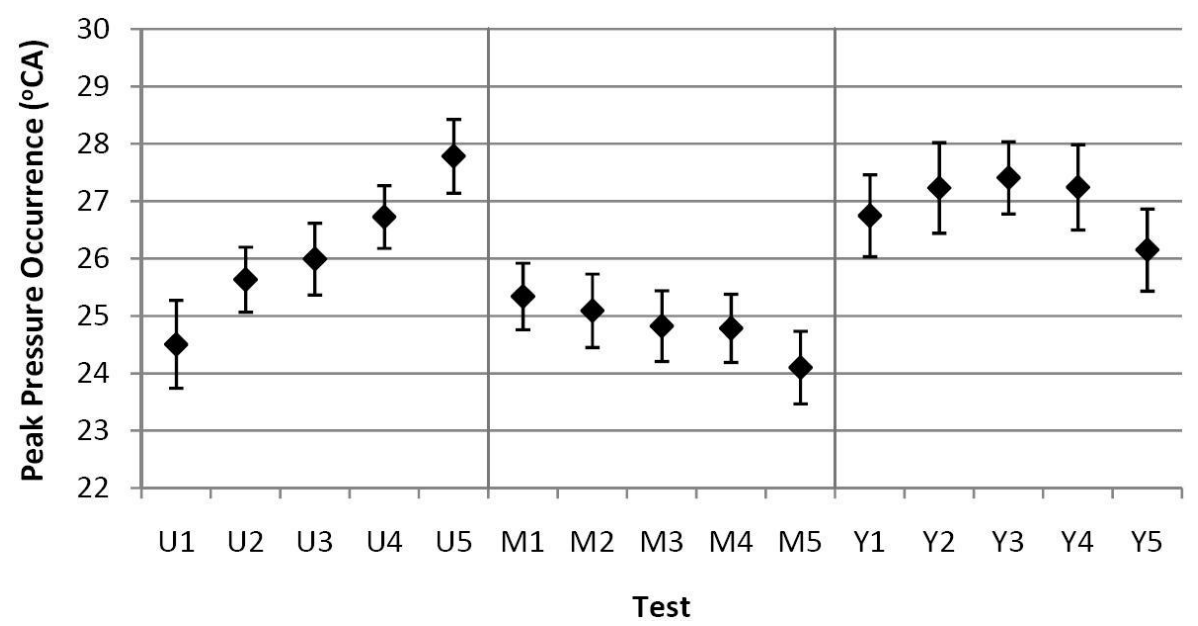

Figure 6.12: Average angle of peak pressure occurrence 


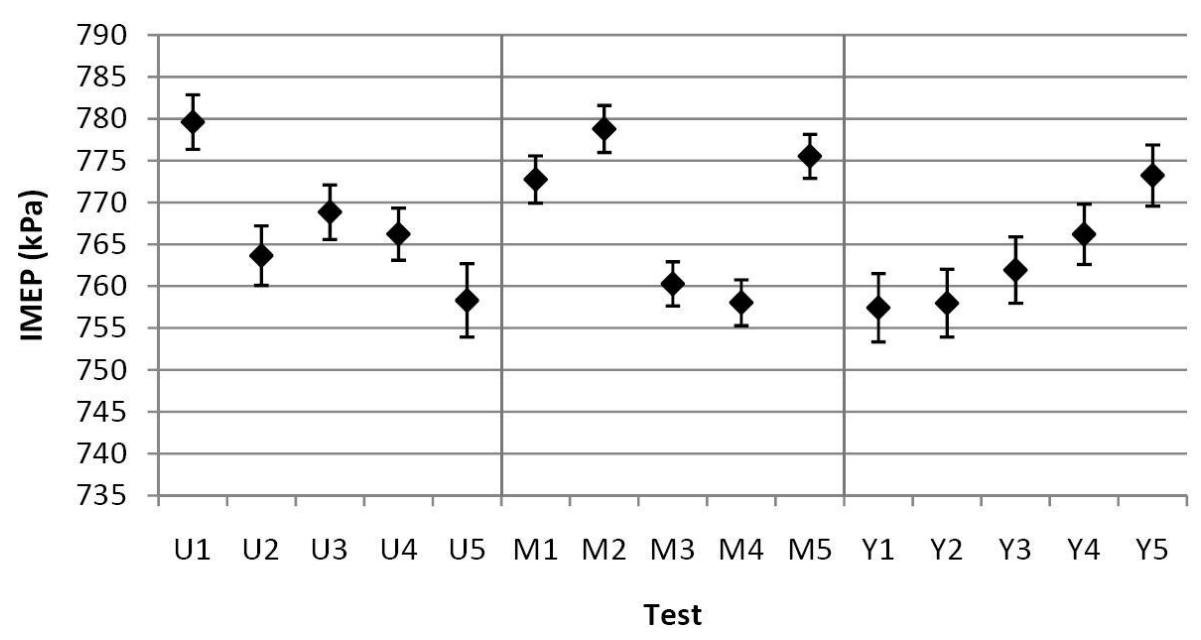

Figure 6.13: Average IMEP

Knock intensity was also calculated from the pressure data to determine if the coatings promote knock under typical operating conditions. Knock intensity values for each test are presented in Figure 6.14. Knock was low for all tests to the point of being essentially negligible. This is an important result, as knock is one of the primary concerns with using TBCs in SI engines. Tests over the full range of engine operating conditions would be necessary to confirm the TBCs do not increase knock. The knock tests discussed in Section 6.2 explore the TBC's tendency to promote knock in extreme operating conditions.

Brake torque was recorded every minute between 10 and 15 minutes of each test to obtain another indicator of power and performance. To compensate for differences in ambient conditions between tests, torque values were corrected to a standard ambient condition by Equation 6.1 adapted from Heywood [3]. In Equation 6.1, $p_{s t, d}$ is standard dry air pressure $(98.205 \mathrm{kPa}), p_{e}$ is experimental air pressure, $p_{v, e}$ is experimental air vapour pressure, $T_{e}$ is experimental air temperature, and $T_{s t}$ is standard air temperature (302.54 K). In the CFR engine, torque is strongly dependent on oil temperature, so corrected torque was plotted against oil temperature as shown in Figure 6.15, and linear trend lines were fitted to the data for clarification. 


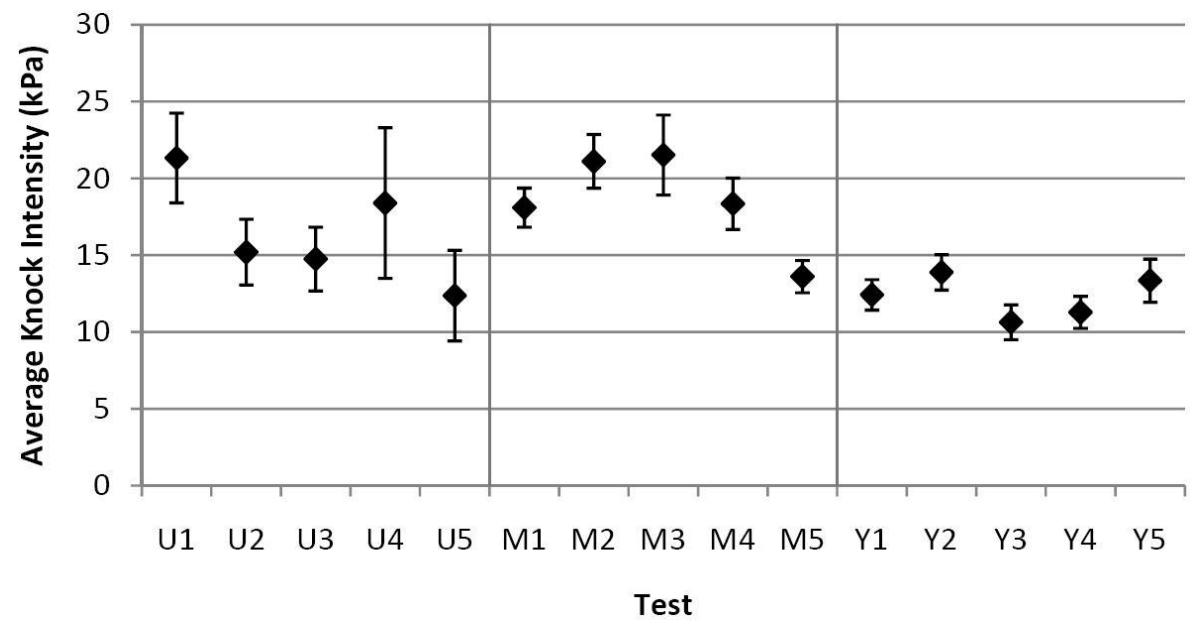

Figure 6.14: Temperature test average knock intensity

$$
\text { Corrected Torque }=\text { Measured Torque } \times\left(\frac{p_{s t, d}}{p_{e}-p_{v, e}}\right) \sqrt{\frac{T_{e}}{T_{s t}}}
$$

Figure 6.15 shows that the metal TBC consistently produced 1-2 \% less torque compared to YSZ. At lower oil temperatures, the most torque was produced with the uncoated piston, but at higher oil temperatures YSZ performed better. The power reduction with the metal TBC may be somewhat due to greater heat loss, but the torque should be viewed with caution because it was certainly affected by variation in test conditions.

The final parameter of interest measured during the temperature tests was exhaust gas temperature. Like piston temperatures, exhaust gas temperatures were measured during the 15th minute at a frequency of $1000 \mathrm{~Hz}$. Average exhaust gas temperatures for each test are presented in Figure 6.16. Variation in exhaust gas temperature was less than $3 \%$, but exhaust gas temperatures also vary with ambient conditions and tended to increase with angle of peak pressure occurrence. 


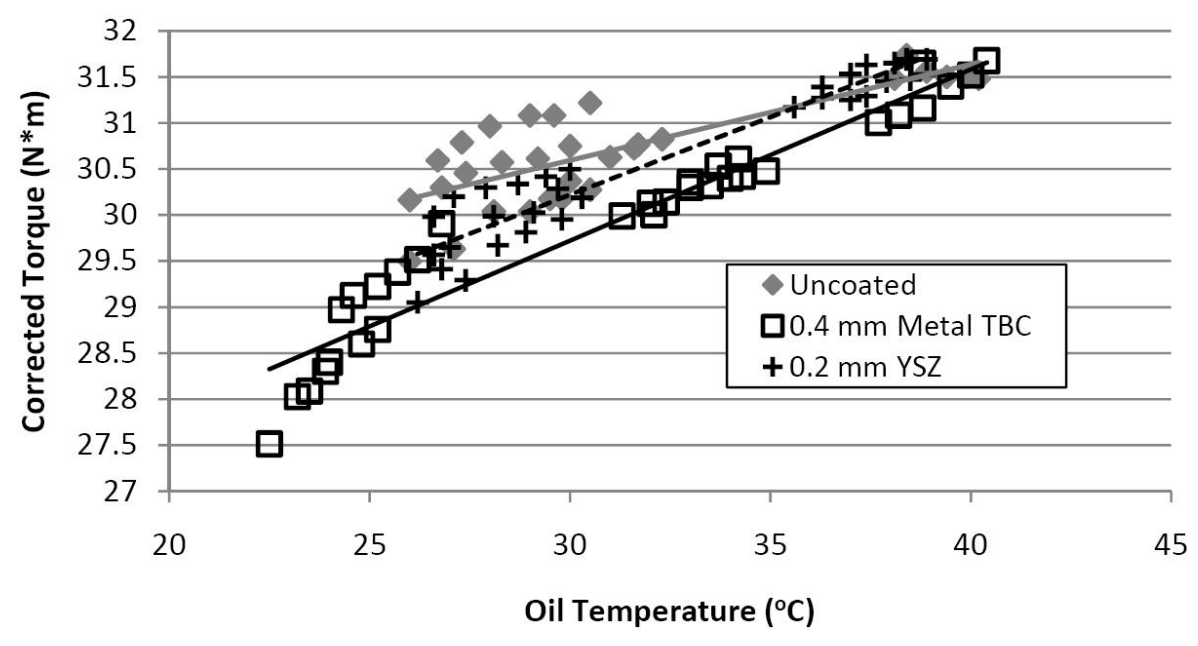

Figure 6.15: Corrected torque vs. oil temperature

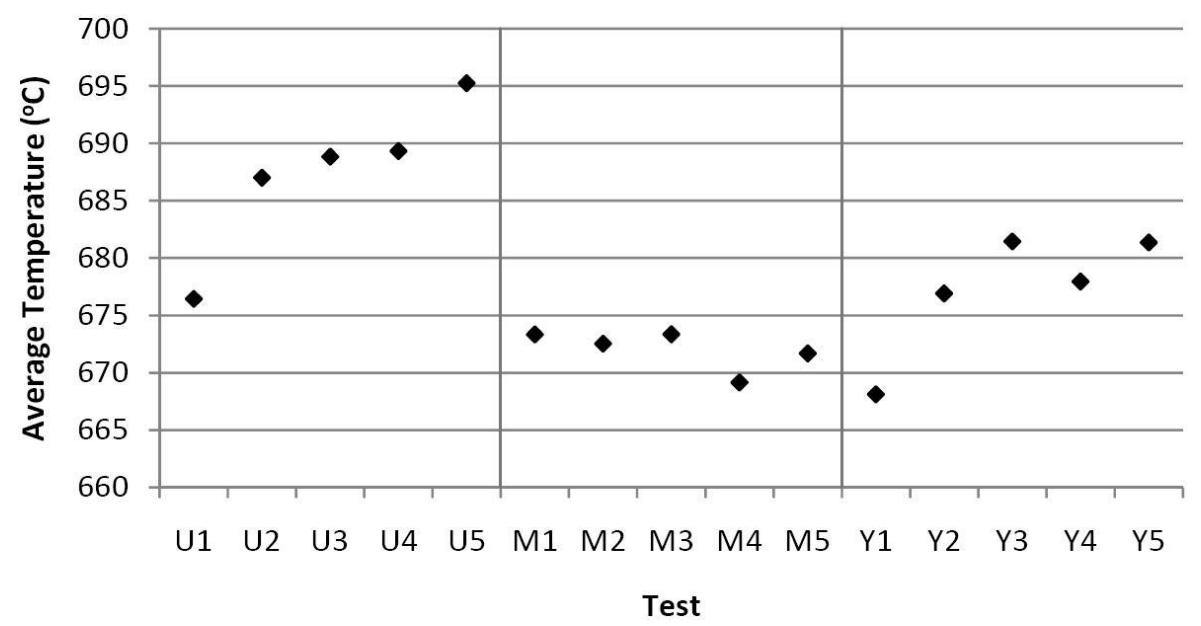

Figure 6.16: Average exhaust gas temperature 


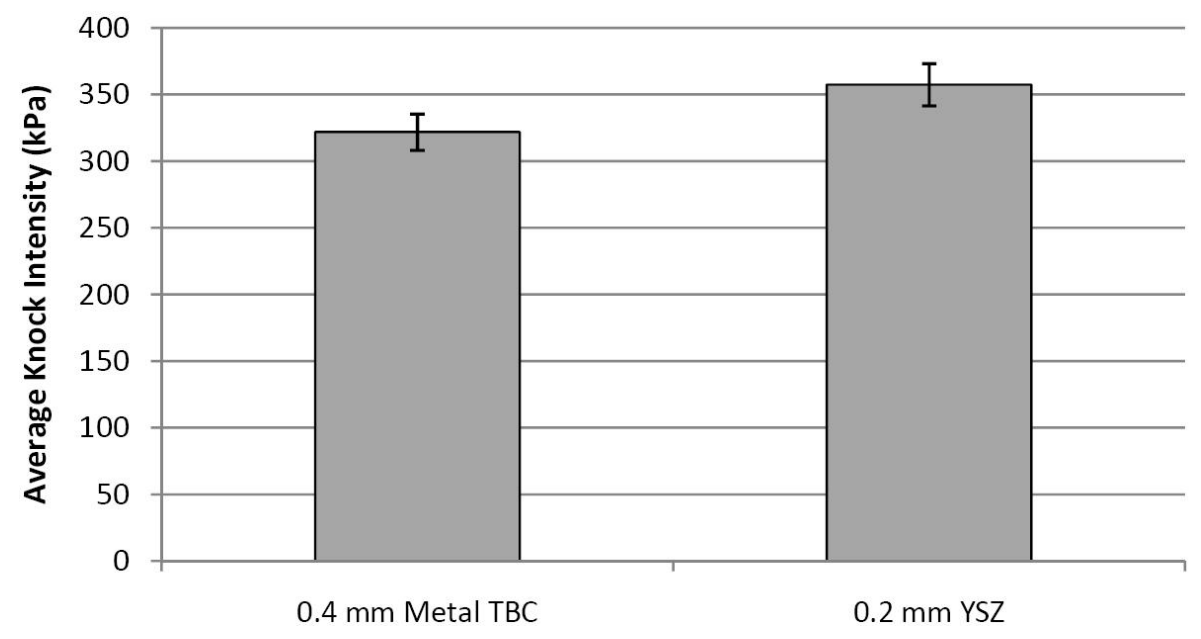

Figure 6.17: Knock test average knock intensity

\subsection{Knock Tests}

Each TBC was put through one knock test during which 600 cycles of pressure data were collected. The test cycle featured $30^{\circ} \mathrm{CA}$ advanced spark timing and $60^{\circ} \mathrm{C}$ heated intake air to promote knock. Average knock intensity results from the knock tests are shown in Figure 6.17. Knock levels were similar for both TBCs, and both easily completed the full test cycle with stable power on the first attempt.

Figure 6.17 does not include results for the uncoated piston because it was not possible to complete the test cycle despite four attempts - once after five temperature test cycles, twice after having the crown freshly cleaned of oil deposits, and once with a different aluminum piston with no copper layer. In all four attempts, knock grew so extreme that power diminished continually over the course of testing.

The cause of the high knock levels with the uncoated piston is not clear. A likely factor was the presence of oil in the combustion chamber and on the piston crown. However, accumulations of oil were also found on the piston crown after both TBC tests, which included successful completion of the knock tests. That the uncoated piston failed to complete the knock test four times suggests that elevated surface temperatures may help 
to prevent knock in engines with poor oil control. This is a counterintuitive result that requires additional work to confirm and understand.

The important result of these tests is that the TBCs did not cause uncontrollable knock even under extreme operating conditions. This result is in agreement with preliminary knock tests described in Section 3.3.

\subsection{Piston Test Results and Discussion Summary}

The metal TBC and YSZ coatings were tested on the surface of a piston crown in the CFR engine. The piston crown was instrumented to measure temperatures and heat flux, and a number of other operating parameters such as cylinder pressure were also measured. Each TBC and the uncoated surface were run through five temperature test cycles and one knock test cycle. The following points summarize the important results of these tests.

1. The metal TBC appeared to be completely intact upon completion of the tests, while the YSZ coating was chipped on its perimeter but otherwise also appeared to be in good condition.

2. Both TBCs significantly damped the temperature swings and peak heat flux at the aluminum piston crown surface. Measurements by thermocouple pair 3 showed that the metal TBC reduced peak heat flux by $69 \%$ and the YSZ reduced peak heat flux by $77 \%$ compared to the uncoated piston.

3. The metal TBC increased average heat flux into the piston crown by approximately $33 \%$ compared to the uncoated and YSZ coated pistons. The likely cause of this result is the metal TBC's rougher surface. Average heat flux into the uncoated and YSZ coated pistons were similar within statistical limits. 
4. Knock was not observed with either TBC or the uncoated piston during the temperature tests which were run under normal engine operating conditions. During the knock tests, which were run under knock promoting conditions, elevated but not uncontrollable levels of knock were observed with both TBCs. However, knock levels were so high with the uncoated piston that it was not possible to complete the knock test. This result is likely due to poor oil control, but it is not clear why the TBCs improved knock resistance. 


\section{Chapter 7}

\section{Conclusions and Recommendations}

The conclusions and recommendations are divided into two sections; the first concerns the development of the surface thermocouple and the second concerns the use of TBCs in SI engines.

\subsection{Surface Thermocouple Development}

A necessary part of this thesis research program was the development of an accurate surface thermocouple suitable for use in aluminum engine components. This section presents the conclusions and recommendations from this work.

\section{Conclusions}

A review of existing surface thermocouple designs found them to be inaccurate for temperature and heat flux measurements in IC engine combustion chambers. This inaccuracy is generally due to the thermocouple materials having lower thermal conductivities and diffusivities than the surrounding aluminum substrate. This difference in properties causes the hot junction to experience larger temperature swings than are occurring at the aluminum surface. 
In the present study, an existing surface thermocouple was modified with the objective of developing a more accurate sensor for engine use. The modified thermocouple consists of a constantan wire cemented in a $0.57 \mathrm{~mm}$ hole drilled through the aluminum component. The constantan wire is one of the thermocouple elements and the aluminum serves as the second element. A thick copper layer applied to the surface by wire arc thermal spray forms the electrical connection between the wire and aluminum at the hot junction. More importantly, the thick copper layer provides a path for heat conduction between the thermocouple tip and the aluminum to allow for temperature equalization.

Finite element analysis was used to determine the optimum thickness of the copper layer. It was found that with a thickness of 100 to $125 \mu \mathrm{m}$, the thermocouple should measure the magnitude of surface temperature swings with less than $6 \%$ error under typical SI engine heat flux conditions. In this thickness range, the delay in peak temperature occurrance should be less than $5^{\circ} \mathrm{CA}$. The thermocouple should measure average surface temperatures with an error of less than $0.23^{\circ} \mathrm{C}$.

The results from engine testing of the surface thermocouple displayed trends similar to those produced by the FEA modeling, suggesting that the thermocouple does perform as expected.

\section{Recommendations}

The development of an accurate surface thermocouple is beneficial for many areas of engine research related to heat transfer. As many of the heat transfer measurements reported in the literature were taken with less accurate thermocouples, there are opportunities for taking new measurements throughout the combustion chamber under various operating conditions. These new measurements could be used to evaluate the accuracy of existing heat transfer correlations. The thermocouple could also be used for further study of TBCs and the effect of surface roughness on heat transfer.

There are also opportunities to improve the design and performance of the thermo- 
couple. New techniques for applying the copper layer that allow for greater thickness control could improve the accuracy of the thermocouple. Improved methods for reducing signal noise would provide clearer surface temperature and heat flux data and reduce the need for digital filtering. These improvements and any others that increase the accuracy of the thermocouple would benefit research in the field of experimental heat transfer.

\subsection{Thermal Barrier Coatings in Spark-Ignition En- gines}

The primary objective of this research program was to investigate the use of metal and YSZ TBCs in SI engines. In a series of preliminary tests, $0.5 \mathrm{~mm}$ thick coatings of the metal TBC were applied to the face of aluminum plugs which were installed in the cylinder wall. The plugs were instrumented with thermocouples to measure average temperatures within the substrate. In the primary piston tests, both the metal TBC and YSZ were applied to the surface of an aluminum piston crown. The metal TBC was $0.4 \mathrm{~mm}$ thick and the YSZ coating was $0.2 \mathrm{~mm}$ thick. The piston was instrumented with surface and in-depth thermocouples to measure temperatures and heat fluxes. Both the cylinder wall and piston tests included knock tests featuring heated intake air and advanced spark timing to promote knock, which was quantified from cylinder pressure data. This section presents the conclusions from these tests and recommendations for future research.

\section{Conclusions}

The following points summarize the conclusions related to the use of TBCs in SI engines.

1. The metal TBC was completely intact after the piston tests, while the YSZ coating was chipped on its perimeter. The cause of the chip was not clear, though this observation supports the notion that the metal TBC is more durable than YSZ. 
2. Neither TBC reduced overall heat flux into the piston crown. Overall heat fluxes through the YSZ coated and uncoated piston surfaces were the same within experimental error, and overall heat flux through the metal TBC was $33 \%$ higher. In the preliminary cylinder wall tests, plug temperatures were generally higher when coated with the metal TBC, also suggesting that the metal TBC increased overall heat flux.

Surface roughness is likely a significant factor behind why the TBCs did not reduce heat flux. The metal TBC was considerably rougher than the YSZ coating, which itself was rougher than the uncoated surface. Tests varying the roughness of the cylinder wall plugs consistently measured higher plug temperatures with rougher surfaces. Literature suggests that roughness increases heat transfer by increasing the effective area available for heat transfer.

It is not likely that average heat flux increased because the TBCs were blocking heat transfer to the in-cylinder gases during the portion of the engine cycle when these gases were cooler than the walls. Simple FEA ignoring roughness found that the TBCs should actually increase heat transfer to the in-cylinder gases during that portion of the cycle.

A point of interest is that, when applied in the thicknesses used for these tests, the TBCs would not be expected to drastically reduce heat transfer. The simple FEA expected the YSZ coating to reduce overall heat flux by only $3 \%$, and the metal $\mathrm{TBC}$ was expected to reduce heat flux by even less.

3. Both TBCs were effective at reducing peak heat flux and damping temperature swings at the aluminum surface. Peak heat flux into the piston crown was reduced by $69 \%$ with the metal TBC and by $77 \%$ with the YSZ coating relative to the uncoated surface.

4. Neither TBC increased the occurrence of engine knock. Knock was not detected 
with either TBC or the uncoated condition when the engine was operating under normal conditions. When the engine was operated under knock promoting conditions, the TBCs produced elevated levels of knock that were not higher than those produced when uncoated. In fact, during its knock test the uncoated piston produced knock levels so high that it could not complete the test. This result suggests that TBCs may protect against knock in engines with poor oil control and large amounts of deposits.

The previous four points indicate that TBCs may be advantageous when used in SI engines even though they do not significantly reduce overall heat transfer. Damping temperature swings and reducing peak heat flux would protect components against thermal fatigue. Coating application could be targeted to areas of the combustion chamber that are particularly susceptible to thermal fatigue. Improved knock resistance would allow engines to optimize spark timing for efficiency and use lower octane fuels or higher compression ratios. However, the test program covered a narrow range of engine operating conditions and more research is required to confirm these findings.

\section{Recommendations}

Much more research is required before TBCs can be considered for use in production SI engines. Rigorous testing with a modern engine with good oil control is necessary for further study of the effect of the TBCs on engine knock. The engine should be run over the full range of speeds and loads necessary for use in a typical vehicle or other application. If possible, the tests should be performed under more closely controlled conditions to determine if the TBCs provide any power or efficiency improvements. The conditions requiring control include oil temperature and intake air temperature, humidity and pressure. Tests should be performed with a variety of coating types, thicknesses and surface finishes to determine the optimum combination. The optimum combination will 
most certainly depend on the type of engine used and the areas of the combustion chamber that are coated.

Endurance testing over hundreds of hours would provide insight into how the accumulation of deposits is affected by elevated surface temperatures. The endurance tests would also help establish the long term durability of the coatings. 


\section{Bibliography}

[1] Special section: The art of the possible. Economist, 389(8606):18-20, 2008.

[2] D.N. Assanis and T. Mathur. The effect of thin ceramic coatings on spark-ignition engine performance. SAE Technical Paper Series, 900903, 1990.

[3] J.B. Heywood. Internal Combustion Engine Fundamentals. McGraw-Hill Inc., New York, NY, 1988.

[4] S. Furuhama and Y. Enomoto. Heat transfer into ceramic combustion wall of internal combustion engines. SAE Technical Paper Series, 870153, 1987.

[5] R. Kamo, D.N. Assanis, and W. Bryzik. Thin thermal barrier coatings for engines. SAE Technical Paper Series, 890143, 1989.

[6] G. Woschni, W. Spindler, and K. Kolesa. Heat insulation of combustion chamber walls - a measure to decrease the fuel consumption of i.c. engines? SAE Technical Paper Series, 870339, 1987.

[7] D.N. Assanis, F.A. Friedman, K.L. Wiese, M.J. Zaluzec, and J.M. Rigsbee. A prototype thin-film thermocouple for transient heat transfer measurements in ceramiccoated combustion chambers. SAE Technical Paper Series, 900691, 1990.

[8] T. Morel, S. Wahiduzzaman, E. F. Fort, D. R. Tree, D. P. DeWitt, and K. G. Kreider. Heat transfer in a cooled and an insulated engine. SAE Technical Paper Series, 890572, 1989. 
[9] W. K. Cheng, V. W. Wong, and F. Gao. Heat transfer measurement comparisons in insulated and non-insulated diesel engines. SAE Technical Paper Series, 890570, 1989.

[10] D. W. Dickey. The effect of insulated combustion chamber surfaces on direct-injected diesel engine performance, emissions and combustion. SAE Technical Paper Series, 890292, 1989.

[11] V. W. Wong, W. Bauer, R. Kamo, W. Bryzik, and M. Reid. Assessment of thin thermal barrier coatings for ceramic i.c. engines. SAE Technical Paper Series, 950980, 1995.

[12] M. Ciniviz, C. Hasimoglu, F. Sahin, and M.S. Salman. Impact of thermal barrier coating application on the performance and emissions of a turbocharged diesel engine. Proceedings of the Institution of Mechanical Engineers, Part D: Journal of Automobile Engineering, 22:2447-2455, 2008.

[13] I. Taymaz. The effect of thermal barrier coatings on diesel engine performance. Surface and Coatings Technology, 201:5249-5252, 2007.

[14] E. Büyükkaya, T. Engin, and M. Cerit. Effects of thermal barrier coating on gas emissions and performance of a lhr engine with different injection timings and valve adjustments. Energy Conversion and Management, 47:1298-1310, 2006.

[15] A. Uzun, İ. Çevik, and M. Akçil. Effects of thermal barrier coating on a turbocharged diesel engine performance. Surface and Coatings Technology, 116-119:505-507, 1999.

[16] S. Jaichandar and P. Tamilporai. Low heat rejection engines - an overview. SAE Technical Paper Series, 2003-01-0405, 2003.

[17] K.Z. Mendera. Effectiveness of plasma sprayed coating for engine combustion chamber. SAE Technical Paper Series, 2000-01-2982, 2000. 
[18] A. Parlak and V. Ayhan. Effect of using a piston with a thermal barrier layer in a spark ignition engine. Journal of the Energy Institute, 80(4):223-228, 2007.

[19] D.J. Nakic, D.N. Assanis, and R.A. White. Effect of elevated piston temperature on combustion chamber deposit growth. SAE Technical Paper Series, 940948, 1994.

[20] R.B. Poola, B. Nagalingam, and K.V. Gopalakrishnan. Performance of thin-ceramiccoated combustion chamber with gasoline and methanol as fuels in a two-stroke si engine. SAE Technical Paper Series, 941911, 1994.

[21] K.S. Moughal and S. Samuel. Exhaust emission level reduction in two-stroke engine using in-cylinder combustion control. SAE Technical Paper Series, 2007-01-1085, 2007.

[22] M. E. Woods, W. Bryzik, and E. Schwarz. 100 hour endurance testing of high output adiabatic diesel engine. SAE Technical Paper Series, 940951, 1994.

[23] D. Saad, P. Saad, L. Kamo, M. Mekari, W. Bryzik, E. Schwarz, and J. Tasdemer. Thermal barrier coatings for high output turbocharged diesel engine. SAE Technical Paper Series, 2007-01-1442, 2007.

[24] R. Soltani, H. Samadi, E. Garcia, and T.W. Coyle. Development of alternative thermal barrier coatings for diesel engines. SAE Technical Paper Series, 2005-01$0650,2005$.

[25] R.P. Tolokan, J.P. Jarrabet, and J.B. Brady. Fiber metal thermal barrier systems for advanced engines. SAE Technical Paper Series, 840899, 1984.

[26] D.-I. Shin, F. Gitzhofer, and C. Moreau. Thermal property evolution of metal based thermal barrier coatings with heat treatments. Journal of Material Science, 42:5915-5923, 2007. 
[27] F. Gitzhofer, J. Mostaghimi, L. Pershin, T. Coyle, S. Chandra, J. Wallace, and J.G Legoux. Metal-based thermal barrier coatings for internal combustion engine: Pilot research (confidential draft report). Technical report, Universite de Sherbrooke, University of Toronto, and Surface Technologies IMI-NRC, Boucherville, 2008.

[28] American Society for Testing Materials, 1916 Race St., Philadelphia 3, Pa. ASTM Manual of Engine Test Methods for Rating Fuels, March 1948.

[29] A. Randolph. Cylinder-pressure-transducer mounting techniques to maximize accuracy. SAE Technical Paper Series, 900171, 1990.

[30] K. Burcar. Cylinder Pressure Measurement System - User's Guide. Department of Mechanical and Industrial Engineering, University of Toronto, January 1996.

[31] F. Millo and C.V. Ferraro. Knock in s.i. engines: A comparison between different techniques for detection and control. SAE Technical Paper Series, 982477, 1998.

[32] M.F.J. Brunt, C.R. Pond, and J. Biundo. Gasoline engine knock analysis using cylinder pressure data. SAE Technical Paper Series, 980896, 1998.

[33] C.S. Draper. Pressure waves accompanying detonation in the internal combustion engine. Journal of the Aeronautical Sciences, 5(6):219-226, 1938.

[34] H. S. Imming. The effect of piston-head temperature on knock-limited power. Technical report, National Advisory Committee for Aeronautics, 1944.

[35] Y. Tsutsumi, K. Nomura, and N. Nakamura. Effect of mirror-finished combustion chamber on heat loss. SAE Technical Paper Series, 902141, 1990.

[36] D.N. Assanis and E. Badillo. Evaluation of alternative thermocouple designs for transient heat transfer measurements in metal and ceramic engines. SAE Technical Paper Series, 890571, 1989. 
[37] J. Chang, Z. Filipi, D. Assanis, T.W. Kuo, P. Najt, and R. Rask. Characterizing the thermal sensitivity of a gasoline homogeneous charge compression ignition engine with measurements of instantaneous wall temperature and heat flux. International Journal of Engine Research, 6:289-309, 2005.

[38] T. Hendricks, J. Ghandhi, and J. Brossman. Instantaneous local heat flux measurements in a small utility engine. In Proceedings of the ASME Internal Combustion Engine Division Spring Technical Conference, 2009.

[39] D.R. Buttsworth. Transient response of an erodable heat flux gauge using finite element analysis. Proceedings of the Institution of Mechanical Engineers, Part D: Journal of Automobile Engineering, 216(8):701-706, 2002.

[40] Y. Heichal, S. Chandra, and E. Bordatchev. A fast-response thin film thermocouple to measure rapid surface temperature changes. Experimental Thermal and Fluid Science, 30(2):153-159, 2005.

[41] P.A. Kinzie. Thermocouple Temperature Measurement. John Wiley \& Sons, Inc., New York, NY, 1973.

[42] A.C. Alkidas and J.P. Myers. Transient heat-flux measurements in the combustion chamber of a spark-ignition engine. Journal of Heat Transfer, Transactions of the American Society of Mechanical Engineers, 104(1):62-67, 1982.

[43] Y. Enomoto and S. Furuhama. Measurement of the instantaneous surface temperature and heat loss of gasoline engine combustion chamber. Proceedings - SAE, 1:1.58-1.63, 1984.

[44] G. Woschni. A universally applicable equation for the instantaneous heat transfer coefficient in the internal combustion engine. SAE Transactions, 76:670931, 1967. 
[45] S.W. Smith. The scientist and engineer's guide to digital signal processing. California Digital Pub., San Diego, CA, 1st edition, 1997.

[46] S. Memme. Design of a piston surface temperature telemetry system (undergraduate thesis). Technical report, University of Toronto, 2009.

[47] National Institute of Standards and Technology. NIST ITS-90 Thermocouple Database, NIST Standard Reference Database 60, Version 2.0 (Web Version), 1995.

[48] G. Borman and K. Nishiwaki. Internal-combustion engine heat transfer. Progress in Energy and Combustion Science, 13(1):1-46, 1987.

[49] L. Pershin. Email correspondence, August 2009.

[50] American Society of Mechanical Engineers. B46.1 - 1995: Surface Texture, Surface Roughness, Waviness and Lay. 1995.

[51] Society of Automotive Engineers Inc. 1996 SAE Handbook: Volume 1 Materials, Fuels, Emissions and Noise. 1996.

[52] Omega Engineering Inc. Thermocouples: An introduction (http://www.omega.com/thermocouples.html), 2009.

[53] J.L. Devore. Probability and Statistics for Engineering and the Sciences. Brooks/Cole - Thomson Learning, 6 edition, 2004.

[54] H. Schenck. Theories of Engineering Experimentation. McGraw-Hill Inc., New York, NY, 1979.

[55] F. Madrid, X. Jorda, M. Vellvehi, C. Guraya, J. Coleto, and J. Rebollo. An effective thermal conductivity measurement system. Review of Scientific Instrumenets, 75(11):4505-4510, 2004. 


\section{Appendix A}

\section{Software Program Descriptions}

This appendix describes the LabVIEW and MATLAB programs that were referred to in the previous chapters. These programs can be found on the accompanying thesis DVD.

\section{A.1 LabVIEW Programs}

Prelim_Temp.vi This LabVIEW program was used for the temperature tests portion of the preliminary cylinder wall tests. The program acquires the six plug thermocouple and the intake air thermocouple voltages at a frequency of $1000 \mathrm{~Hz}$, and averages the data into one second intervals. Voltages are converted to temperatures using the software's built-in type $\mathrm{K}$ thermocouple calibration. Temperatures are recorded to a .txt file.

Prelim_Knock.vi This program was used for the knock tests portion of the preliminary cylinder wall tests. The program acquires voltages from the cylinder and intake pressure transducers and encoder $\mathrm{Z}$ pulse, using encoder $0.2^{\circ} \mathrm{CA}$ pulse as sampling clock. Cylinder pressure data are fed through a high pass filter with a cut-off frequency of 3000 
Hz. Raw and filtered pressure data are recorded to a .lvm file for further processing by "Prelim_Knock.m". The program also records plug temperatures in similar manner as "Prelim_Temp.vi".

TC_Dev_Temp.vi This program was used for the engine testing portion of the surface thermocouple development. The program acquires surface thermocouple voltages as a function of both time and crank angle. Data measured as a function of time are sampled at a frequency of $1000 \mathrm{~Hz}$ and averaged into one second intervals. Two control plug and the intake air thermocouples are also acquired in this mode. The program converts these voltages to temperatures and records to a .txt file. Data measured as a function of crank angle use the encoder's $0.2^{\circ} \mathrm{CA}$ pulse as the sampling clock. The encoder's $\mathrm{Z}$ pulse is also acquired in this mode. The program converts the surface thermocouple voltages into temperatures and records to a lvm file for further processing by "TC_Dev_Temp.m".

Piston_T\&P.vi This program was used for all pressure and temperature measurements during the piston tests. The program acquires piston thermocouple, exhaust gas thermocouple and SCB-68 temperature sensor voltages at a frequency of $1000 \mathrm{~Hz}$. Data are averaged into one second intervals, converted to temperatures and written to a .txt file. When desired, program also acquires temperature signals instantaneously using the encoder's $0.2^{\circ} \mathrm{CA}$ pulse as the sampling clock. These data are written to a .lvm file for further processing by "Piston_T\&HF.m". The program also measures instantaneous cylinder pressure data when desired. This data includes the cylinder and intake pressure transducer and encoder Z pulse voltages. Cylinder 
pressure data are fed through a high pass filter with a cut-off frequency of $3000 \mathrm{~Hz}$. All raw voltages and the filtered pressure data are recorded to a .lvm file for further processing by "Piston_P.m".

\section{A.2 MATLAB Programs}

Prelim_Knock.m This MATLAB program takes the .lvm data file from "Prelim_Knock.vi" and calculates knock intensity, occurrence angle and other indicators for each engine cycle sampled. These indicators are written to a .txt file. The program also provides the user with the option of creating a .txt file containing cylinder pressure versus volume and crank angle.

TC_Dev_Temp.m This program takes the .lvm file of instantaneous temperature data from "TC_Dev_Temp.vi" and calculates statistics for each engine cycle sampled, including maximum and minimum temperatures. Prior to calculating statistics, the program eliminates noise spikes occasionally found around spark and exhaust valve closure. The program also shifts temperature data to offset the delays introduced by the analog filters and smooths with a moving average filter. The program provides the user with the option of creating a .txt file containing surface temperature versus volume and crank angle.

Piston_T\&HF.m This program takes the .lvm file of instantaneous thermocouple data from "Piston_T\&P.vi" and calculates temperature and heat flux statistics. Prior to calculating statistics, the program shifts the data to offset the delays introduced by the analog filters and then applies a moving average filter to further smooth the data. The program provides the user with the option of creating a .txt file containing of piston temperatures and heat fluxes versus volume and crank angle. 
Piston_P.m This program takes the .lvm file of instantaneous pressure data from "Piston_T\&P.vi" and calculates pressure and knock statistics which are written to a .txt file. The program also provides the user with the option of creating a .txt file containing cylinder pressure versus volume and crank angle. 


\section{Appendix B}

\section{Piston Modification Drawings}

This appendix contains drawings of the modifications made to the piston prior to instal-

lation of the thermocouples. Figure B.1 shows the unmodified piston for reference, and Figures B.2 and B.3 show the modified piston with dimensions. 


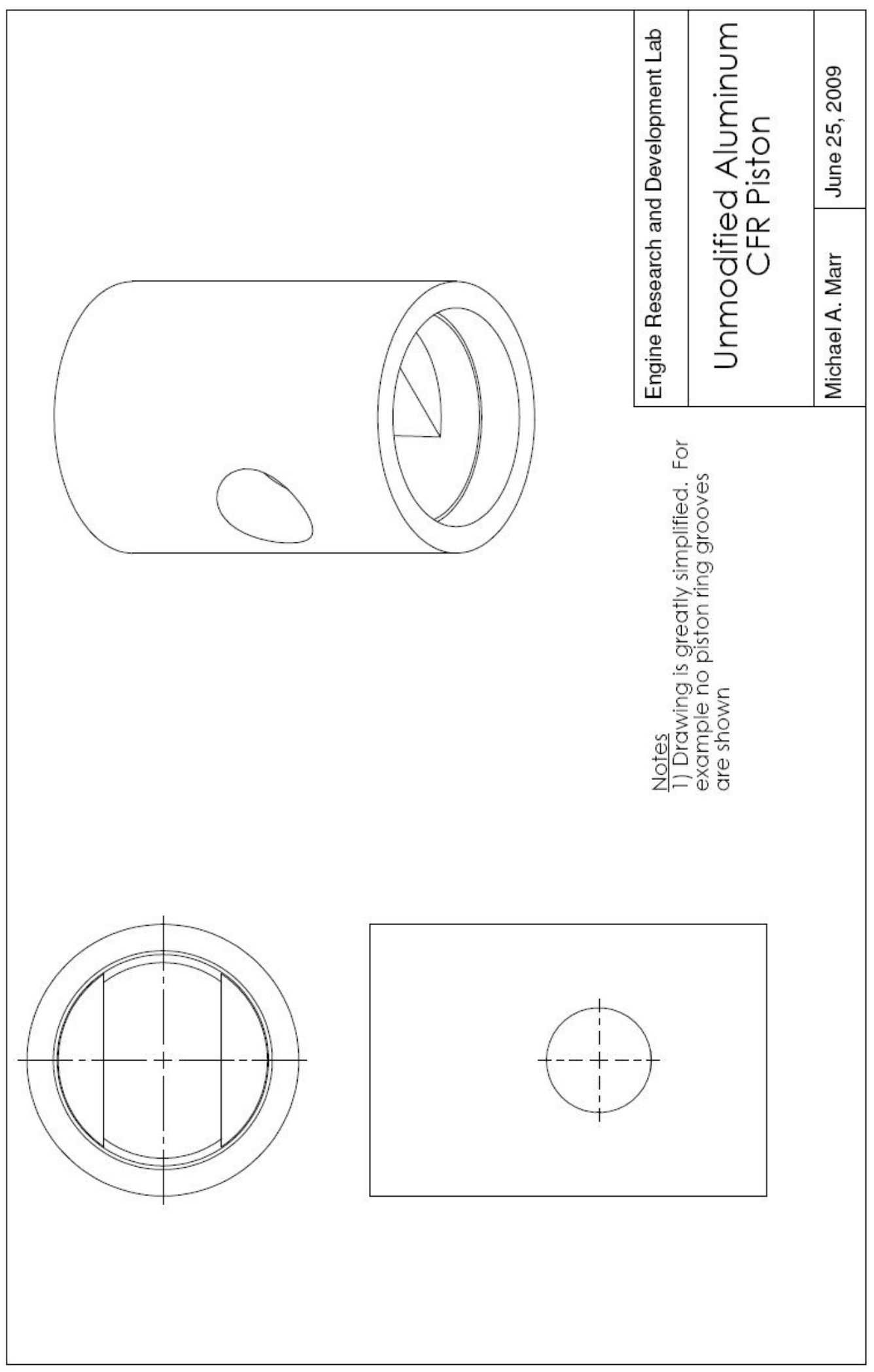

Figure B.1: Unmodified aluminum CFR piston drawing 


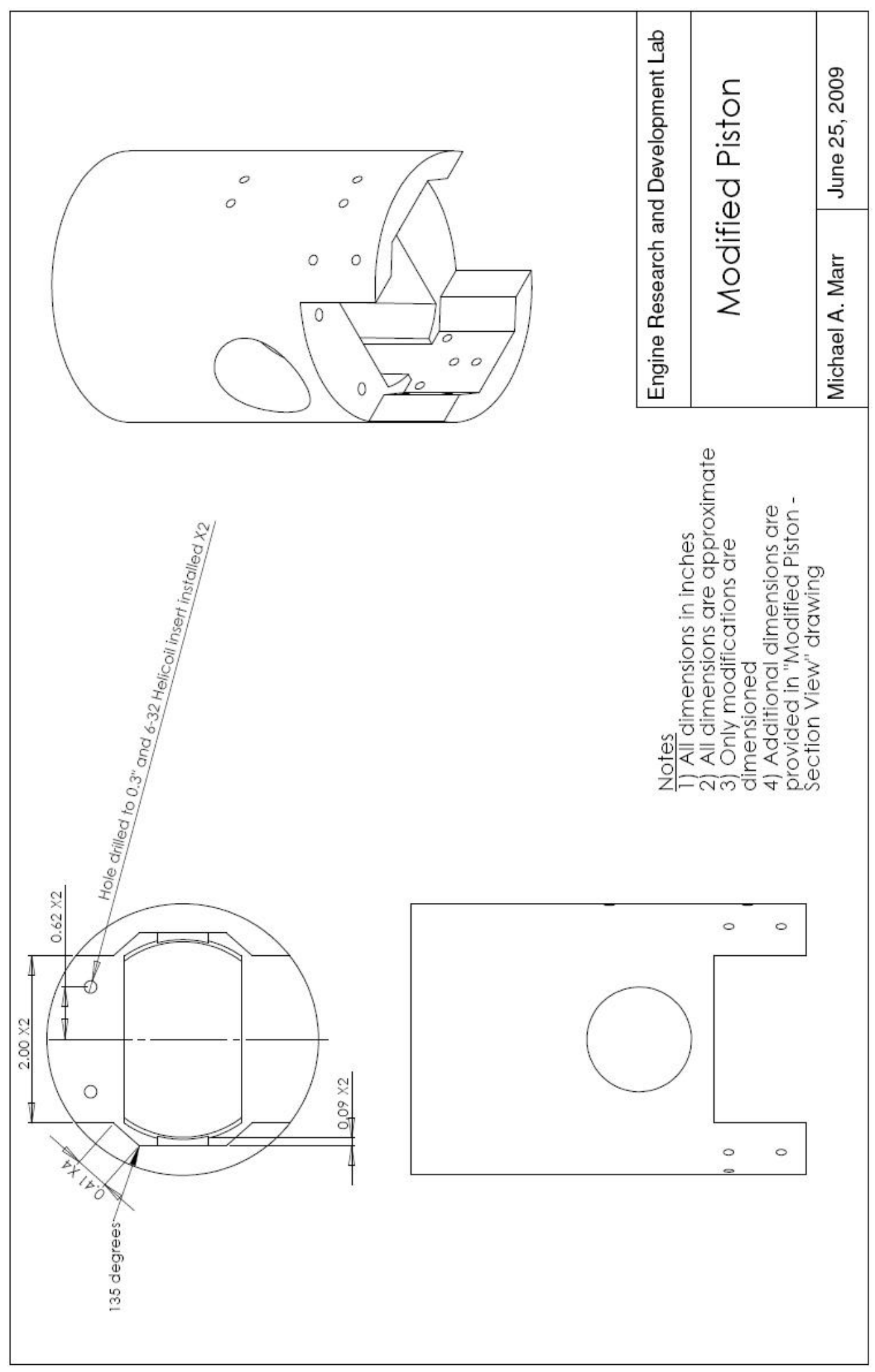

Figure B.2: Modified piston drawing 


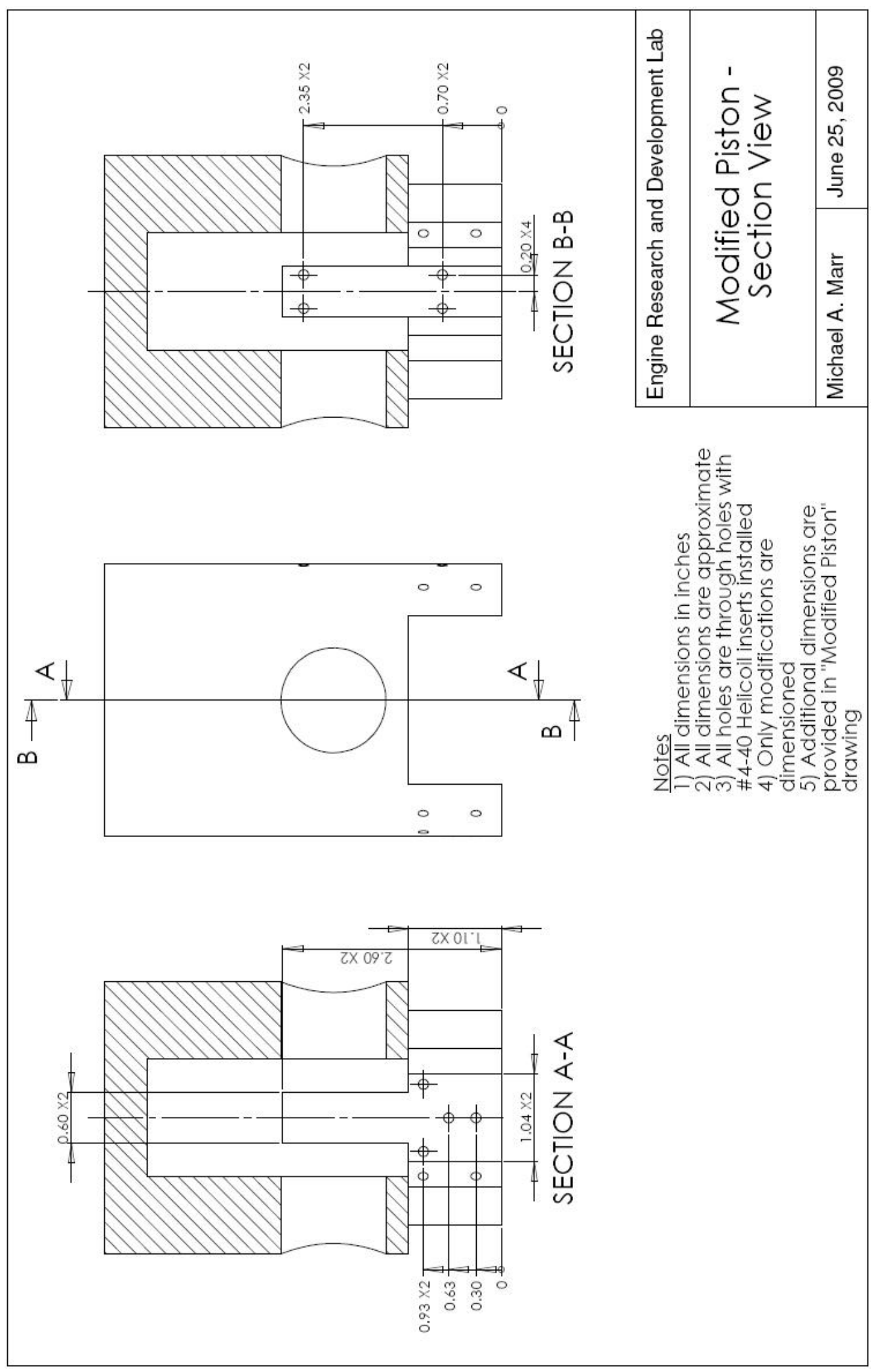

Figure B.3: Modified piston - section view drawing 


\section{Appendix C}

\section{Heat Flux Calculation}

Instantaneous heat flux into combustion chamber surfaces can be calculated from the solution to the one-dimensional unsteady heat conduction equation given by Equation (C.1). The solution by Fourier analysis was outlined by Borman and Nishiwaki [48].

$$
\frac{\partial T}{\partial t}=\alpha \frac{\partial^{2} T}{\partial^{2} x}
$$

The temperatures measured by a surface and in-depth thermocouple pair are used for boundary conditions:

$$
\begin{aligned}
& T(0, t)=T_{s}(t) \\
& T(l, t)=T_{i}
\end{aligned}
$$

$T_{s}$ is measured by the surface thermocouple and $T_{i}$ is measured within the wall at a depth $l$ by the in-depth thermocouple where temperatures are assumed steady over the engine cycle. $T_{s}$ needs to be represented as a Fourier series:

$$
T_{s}(t)=T_{s, m}+\sum_{n=1}^{N}\left[A_{n} \cos (n \omega t)+B_{n} \sin (n \omega t)\right]
$$


$T_{s, m}$ is the average surface temperature, and $\omega$ is the frequency of the temperature cycle, which corresponds to twice the engine rotation frequency. $A_{n}$ and $B_{n}$ are the Fourier coefficients which can be determined by performing a Fast Fourier Transform on the surface temperature data. $N$ is the number of harmonics. Solving Equation C.1 with the boundary conditions produces the following temperature profile:

$$
T(x, t)=T_{s, m}-\frac{x}{l}\left(T_{s, m}-T_{i}\right)+\sum_{n=1}^{N} e^{\phi_{n} x} F_{n}(x, t)
$$

Where

$$
\begin{aligned}
F_{n}(x, t) & =A_{n} \cos \left(n \omega t-\phi_{n} x\right)+B_{n} \sin \left(n \omega t-\phi_{n} x\right) \\
\phi_{n} & =\sqrt{\frac{n \omega}{2 \alpha}}
\end{aligned}
$$

From equation (C.3), heat flux through the surface can be calculated from Fourier's Law for Heat Conduction:

$$
\begin{aligned}
\dot{q}_{s}(t)= & -k \frac{\partial T(0, t)}{\partial x} \\
= & \frac{k}{l}\left(T_{s, m}-T_{i}\right) \\
& +k \sum_{n=1}^{N} \phi_{n}\left[\left(A_{n}+B_{n}\right) \cos (n \omega t)+\left(A_{n}-B_{n}\right) \sin (n \omega t)\right]
\end{aligned}
$$




\section{Appendix D}

\section{Pictures of Piston Crown After}

\section{Testing}

This appendix contains pictures of the piston crown with each coating after completion of the temperature and knock tests. The chip in the YSZ coating is visible at the 4 o'clock position in Figure D.3. 


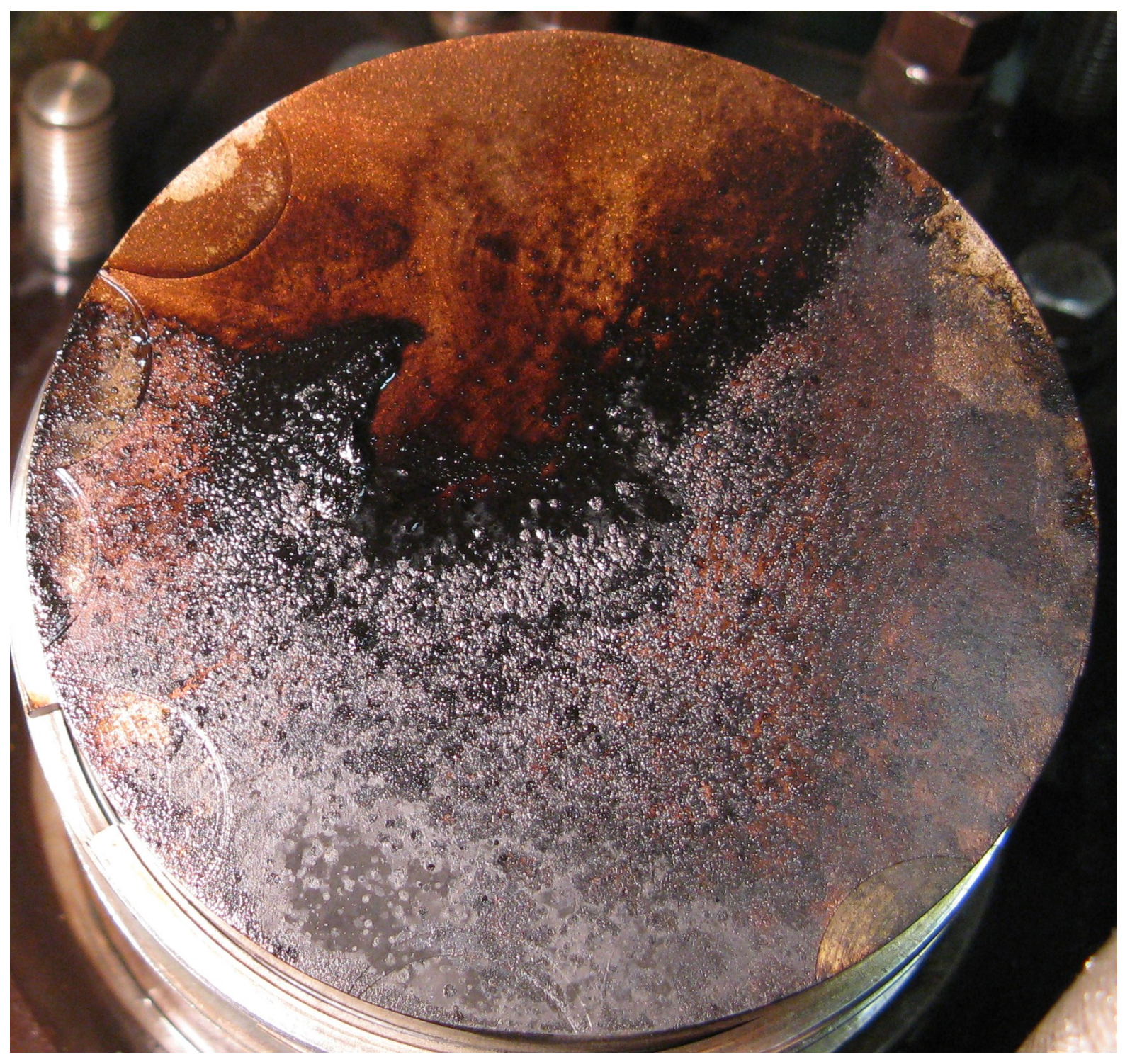

Figure D.1: Uncoated piston crown after testing 


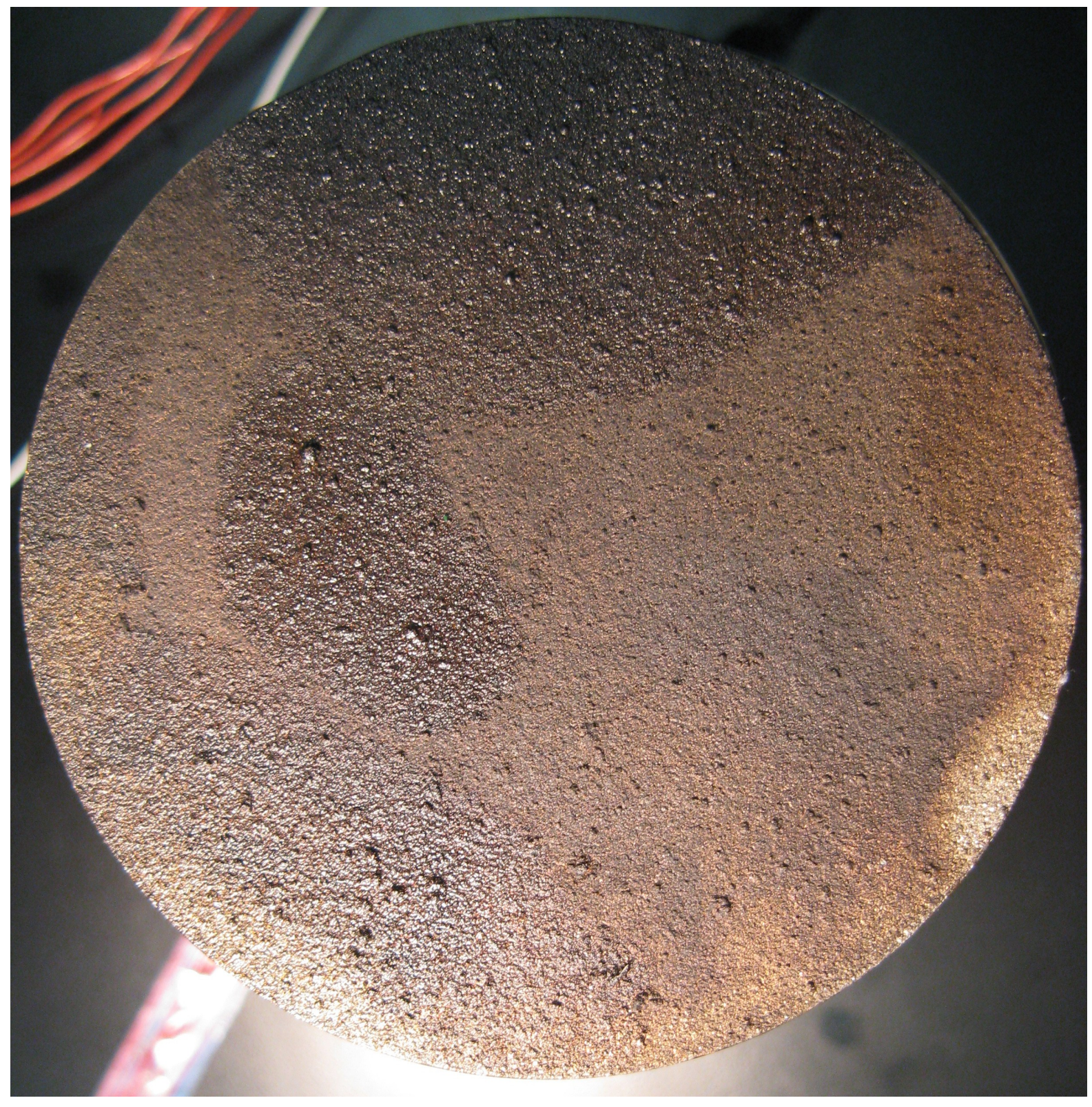

Figure D.2: Metal TBC coated piston crown after testing 


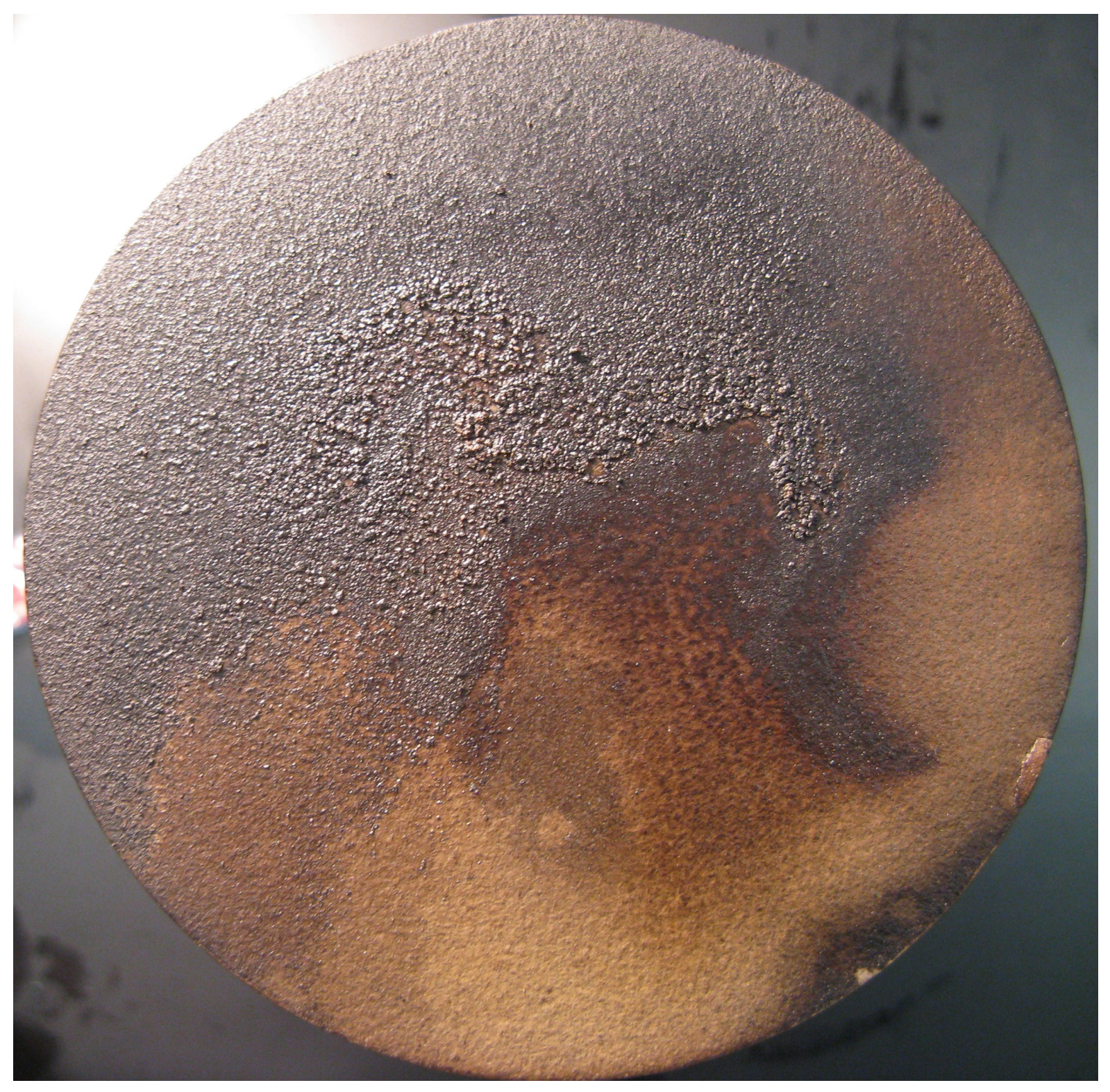

Figure D.3: YSZ coated piston crown after testing 


\section{Appendix E}

\section{Heat Flux Error Analysis}

This appendix contains an error analysis of the heat flux results presented in Chapter 6 . Errors associated with the average heat flux results are discussed first, followed by the

errors associated with the instantaneous heat flux results. The following discussion does not include the errors associated with the assumption that heat flux is one-dimensional.

\section{E.1 Average Heat Flux Error Analysis}

Average heat flux values in Figure 6.6 were calculated from Equation 5.3, which is repeated below.

$$
\dot{q}_{s, m}=\frac{k}{l}\left(T_{s, m}-T_{i}\right)
$$

Uncertainties of the calculated $\dot{q}_{s, m}$ values depend on the errors associated with each of the other variables in Equation 5.3.

\section{E.1.1 Average Heat Flux Errors}

The errors associated with the right-hand variables in Equation 5.3 can be divided into errors of accuracy and errors of precision. 


\section{Errors of Accuracy}

Accuracy errors arise due to incorrect calibration of a measurement device or inaccurate estimation of a variable's value if it is not measured. For example, an improperly calibrated multimeter that reads $3.5 \mathrm{~V}$ when measuring a signal with a true value of $3.0 \mathrm{~V}$. No matter how many times the measurement is repeated, the multimeter always reads $3.5 \mathrm{~V}$ instead of $3.0 \mathrm{~V}$.

In some cases, the value of an accuracy error is known, or at least it can be estimated, and measurements can be corrected to offset the error. In other cases, there is no information on the error's value, and it is only possible to generate an uncertainty window.

The errors and uncertainties of the input variables in Equation 5.3 due to accuracy errors are discussed below.

$k \quad$ The thermal conductivity of the aluminum was estimated as $130 \mathrm{~W} / \mathrm{mK}$ to match that of ANSI 222.0 aluminum alloy, a common piston alloy. The exact piston material was not known. A number of aluminum alloys have been used for pistons, and a survey of these found thermal conductivities ranging from 104 to $151 \mathrm{~W} / \mathrm{mK}$ [51]. For simplicity, the uncertainty in $k$ is assumed to be $+/-26 \mathrm{~W} / \mathrm{mK}$.

$l \quad$ It was attempted to install the in-depth thermocouples with their hot junctions $5 \mathrm{~mm}$ from piston surface. There is uncertainty about the depths to which the holes were drilled, and the locations of the hot junctions within the holes. These uncertainties are estimated to be $+/-0.254 \mathrm{~mm}(0.01 ")$ and $+/-0.2 \mathrm{~mm}$, respectively.

$T_{s, m} \quad$ Estimates for $T_{s, m}$ errors can be made from the FEA calculated surface thermocouple temperatures shown in Figure 4.5. With a copper layer thickness of $125 \mu \mathrm{m}$, as was used for the uncoated piston tests, the thermocouple 
should measure average temperatures $0.17^{\circ} \mathrm{C}$ above true average temperatures. With a copper layer thickness of $400 \mu \mathrm{m}$, as was used for the metal TBC and YSZ piston tests, the thermocouple should measure average temperatures $0.08^{\circ} \mathrm{C}$ above true average temperatures.

$T_{i} \quad$ The FEA calculations shown in Figure 4.18 provide the best available error estimate for the in-depth thermocouple. In the figure, the average of the in-depth temperature curve is $0.42^{\circ} \mathrm{C}$ higher than the average of the true curve.

The temperature difference $\left(T_{s, m}-T_{i}\right)$ was also subject to errors in conversion from thermocouple voltages to temperatures. This uncertainty is assumed to be $0.75 \%$, as is standard for type $\mathrm{J}$ and $\mathrm{K}$ thermocouples [52].

There are a number of additional temperature measurement accuracy errors that had approximately the same influence on both $T_{s, m}$ and $T_{i}$. These errors should essentially cancel out in calculations with Equation 5.3. An example of such an error is the voltage offset introduced by the filter-amplifier modules. This offset was manually adjusted to be the same for all thermocouples.

\section{Errors of Precision}

Errors of precision arise from a measurement device's inability to provide repeatable readings for what should be an identical measurement. For example, during three separate measurements of a $3.0 \mathrm{~V}$ signal, the multimeter reads 2.9, 2.6 and $3.4 \mathrm{~V}$.

Regarding the variables in Equation $5.3, l$ had no precision errors and $k$ should have had only minimal precision errors from slight changes in thermal conductivity due to temperature variation. Precision errors for $\left(T_{s, m}-T_{i}\right)$ were due to day-to-day changes in test conditions and random DAQ system errors. The magnitude of the uncertainty window for these errors can be calculated from the sample Confidence Interval (CI) from the equation below, adapted from [53]. 


$$
C I_{\alpha}=+/-\frac{t_{\alpha / 2, v} s}{\sqrt{N}}
$$

In Equation E. $2, t_{\alpha / 2, v}$ is the Student's t value for a given alpha level and degrees of freedom, $s$ is the sample standard deviation, and $N$ is the number of samples. Alpha level is the same as the level of significance, which is equal to one minus the confidence level.

\section{E.1.2 Average Heat Flux Error and Uncertainty Adjustments}

After determining the errors and uncertainties, the first step is to adjust the results to offset the input variable errors with known or estimated values. In this case, these adjustments are:

$T_{s, m} \quad-0.17^{\circ} \mathrm{C}$ (Uncoated), $-0.08^{\circ} \mathrm{C}$ (metal TBC and YSZ)

$T_{i} \quad-0.42^{\circ} \mathrm{C}$

The error adjusted average heat fluxes are shown in Figure E.1. The error bars shown still represent the $95 \%$ confidence interval, determined according to Sub-Section 2.2.1, based upon variation in the measurements. The uncertainty windows described in SubSection E.1.1 are not yet included in the error bars. Figure E.1 is fully sufficient for relative comparisons of average heat flux, and the figure shows the same general results as Figure 6.6. Namely, average heat fluxes into the YSZ coated and uncoated pistons were the same within error limits, while heat flux into the metal TBC coated piston was approximately $30 \%$ higher.

Next, the error bars can be enlarged to include all uncertainty. The total uncertainty calculation is described by Schenck [54]. For Equation 5.3, this uncertainty can be calculated as shown below.

$$
\left(\frac{w_{\dot{q}_{s, m}}}{\dot{q}_{s, m}}\right)^{2}=\left(\frac{w_{k}}{k}\right)^{2}+\left(\frac{w_{l}}{l}\right)^{2}+\left(\frac{w_{T_{s, m}-T_{i}}}{T_{s, m}-T_{i}}\right)^{2}
$$




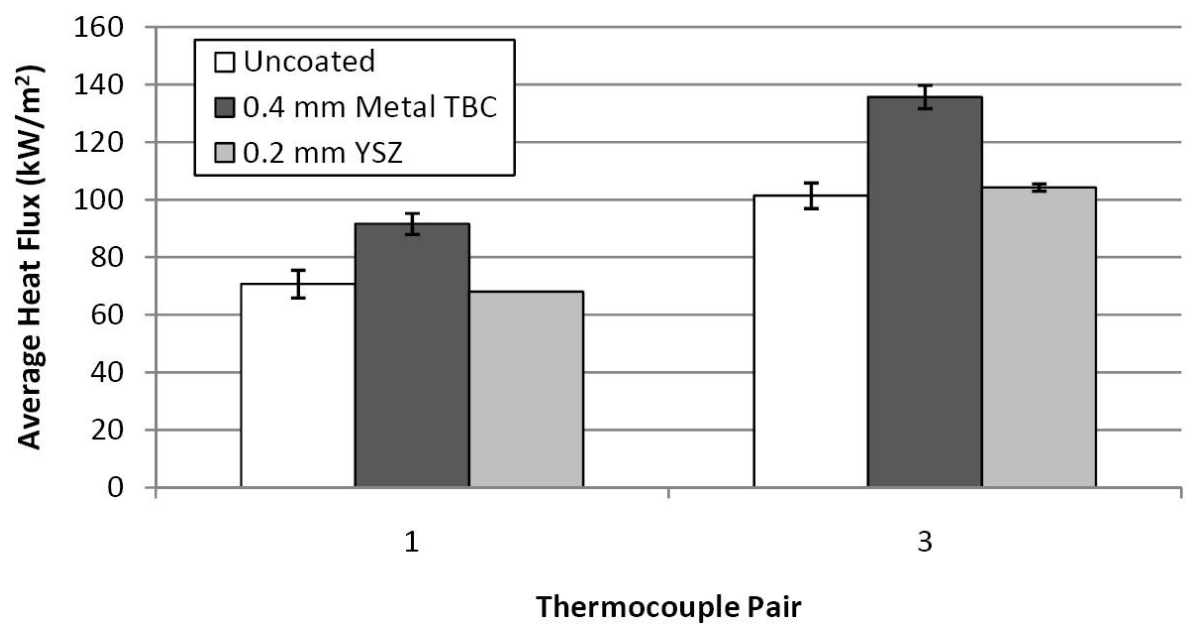

Figure E.1: Average heat flux into piston crown after accuracy error adjustment

In Equation E.3, w represents the uncertainty window at a given confidence level, which is chosen to be $95 \%$. For most of the $w$ values, it was necessary to assume the values were for a $95 \%$ confidence level, as it was not possible to quantitatively determine a true confidence level. When there are multiple independent uncertainties for each individual variable, that variable's total uncertainty is calculated by the square root of the sum of each independent uncertainty squared. The various $w$ values are defined below, and justification for these values can be found in Appendix Sub-Section E.1.1.

$$
\begin{array}{ll}
w_{k} & +/-26 \mathrm{~W} / \mathrm{mK} \\
w_{l} & +/-\sqrt{0.254^{2}+0.2^{2}}=+/-0.323 \mathrm{~mm} \\
w_{T_{s, m}-T_{i}} & +/-\sqrt{\left(0.0075 *\left(T_{s, m}-T_{i}\right)\right)^{2}+\left(C I_{\alpha=0.05}\left[T_{s, m}-T_{i}\right]\right)^{2}}
\end{array}
$$

Figure E.2 presents the average heat fluxes into the piston crown after the accuracy error adjustment (as in Figure E.1) and with the full uncertainty windows as calculated from Equation E.3. Figure E.2 provides information about the uncertainty for the absolute heat flux values. However, for the purpose of making relative comparisons between the two TBCs and the uncoated surface, Figure E.1 is more appropriate. The additional 


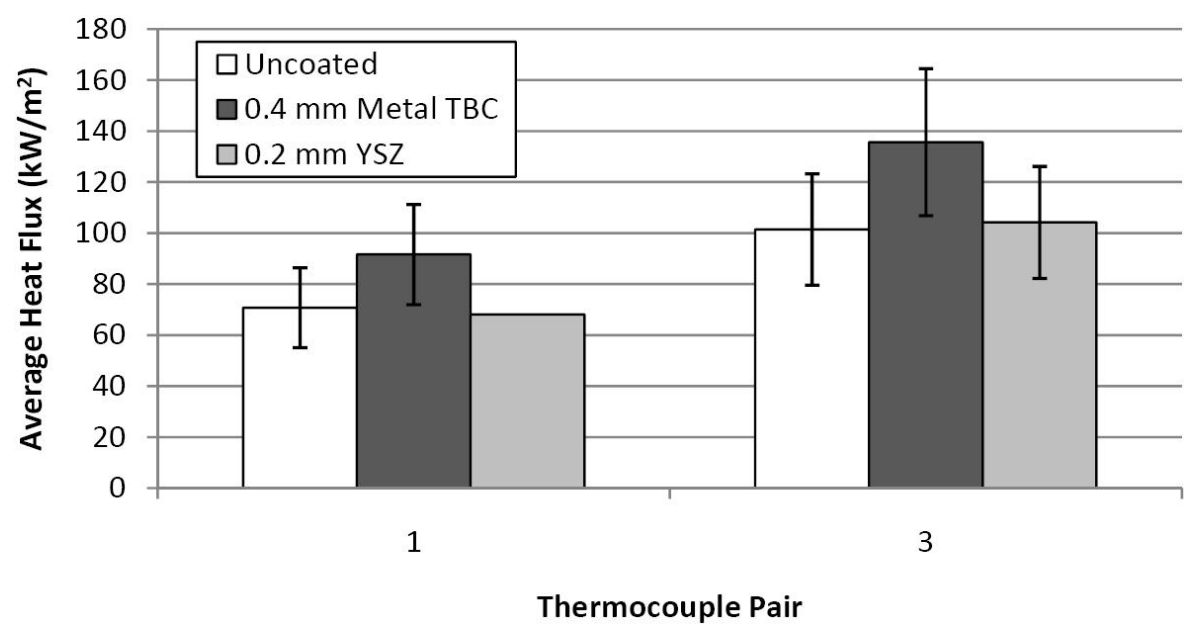

Figure E.2: Average heat flux into piston crown after accuracy error adjustment with full $95 \%$ confidence level uncertainty windows

uncertainties accounted for by the error bars in Figure E.2 are all accuracy errors, which had nearly the same value for both TBCs and the uncoated piston.

\section{Hypothetical Uncertainty Windows}

The uncertainty ranges in Figure E.2 are large primarily because of the large uncertainty about the value of thermal conductivity. This uncertainty is large because $k$ was not measured and the composition of the alloy was not known. In future experiments, $k$ will likely be measured and therefore the total uncertainty surrounding the average heat flux values will be smaller. To obtain a rough prediction for total uncertainty in future experiments, a hypothetical error analysis was performed assuming an uncertainty window for $k$ of $+/-6 \%$, as could be expected for thermal conductivity measurements of aluminum alloys [55]. Figure E.3 shows the average heat flux with the error bars calculated by this hypothetical analysis. 


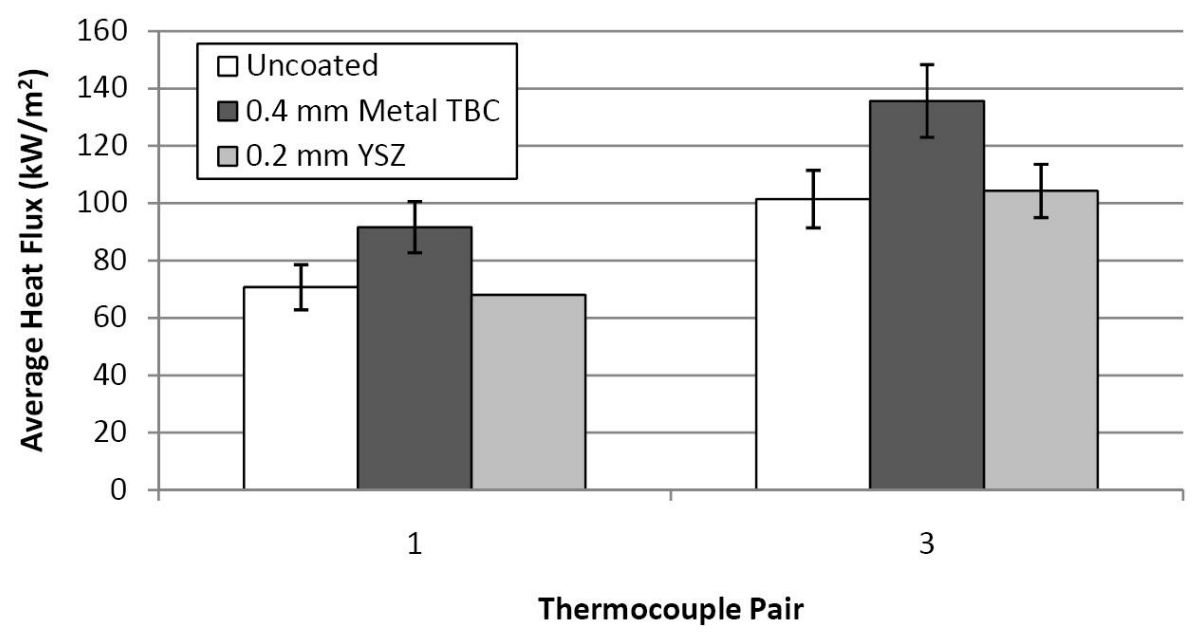

Figure E.3: Average heat flux into piston crown after accuracy error adjustment with hypothetical $95 \%$ confidence level uncertainty windows

\section{E.2 Instantaneous Heat Flux Error Analysis}

The instantaneous heat flux curves in Figures 6.4 and 6.5 were calculated from Equation C.4, which is repeated below.

$$
\begin{aligned}
\dot{q}_{s}(t)= & -k \frac{\partial T(0, t)}{\partial x} \\
= & \frac{k}{l}\left(T_{s, m}-T_{i}\right) \\
& +k \sum_{n=1}^{N} \phi_{n}\left[\left(A_{n}+B_{n}\right) \cos (n \omega t)+\left(A_{n}-B_{n}\right) \sin (n \omega t)\right]
\end{aligned}
$$

Equation C.4 is divided into steady and unsteady components. The steady component is identical to Equation 5.3 and its error analysis would be the same as discussed in Section E.1.1. The unsteady component of Equation C.4 includes the derivative of the Fourier Series representation of the unsteady surface temperature, with respect to depth.

Quantification of uncertainty windows for the instantaneous heat flux results is beyond the scope of this research project. This author is not aware of any publication including such an error analysis. Instead, the qualitative errors of the unsteady component of the 
equation are discussed below.

Unsteady heat flux is proportional to $\sqrt{k \rho c}$ (from $k \phi_{n}$ ), where $\rho$ is the density and $c$ is the specific heat capacity of the metal, and it is also proportional to $\sqrt{\omega}$. Errors in these variables will propagate through to the unsteady heat flux component in proportion to $\sqrt{1+\text { errorfraction }}$.

Errors will also arise due to thermocouple inaccuracy at measuring transient surface temperatures. As illustrated in Figure 4.6, FEA calculates that the surface thermocouple is capable of measuring temperature swings within $6 \%$ of true values. Errors will also arise due to noise in the temperature measurements. As can be seen in Figures 6.2 and 6.4 , noise in the temperature signal is amplified by the instantaneous heat flux calculation. 